\title{
4 Die geschlossene Venerologische Station der Poliklinik Mitte in Halle (Saale)
}

\subsection{Gründung und Aufbau}

In der Stadt Halle (Saale) wurde nach dem Ende des Zweiten Weltkriegs kein Fürsorgeheim für Geschlechtskranke eröffnet. Vielmehr wurden geschlechtskranke Frauen entweder ins Gefängnis gebracht, wenn „keine Möglichkeit einer stationären Behandlung in einem Krankenhaus gegeben“"war. ${ }^{147}$ Alternativ wurden geschlechtskranke Mädchen in provisorischen Einrichtungen betreut und medizinisch versorgt - beispielsweise in der Christian-Thomasius-Schule in Halle (Saale), im Frauen- und Mädchenzufluchtheim, Weidenplan 5 in Halle (Saale), oder in den Borsdofer Anstalten bei Leipzig. ${ }^{148}$ Weitere Betreuungsmöglichkeiten für Geschlechtskranke boten sich in Ambulatorien sowie in der „Beobachtungsstation im Fachkrankenhaus II“, die im traditionsreichen Bergmannstrost-Krankenhaus zur Unterstützung der ambulanten Stationen eingerichtet wurde. ${ }^{149}$ Dabei bildeten diese Stationen einen wesentlichen Knotenpunkt, da die aufgegriffenen und dort eingelieferten Personen nach einer medizinischen Untersuchung an Beobachtungsstationen, Heime

147 StAH: A 2.23 Jugend- und Fürsorgeamt Nr. 27, Bd. 4. Kriminalpolizei der Provinz Sachsen, Kriminalpolizeileitstelle. An den Herrn Oberbürgermeister Jugend- und Fürsorge-Amt Halle, Halle (Saale), den 15. Oktober 1945.

148 StAH: A 2.23 Jugend- und Fürsorgeamt Nr. 27, Bd. 4. Vermerk, Halle (Saale), den 9. Februar 1946.

149 StAH: A 2.23 Jugend- und Fürsorgeamt Nr. 27. Bd. 4. Bericht über zwei Vorträge am 26. 5. und 27. 5. 1948 im Pol. Präsidium Bekämpfung der Geschlechtskrankheiten betreffend. Halle (Saale), den 29. Mai 1948. 
oder Arbeitslager weitergeleitet werden sollten. ${ }^{150} \mathrm{Im}$ Arbeitslager Schönebeck wurden vor allem in den $1940 e r$ Jahren verstärkt geschlechtskranke Personen untergebracht. ${ }^{151}$ Das Arbeitslager wurde mit „Frauen und Mädchen beschickt, die bestimmte Voraussetzungen (mehrmalige Erkrankung an Lues und Go und unsoliden Lebenswandel)“" erfüllten. ${ }^{152}$ Bei Neueinweisungen blieben die Frauen und Mädchen sechs Monate hier, bei Wiedereinweisungen auf unbestimmte Zeit. ${ }^{153}$

Anfang der 1950er Jahre setzte in der Stadtverwaltung von Halle (Saale) ein Umdenken ein. Künftig sollte der Aspekt der Erziehung, als Teil der Prävention, stärker betont werden. Hierzu heißt es in einer Vorlage für die Stadtverwaltung, dass die Wiedereingliederung der Gefährdeten „in das gesellschaftliche Leben (...) nur bei intensiver, geduldiger Beeinflussung durch geschulte moderne Pädagogen in geschlossenen Anstalten versucht werden [kann]. Bestimmung des Menschen ist, nützliche Arbeit zu leisten. Dieser Urinstinkt ist bei den gefährdeten Menschen durch das maßlose Triebleben überwuchert. Er muß freigelegt, gestärkt oder überhaupt erst einmal geweckt werden. " ${ }^{554}$ Als pädagogische Grundlage für dieses Freilegen des „Arbeitstriebes“ sollten die Schriften des sowjetischen Schriftstellers Anton Semjonowitsch Makarenko (1888-1939) dienen.

Makarenko hatte von 1912 bis 1917 am pädagogischen Lehrerbildungsinstitut in Poltawa studiert und war ab 1920 an der Neuorganisation der Schulen als Arbeitsschulen im Gouvernement Poltawa beteiligt. Bekannt wurde er durch den Aufbau eines Arbeitsheims für straffällig gewordene Jugendliche, der späteren Gorki-Kolonie (1920-1928) und seine dort entwickelte Pädagogik. ${ }^{155}$ Anstelle einer militärisch geführten Jugendstrafkolonie entstand unter seiner Führung die erste koedukative pädagogische Einrichtung dieser Art in der Sowjetunion. Dieses Konzept veröffentlichte er in Büchern und Artikeln - beispielsweise in dem Roman Ein pädagogisches Poem. ${ }^{156}$ Darin beschrieb er eine Form der Kollektiverziehung, die zum Ziel die Erziehung einer allseitig entwickelten Persönlichkeit hatte. Sie basierte auf einer Einheit von verinnerlichter Disziplin, Selbstverwaltung und nützlicher Arbeit. Die Disziplin wurde zusätzlich durch ein hierarchisches System gesichert, in dem der Neuling

150 Vgl. zu den Ambulatorien für Geschlechtskrankheiten: Krumbiegel: Polikliniken in der SBZ, DDR (Anm. 45), S. $167 f$.

151 StAH: A 2.23 Jugend- und Fürsorgeamt Nr. 27. Bd. 4. Oberregierungsrat. An das Sozialamt - Jugendamt, Halle (Saale), den 27. November 1947.

152 StAH: A 2.23 Jugend- und Fürsorgeamt Nr. 27. Bd. 4. Bericht über zwei Vorträge am 26.5. und 27.5.1948 im Pol. Präsidium Bekämpfung der Geschlechtskrankheiten betreffend. Halle (Saale), den 29. Mai 1948.

153 Vgl. zu Schönebeck: Korzilius: „Asoziale“ und „Parasiten“ im Recht der SBZ, DDR (Anm. 43), S. 74ff.

154 StAH: A 2.23 Jugend- und Fürsorgeamt Nr. 27. Bd. 4. Ausführungen von Kolln M. für eine Vorlage gem. Beschluss der Stadtv. 0. Datum [wahrscheinlich August 1951].

155 Zimmermann V (2004) „Den neuen Menschen schaffen“. Die Umerziehung von schwererziehbaren und straffälligen Jugendlichen in der DDR (1945-1990). Böhlau Verlag Köln, Weimar, Wien, S. 51f.

156 Makarenko A S (1962) Ein pädagogisches Poem. Der Weg ins Leben. Aufbau-Verlag Berlin. 
zunächst keine persönlichen Freiheiten hatte, aber durch ein persönlich für ihn verantwortliches Vollmitglied der Kommune betreut wurde. ${ }^{157}$

Im hallischen Diskussionspapier heißt es: „In seinem ,Pädagogischen Poem. Der Weg ins Leben' schildert er [Makarenko] die Erfolge seiner Erziehungsarbeit bei Jugendlichen, die verwahrlost sind. Unsere Zeit sieht den Sinn des Lebens im Einsatz für eine allgemeine, gleichmäßige Höherentwicklung der Gesellschaft und könnte auf dieser Grundlage das Problem der Gefährdetenbetreuung und im Großen gesehen das der Bekämpfung der Geschlechtskrankheit lösen. "158 Dieses Diskussionspapier beschrieb den grundsätzlichen Wandel im künftigen Umgang mit Geschlechtskranken in Halle (Saale): Nicht Arbeitslager, sondern geschlossene Einrichtungen und pädagogische Unterweisungen sollten künftig Anwendung finden.

Eine solche Einrichtung war die geschlossene Venerologische Station der Poliklinik Mitte in Halle (Saale). Diese Station wurde im Jahr 1961 in der Kleinen Klausstraße 16 errichtet. Sie ging aus einer Beobachtungs- und Fürsorgestelle für geschlechtskranke Mädchen und Frauen hervor. Von der ursprünglichen Beobachtungs- und Fürsorgestelle in der Kleinen Klausstraße 16 existiert ein Bauplan vom 7. Juli 1949, der einen näherungsweisen Einblick in die geschlossene Venerologische Station von 1961 bietet. Aus diesem Plan geht hervor, dass im linken Seitenflügel eine Wohnung für Pflegerinnen, eine Wäschekammer, ein Röntgen- und ein Umspannraum sowie zwei Schlafräume, eine Teeküche, ein Waschraum und eine Toilette für das Personal bzw. ein Waschraum und Toiletten für die Patientinnen vorgesehen waren. Im rechten Seitenflügel waren ein Zimmer, ein Wohnraum und eine Küche geplant. Der Mittelflügel an der Großen Nikolaistraße war von links nach rechts wie folgt aufgebaut: Einem großen Schlafsaal mit vier Fenstern zur Großen Nikolaistraße und einem Fenster zum Innenhof schloss sich ein etwas kleinerer Tagesraum mit drei Fenstern zur Großen Nikolaistraße und drei Fenstern zum Innenhof an. Der angrenzende Behandlungsraum, das Arztzimmer und das Aufnahmebüro hatten jeweils ein Fenster zum Innenhof. Diese drei Räume waren durch einen Flur miteinander verbunden, der vom Tagesraum (links) bis zum Pförtner im Treppenhaus (rechts) reichte (Abb. 7). ${ }^{159}$

157 Vogel R M (2010) Auf dem Weg zum neuen Menschen. Umerziehung zur „sozialistischen Persönlichkeit“ in den Jugendwerkhöfen Hummelshain und Wolfersdorf (1961-1989). Peter Lang Frankfurt am Main (u. a.), S. $46 f f$.

158 StAH: A 2.23 Jugend- und Fürsorgeamt Nr. 27. Bd. 4. Ausführungen von Kolln (Anm. 154).

159 StAH: A 2.4 Bauakte Kleine Klausstraße 16. Bauplan für das Grundstück Kleine Klausstr. 16 „Fachkrankenhaus und Beobachtungsstelle im Mittelflügel an der Gr.-Nikolai-Str." 


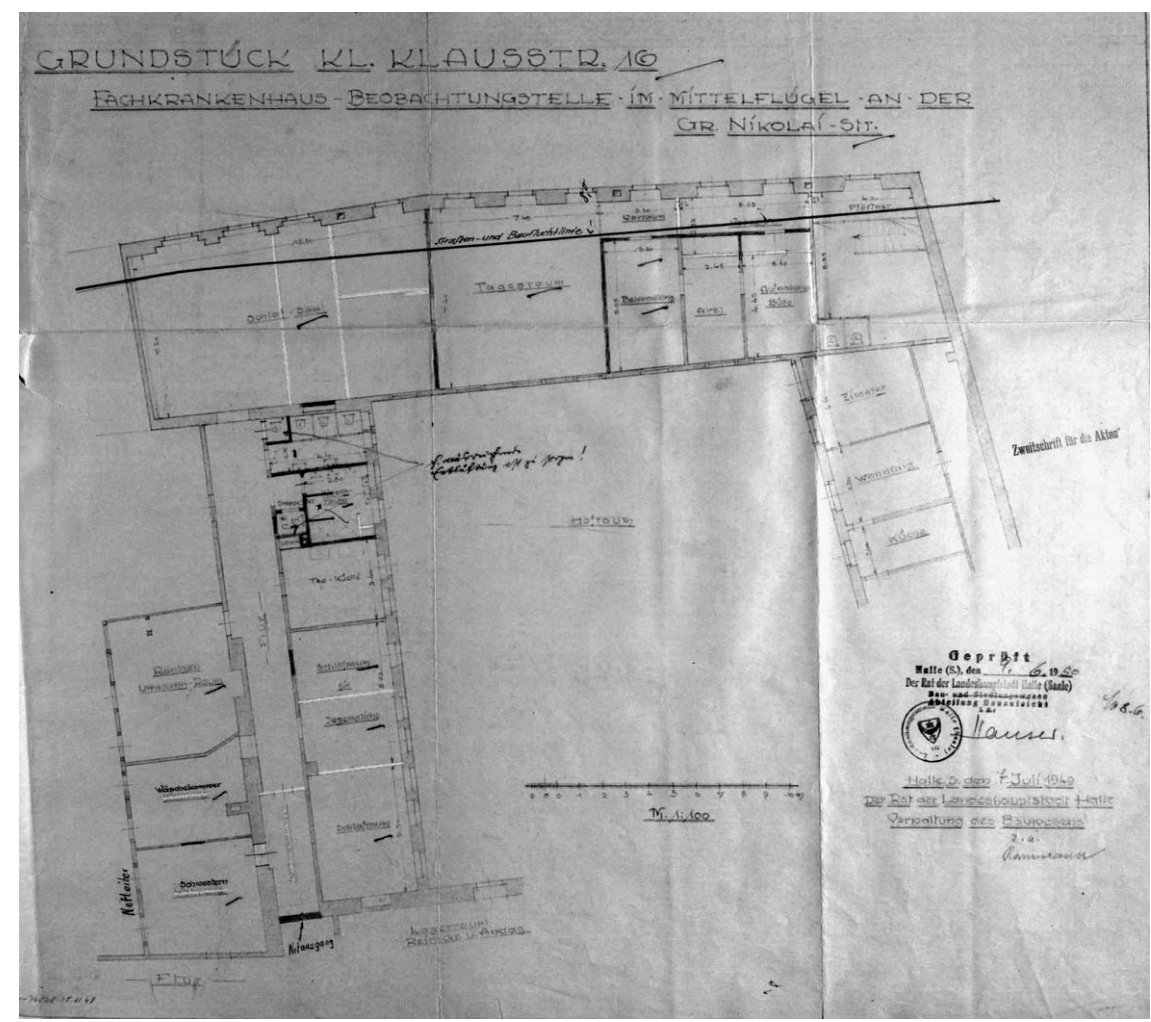

Abb. 7 Bauplan für das Grundstück Kleine Klausstraße 16 „Fachkrankenhaus und Beobachtungsstelle im Mittelflügel an der Gr-Nikolai-Str." (1947)

Die geschlossene Venerologische Station war Teil der 1961 eröffneten Poliklinik Mitte. Diese Poliklinik stellte die Versorgung der Bevölkerung im Zentrum der Stadt sicher und war Teil eines Netzes der ambulanten Versorgung der Stadt Halle (Saale). Hierzu gehörten die Poliklinik Süd, die 1947 in den Räumen des Bergmannstrost-Krankenhauses eröffnet wurde. ${ }^{160}$ Hier befand sich auch die „Beobachtungsstation im Fachkrankenhaus II“ für geschlechtskranke Mädchen und Frauen, die bis 1951 ein wesentlicher Anlaufpunkt für Geschlechtskranke war. Neben der Poliklinik Süd wurden 1950 die Poliklinik Nord am Reileck, 1951 die Poliklinik des VEB Waggonbau Ammendorf und die Poliklinik des Reichsbahnausbesserungswerks (RAW) eröffnet, um verstärkt „, fürsorgerische und prophylaktische Aufgaben“ übernehmen zu können. ${ }^{161}$

160 Bruns E (1983) Vom „Bergmannstrost“-Krankenhaus zur Poliklinik Süd-Halle. Diss., Halle (Saale).

161 Kaiser W, Sühs H (1972) 25 Jahre hallesche Poliklinik. Martin-Luther-Univ. Halle-Wittenberg Halle (Saale), S. 44. 


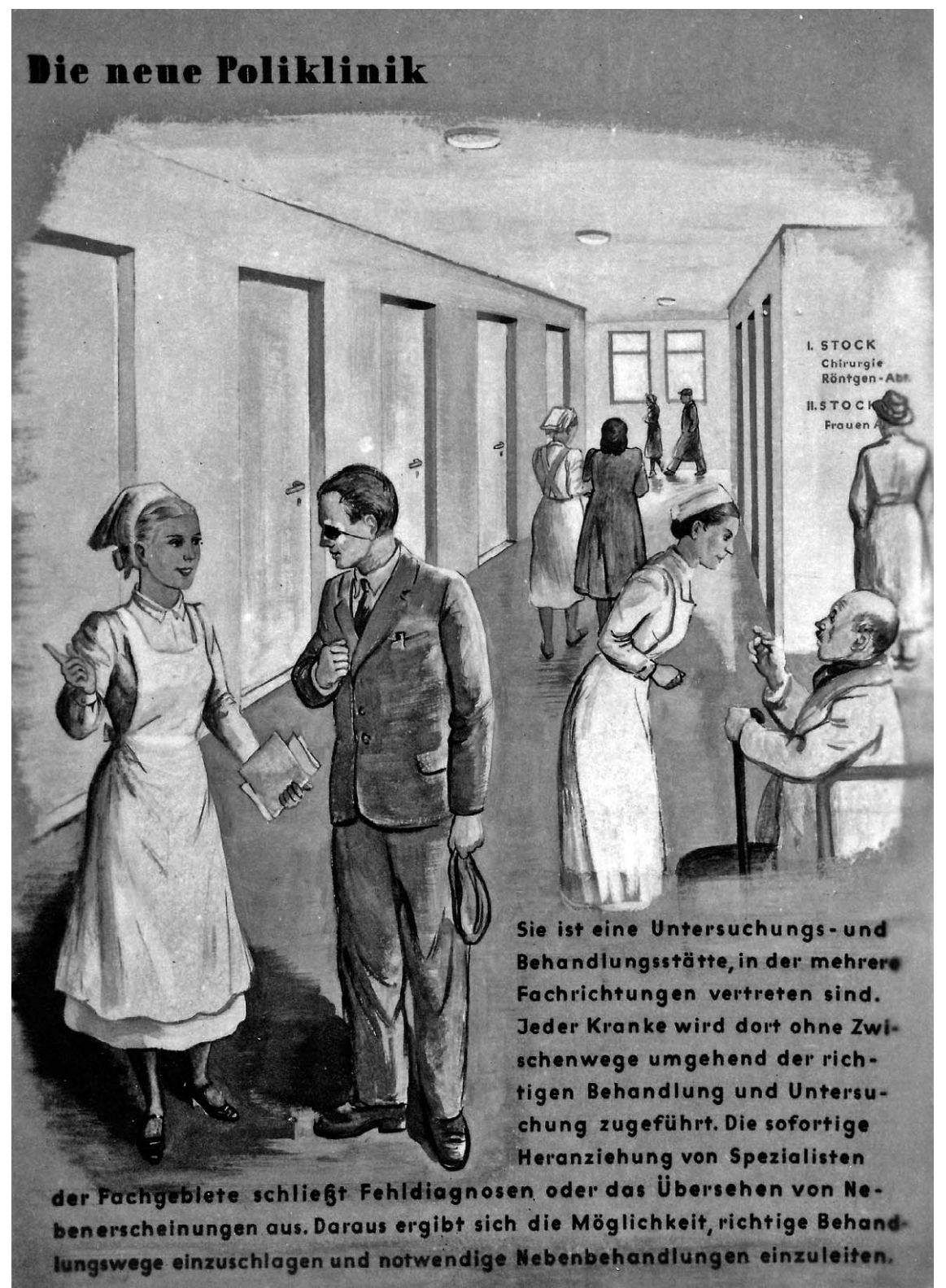

Abb. 8 Die neue Poliklinik (Plakat mit den Aufgaben von Polikliniken um 1948)

Doch schon ein Jahr nach der Eröffnung der Poliklinik Nord am Reileck wurden Kapazitätsprobleme bei der Versorgung der Patienten sichtbar. Als Konsequenz wurde am 1. Januar 1961 mit der Poliklinik Mitte die dritte städtische Poliklinik eröffnet. Ärztlicher Direktor wurde Gerd Münx, der zugleich Leiter der geschlossenen Venerologischen Abteilung war. Die Poliklinik entstand auf 
dem Baugrundstück Kleine Klausstraße 16, in einem Renaissancebau aus dem 16. Jahrhundert. Die Umbauarbeiten an dem Gebäude, in dem 1696 ein Gasthaus und später das Hotel „Zum Kronprinzen“ einzogen, erwiesen sich als schwierig. ${ }^{162}$ Im Erdgeschoss wurden fünf Sprech- und Behandlungszimmer sowie ein Operationssaal und im Seitenflügel zwei Laborräume eingerichtet.

Zeitzeugen beschreiben die Poliklinik Mitte wie folgt: „Die Poliklinik ging um einen Hof rum im Quadrat. “" ${ }^{63}$ „Wenn man reinkommt in dieses Gebäude, war auf der linken Seite eine kleine Pforte, also wo man sich anmelden musste, wo man hin wollte als Patient und wenn man weiter hineinging in dieses Gebäude, war ein riesengroßes [Vestibül, F.St. u. M.S.], auf der rechten Seite waren die Röntgenräume und auf der linken Seite war unten eine große Chirurgie (...). " ${ }^{164}$ Neben der Chirurgie und den Röntgenräumen gab es einen Augenarzt, einen Allgemeinmediziner und einen Internisten. Das „waren immer so Abteilungen, vor jeder Tür waren so kleine Wartezonen eingerichtet “" ${ }^{165}$ Des Weiteren befanden sich im Erdgeschoss ein Speisesaal, eine Physiotherapie und eine Hals-Nasen-Ohren-Abteilung. Am Ende folgten „hinten das Labor und Kinderabteilung “. ${ }^{166}$ In der zweiten Etage waren die zwei Hautabteilungen: „Wenn man die Treppe hochging, eine große breite Treppe bis in den zweiten Stock, war dann auf der linken Seite die Hautabteilung, die ambulante Hautabteilung und dann wiederum noch von dort verbunden eine Tür auf diese geschlossene V-Station, so haben wir die genannt. " ${ }_{167}$ Patienten, die regelmäßig in der Poliklinik Mitte ambulant behandelt wurden, kamen teilweise mit den zwangseingewiesenen Mädchen und Frauen der geschlossenen Venerologischen Station in Berührung.

Die geschlossene Venerologische Station war rund um die Uhr mit einer vergitterten Tür verschlossen: „Eine geschlossene Station heißt, also man kam nur mit einem besonderen Schlüssel oder mit Klopfzeichen da hinein. " ${ }^{168} \mathrm{Hin}$ ter der Tür „war es sehr geheimnisvoll“. ${ }^{169}$ Betrat man die geschlossene Venerologische Station, dann traf man direkt am Eingang auf eine Citterbox „,mit einem Holzhocker drinnen“, wie sich eine ehemalige Zwangseingewiesene erinnert. ${ }^{170}$ Andere Zeitzeuginnen berichten: „Also, es war vorne dieser Bretterverschlag, dann war ein Bad, Flur - der ging so ein bisschen um die Ecke

162 Köster K (2011) Mediziner, Monarchen und Musiker. Das Hotel „Zum Kronprinzen“ als ein Mittelpunkt des gesellschaftlichen Lebens in Halle während des 19. Jahrhunderts. Hallesche Hefte 3, 15-22.

163 Interview mit Frau HZA, geführt von Maximilian Schochow, Halle (Saale), den 13. Mai 2014.

164 Interview mit Frau HZB, geführt von Maximilian Schochow, Halle (Saale), den 15. Mai 2014.

165 Interview mit Herrn HZC, geführt von Florian Steger und Maximilian Schochow, Halle (Saale), den 11. Februar 2014.

166 Interview mit Frau HZA (Anm. 163).

167 Interview mit Frau HZB (Anm. 164).

168 Interview mit Frau HZA (Anm. 163).

169 Interview mit Frau HZD, geführt von Florian Steger und Maximilian Schochow, Halle (Saale), den 11. Dezember 2013.

170 Interview mit Frau HPA, geführt von Maximilian Schochow, Halle (Saale), den 13. Mai 2014. 
und da waren Patientenzimmer. “"171 In den Zimmern standen Betten: „Es waren wirklich 5-Bett-Zimmer. Immer.“ “72 Am „Fenster war ein Tisch. Und da waren Stühle noch drum herum“. ${ }^{173}$ Auch von anderen Zeitzeuginnen wird ein großer langer Tisch beschrieben, an dem „die Frauen saßen “ ${ }^{174}$ und beispielsweise „ihre Würfelspiele machten“. ${ }^{175}$ Darüber hinaus gab es ein Untersuchungszimmer und ein Zimmer für die Schreibkraft. „In dem Untersuchungszimmer war ein Gynstuhl drin. " ${ }^{176}$ Sowohl die Räumlichkeiten, in denen die Zwangseingewiesenen ihren Alltag verbrachten und größtenteils sich selbst überlassen waren, als auch der Untersuchungsraum mit dem gynäkologischen Stuhl werden von allen Zeitzeuginnen als steril und freudlos beschrieben: „Es waren kahle Räume, keine Bilder, die Fenster waren vergittert. Da war vorne ein Aufenthaltsraum für diese Patienten, für dieses Klientel (...), diese Frauen, meistens Jüngere, die dort mit kahl geschorenen Köpfen saßen tagsüber und den graublauen Kitteln, ein stumpfer Gesichtsausdruck (...). Sie warteten halt auf ihre Mahlzeiten, gegebenenfalls, wenn sie sich gut verhalten hatten, bekamen sie zur Belohnung mal eine Zigarette, weil, es waren fast alles Raucher. Wenn die Stimmung halt nicht so gut war, wurden auch die Fenster nicht geöffnet. Von daher war eine stickige schlechte Luft in diesen Räumlichkeiten, was alles für die Angestellten sehr unangenehm war. “177

Eine ehemalige Oberschwester der Poliklinik Mitte bestätigt die Aussage, dass alle Fenster der geschlossenen Venerologischen Station vergittert waren: „Alles vergittert, sämtliche Fenster bis auf eins, das in den Hof ging und unser ehemaliger Chef war ja erfinderisch. Der sagte, wir machen da unter das Fenster eine Bremse, und er schüttete Sand hin, jede Menge, sodass, wenn jemand aus den Fenster sprang, und die wollten ja alle raus, die wollten ja nicht eingesperrt sein, dann landeten sie auf dem Sand. Es ist keiner gesprungen in den dreißig Jahren, wo ich dort war. “" ${ }^{178}$ Man rechnete also vonseiten der Stationsleitung stets mit einem Ausbruch der Zwangseingewiesenen. Dies deutet darauf hin, dass dem dort tätigen medizinisch-pflegerischen Personal bewusst war, dass die Mädchen und Frauen gegen ihren Willen auf der Station festgehalten wurden.

171 Interview mit Frau HZD (Anm. 169).

172 Interview mit Frau HZA (Anm. 163).

173 Interview mit Frau HZD (Anm. 169).

174 Interview mit Frau HZE, geführt von Florian Steger und Maximilian Schochow, Halle (Saale), den 9. Januar 2014.

175 Interview mit Frau HZD (Anm. 169).

176 Interview mit Frau HZE (Anm. 174).

177 Interview mit Frau HZB (Anm. 164).

178 Interview mit Frau HZA (Anm. 163). 


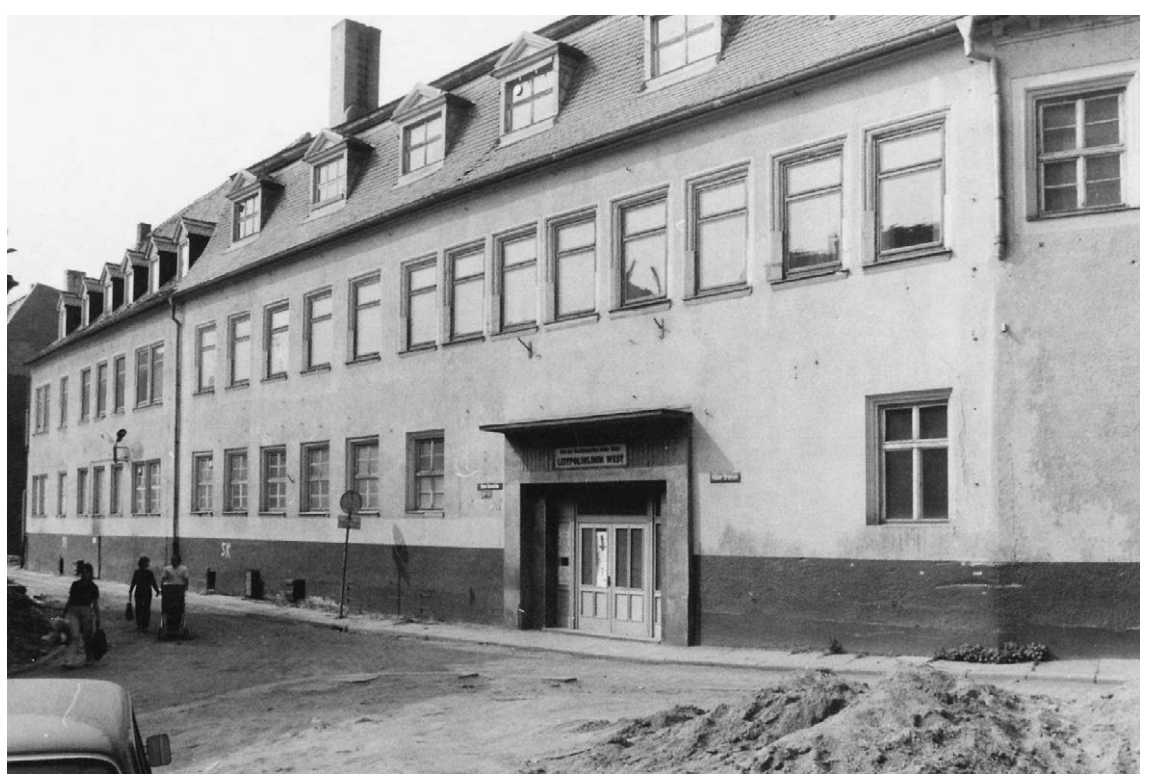

Abb. 9 Die Poliklinik Mitte in Halle (Saale) (um 1985)

Seit Gründung der Poliklinik Mitte wurde die Einrichtung mehrfach umstrukturiert: „Wir waren mal selbstständig, dann wurden wir Bezirkskrankenhaus, dann wurden [wir] Poliklinik und stationär geteilt. Also, es war immer ein Hin und Her." ${ }^{179}$ Ein Zeitzeuge, der im ersten Monat der Gründung der Poliklinik Mitte seine Famulatur auf der geschlossenen Venerologischen Station absolvierte, schildert, dass es eine geschlossene Station für Männer gegeben habe. Diese musste geschlossen werden, weil das Personal den männlichen Zwangseingewiesenen nicht gewachsen war: „Es gab auch mal, das habe ich aber nicht erlebt, eine Männerstation, aber die Schwestern wurden mit den Männern nicht fertig, die büxten aus, kletterten aus dem Fenster, gingen dann in die entsprechenden Etablissements (...), wo man sich traf, und da wurde das aufgegeben. " ${ }^{180}$ Ähnlich äußert sich eine Pflegerin, die im Sommer 1961 in der Poliklinik die Arbeit aufgenommen hatte: „Da soll also, glaube ich, auch noch eine Männerstation existiert haben, die aber dann wegfiel. Die wurde irgendwann wegrationalisiert. Als ich anfing, waren die Männer schon nicht mehr da. " 181

Im Zuge der strukturellen Neuausrichtung der Poliklinik Mitte wurde auch das Ende der geschlossenen Venerologischen Station Ende der 1970er Jahre eingeleitet. Einige Gründe für die Umstrukturierung gehen aus einem Beratungs-

179 Interview mit Frau HZA (Anm. 163).

180 Interview mit Herrn HZF, geführt von Florian Steger und Maximilian Schochow, Halle (Saale), den 8. April 2014. 181 Interview mit Frau HZA (Anm. 163). 
protokoll zwischen dem Prorektor für Medizin der Martin-Luther-Universität und dem Bezirksarzt des Bezirks Halle (Saale) vom 10. Juni 1982 hervor: „So existiert im Bezirk Halle zur Zeit kein Anlaufpunkt (Universitäts-Hautklinik aus Kapazitätsgründen dazu nicht in der Lage) zur differenzierten Diagnostik von Patienten mit Geschlechtskrankheiten (seit Jahren höchste Zuwachsrate an Geschlechtskrankheiten in dem medizinischen Kooperationsbereich I).“ Konkret in Zahlen ausgedrückt hieß das, es fehlten 1982 im klinischen Bereich von Halle (Saale) 6o Betten zur Versorgung von Haut- und Geschlechtskranken. ${ }^{182}$ Um die Frage der Kapazitäten zu lösen, wurde ein Trägerwechsel vorgeschlagen. Die Universitätshautklinik, die zu keinem Zeitpunkt mit der geschlossenen Venerologischen Station in Verbindung stand, sollte aus einem Gebäude mit der Adresse am Harz ausziehen und ihre Kapazitäten im Universitätsklinikum in Kröllwitz bündeln. Dort wurde im zweiten Bettenhaus die Hautklinik mit Bettenstationen eingerichtet. Das freiwerdende Gebäude wiederum wurde an das Bezirkskrankenhaus Halle (Saale) übergeben, welches in der Klinik am Harz eine dermatologische Abteilung einrichten sollte. ${ }^{183}$

Am 9. Dezember 1982 teilte der Ärztliche Direktor des Bezirkskrankenhauses Halle (Saale) der SED-Bezirksleitung Halle (Saale) mit, „daß die Hautklinik des Bezirkskrankenhauses Halle planmäßig am 6. Dezember 1982 dem Chefarzt Obermedizinalrat Dr. med. Narwutsch übergeben werden konnte und damit das Objekt, das wir von der Martin-Luther-Universität Halle-Wittenberg übernommen haben, betreuungswirksam ist“. ${ }^{184}$ Das Bezirkskrankenhaus Halle (Saale), sprich die Poliklinik Mitte, hatte ihre Hautabteilung vollständig mit Ärzten, Pflegekräften, Krankenunterlagen und Mobiliar in die Räume der Hautklinik am Harz verlagert. In der neuen Klinik blieben die Hautambulanz und der stationäre Bereich strikt getrennt. Dort arbeiteten bis 1992 eine Oberärztin, zwei Fachärzte, ein Arzt in Weiterbildung sowie OP-Schwestern und Sprechstundenhilfen. ${ }^{185}$ In der Poliklinik Mitte gab es nach 1982 keine Hautabteilung mehr. Mit der Inbetriebnahme der Hautklinik am Harz durch das Bezirkskrankenhaus Halle (Saale) endete gleichzeitig die Geschichte der geschlossenen Venerologischen Station der Poliklinik Mitte in Halle (Saale). Nach dem Zusammenbruch der DDR und der deutschen Wiedervereinigung wurde die Poliklinik Mitte in ein Ärztehaus umgewandelt.

182 Archiv der Diakonie: Hautklinik ab Apr. 98 - Neue Mappe, Gefäßchirurgie, IST. Protokoll einer Beratung zwischen dem Prorektor für Medizin der Martin-Luther-Universität und dem Bezirksarzt des Bezirkes Halle, Halle (Saale), den 10. Juni 1982.

183 Archiv der Diakonie: Hautklinik ab Apr. 98 - Neue Mappe, Gefäßchirurgie, IST. Schreiben von Chefarzt Dr. habil. Kühn an das Evangelische Diakoniewerk Halle, Halle (Saale), den 5. Mai 1993.

184 Archiv der Diakonie: Hautklinik ab Apr. 98 - Neue Mappe, Gefäßchirurgie, IST. Ärztlicher Direktor des Bezirkskrankenhauses Halle, Halle (Saale), den 9. Dezember 1982.

185 Archiv der Diakonie: Hautklinik ab Apr. 98 - Neue Mappe, Gefäßchirurgie, IST. Schreiben (Anm. 183). 


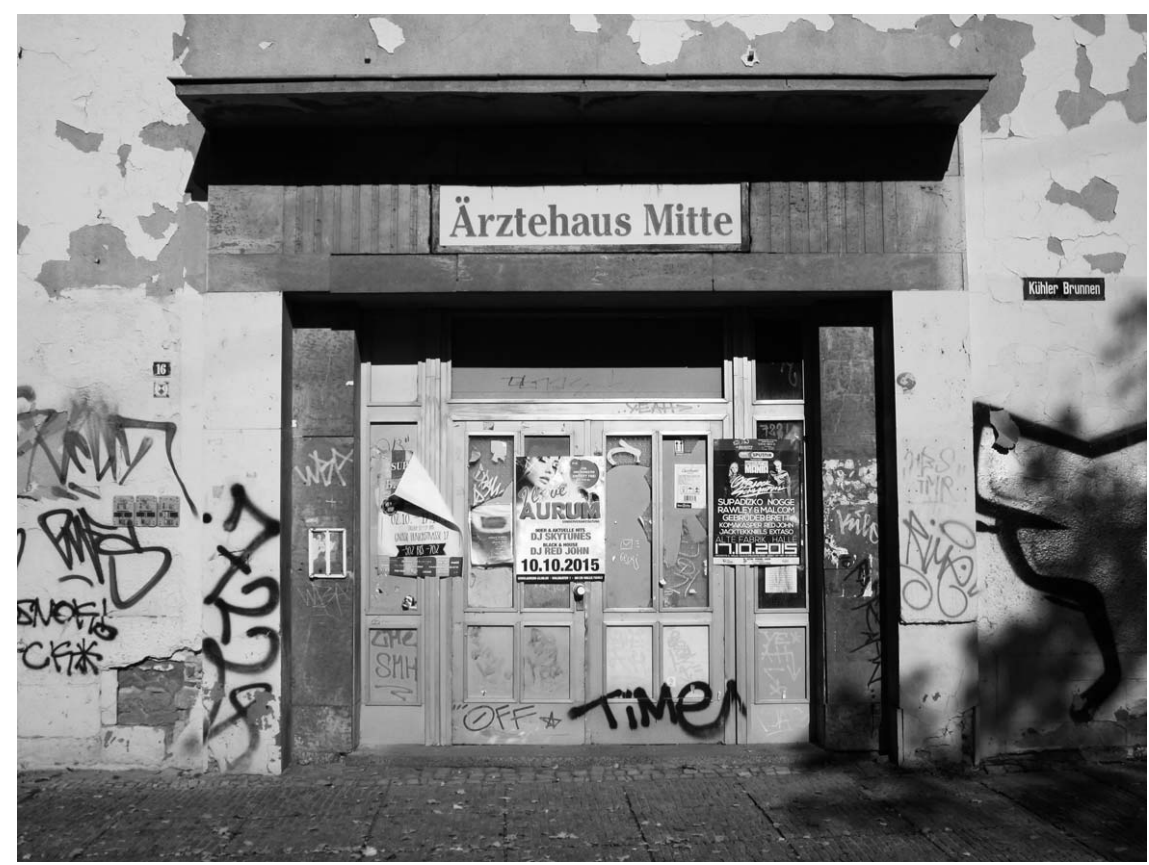

Abb. 10 Ärztehaus in der ehemaligen Poliklinik Mitte in Halle (Saale) (2015)

\subsection{Die Funktion der Station}

Einzelne geschlossene Venerologische Stationen hatten eine Hausordnung, in denen der interne normative Rahmen für die Behandlung von Geschlechtskranken vorgegeben und die Funktion der Einrichtungen benannt wurden. Aus der „Hausordnung. Für die Patientinnen der geschlossenen Geschlechtskranken Frauenstation im Stadtkrankenhaus Mitte Halle(S) Kleine Klausstr. 16“, die am 23. April 1963 in Kraft trat, gehen vier Funktionen hervor: Erziehungsstätte, Behandlungsstätte, Isolierstätte und Disziplinarstätte. ${ }^{186}$ Die Hausordnung wurde nicht von staatlichen Stellen, etwa dem Rat des Kreises, Abteilung Gesundheits- und Sozialwesen, oder einer Bezirksstelle vorgegeben. Nicht einmal das Ministerium für Gesundheitswesen war an der Erstellung beteiligt. Vielmehr wurde die Hausordnung vom Ärztlichen Direktor der Poliklinik Mitte verfasst. Entsprechend wurden die Regelungen zur Funktion und zum Alltag der Zwangseingewiesenen auf der geschlossenen Venerologischen Station nicht politisch vorgegeben, sondern von einer politisierten Medizin eigenständig entworfen. ${ }^{187}$

Die Hausordnung der geschlossenen Venerologischen Station in Halle (Saale) hatte eine besondere Vorgeschichte. Im Jahr 1961 war eine Frau zur Beobach-

186 BArch Best. DQ 1. Nr. 4228, unpag. Hausordnung (Anm. 24).

187 BArch Best. DQ 1. Nr. 4228, unpag. Hausordnung (Anm. 24), S. 1. 
tung in die geschlossene Venerologische Station von Halle (Saale) eingeliefert worden. Weiter heißt es in einem Schreiben aus dem Jahr 1962: „Wegen undisziplinierten Verhaltens der Eingewiesenen griff das sogenannte Selbsterziehungskollektiv der Patientinnen ein und hat als Erziehungsmaßnahme der den Kopf völlig kahl geschoren. Derartige Dinge sind damals mit Wissen des Direktors (Herr Dr. Münx) schon wiederholt vorgekommen. "188 Dieser Übergriff war an die Generalstaatsanwaltschaft der DDR weitergeleitet worden, die wiederum das Ministerium für Gesundheitswesen im Mai 1962 darüber informierte, dass im Zusammenhang mit den Vorkommnissen in der geschlossenen Venerologischen Station von Halle (Saale) ermittelt werden würde. Im Juni desselben Jahres wurde ein Rundschreiben des Ministeriums für Gesundheitswesen an alle Räte der Bezirke versandt, in dem die Ereignisse im Stadtkrankenhaus Mitte Halle (Saale) angesprochen und vom Ministerium für Gesundheitswesen ausdrücklich missbilligt wurden. ${ }^{189}$ Cleichzeitig wurden Räte der Bezirke aufgefordert, den Vorfall zum Anlass zu nehmen, „bei entsprechender Gelegenheit die Kreisärzte bzw. Ärztlichen Direktoren darauf hinzuweisen, daß solche Handlungen von den Mitarbeitern der Gesundheitseinrichtungen zu verhindern sind“. ${ }^{190}$ Das Ministerium für Gesundheitswesen wusste demnach seit Anfang der 196oer Jahre von der menschenunwürdigen Behandlung und den Erziehungsmaßnahmen an den Mädchen und Frauen in der geschlossenen Venerologischen Station in Halle (Saale). Gleichzeitig war das Ministerium aufgefordert, allgemein verbindliche Vorgaben für die Hausordnungen in geschlossenen Venerologischen Stationen der DDR vorzugeben.

Doch nicht das Ministerium für Gesundheitswesen, sondern verschiedene „Dermato-Venerologen“ erarbeiteten Entwürfe für die Hausordnungen dieser Stationen. Einen solchen Vorschlag unterbreitete unter anderem der „BezirksDermato-Venerologe“ aus Erfurt in einem Schreiben vom 4. Oktober 1962 dem Ministerium für Gesundheitswesen in Berlin. Diesem Schreiben legte er die zu diesem Zeitpunkt gültige Hausordnung der geschlossenen Abteilung der Hautklinik der Medizinischen Akademie Erfurt bei (Abb. 11). ${ }^{191}$ In der Hausordnung wurde die Aufnahme in die geschlossene Station geregelt, der Tagesablauf beschrieben sowie die Funktion benannt - Arbeit, Disziplinierung, Isolierung und Behandlung. ${ }^{192}$

188 BArch Best. DQ 1. Nr. 4228, unpag. Generalstaatsanwaltschaft der Deutschen Demokratischen Republik, Ministerium für Gesundheitswesen, Staatssekretär, Berlin, 5. Mai 1962, Schwärzung im Original.

189 BArch Best. DQ 1. Nr. 4228, unpag. Ministerium für Gesundheitswesen an Rat d. Bezirks Abt. Gesundheits- und Sozialwesen. An alle Räte der Bezirke, Berlin, den 15. Juni 1962.

190 BArch Best. DQ 1. Nr. 4228, unpag. Ministerium für Gesundheitswesen. Räte der Bezirke (Anm. 189)

191 BArch Best. DQ 1. Nr. 4228, unpag. Rat des Bezirkes Erfurt Abt. Gesundheits- und Sozialwesen Dr. G. (Bezirks-Dermato-Venerologe) an Ministerium f. Gesundheitswesen Sektor spezieller Gesundheitsschutz Dr. M., Erfurt, den 4. Oktober 1962.

192 BArch Best. DQ 1. Nr. 4228, unpag. Rat des Bezirkes Erfurt Dr. G. an Ministerium (Anm. 191). 


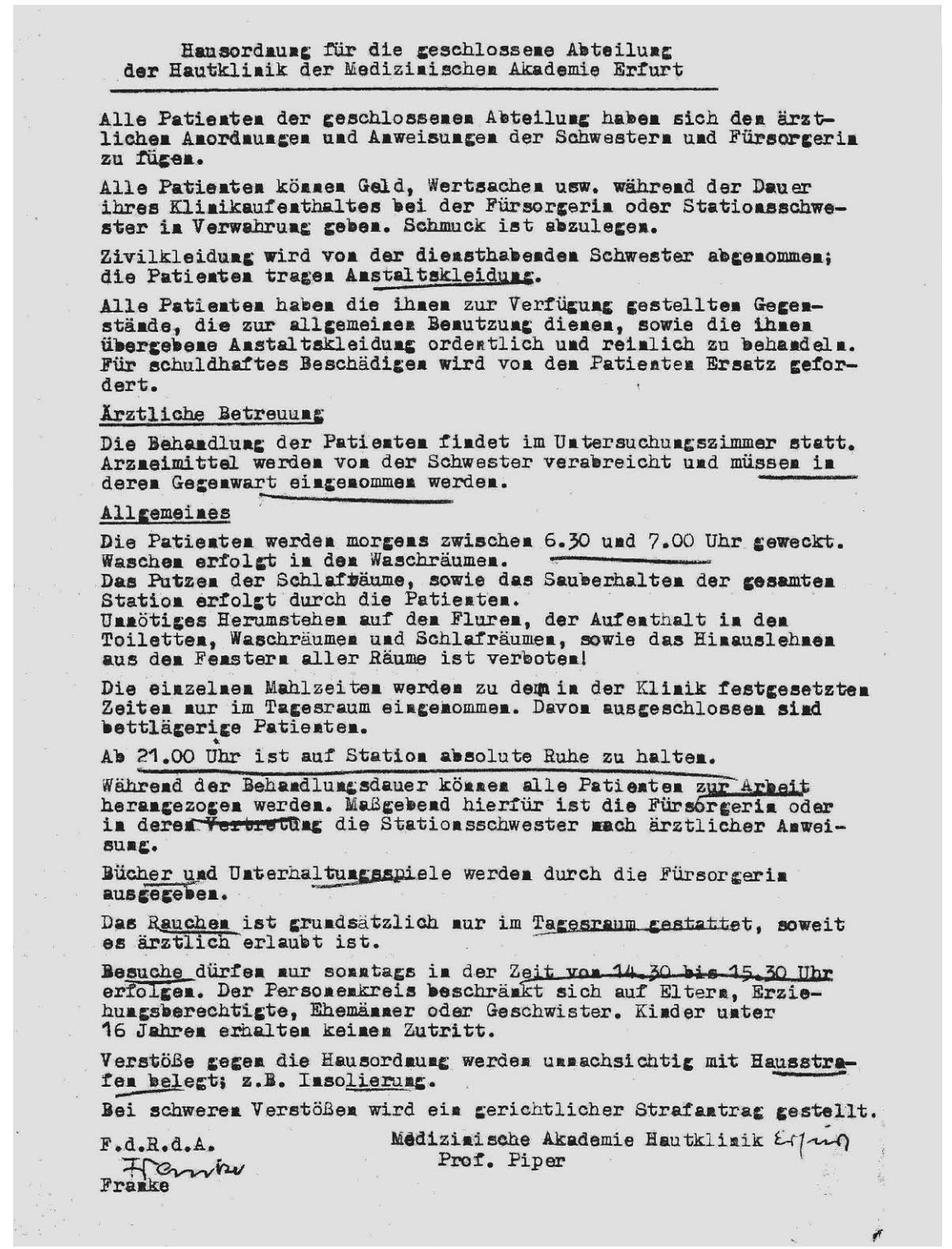

Abb. 11 Hausordnung für die geschlossene Abteilung der Hautklinik der Medizinischen Akademie Erfurt

Ob das Ministerium die Hausordnung von Erfurt als Arbeitsgrundlage verwendet hat bzw. an die anderen Einrichtungen mit geschlossenen Abteilungen wie Leipzig-Thonberg oder die Poliklinik Mitte in Halle (Saale) geschickt hat, ist nicht bekannt. Sicher ist, dass der Ärztliche Direktor der Poliklinik Mitte in Halle (Saale) am 23. April 1963 eine Hausordnung für die geschlossene Venerologische Station erließ. Diese weist eine gewisse Ähnlichkeit mit der 
Hausordnung der geschlossenen Abteilung der Hautklinik in Erfurt auf. Die Hausordnung von Halle (Saale) ist in mehrere Kapitel gegliedert, denen eine Art Präambel vorangestellt ist. In den einzelnen Kapiteln werden Regelungen zur Aufnahme und zum Verhalten auf der Station festgeschrieben. Darüber hinaus finden sich einige Ausführungen zu Disziplinarmaßnahmen gegenüber den Zwangseingewiesenen, beispielsweise die Nachtruhe außerhalb des Bettes auf einem Hocker. ${ }^{193}$ Überdies wird in der von Münx verfassten Präambel deutlich, wie eine politisierte Medizin Ideen aufgreift, diese modifiziert und dann zu eigenen Normen macht.

In der Präambel wird ausgeführt: „Entsprechend des Charakters unserer Staats- und Gesellschaftsordnung sind die in die geschlossene Station eingewiesenen Patientinnen aufgrund der Verordnung zur Bekämpfung der Geschlechtskrankheiten vom 23. Februar 1961 vorübergehend von der Gesellschaft isoliert. Durch erzieherische Einwirkung muss erreicht werden, dass diese Bürger nach ihrer Krankenhausentlassung die Gesetze unseres Staates achten, eine gute Arbeitsdisziplin zeigen und sich in ihrem Verhalten in unserer Gesellschaft von den Prinzipien des sozialistischen Zusammenlebens der Bürger unseres Staates leiten lassen. Die Zeit des Aufenthaltes in der geschlossenen Station dient der Erkennung bzw. Ausheilung ihrer Volkskrankheit sowie der Vorbereitung auf ihr weiteres Leben unter den genannten neuen Bedingungen sowie unter strengster Beachtung der oben angeführten Verordnung. Deshalb sind die Einhaltung aller Ordnungsregeln innerhalb der geschlossenen Station und die bedingungslose Befolgung mündlicher Anweisungen des Schwesternpersonals unbedingte Notwendigkeiten. " ${ }^{194}$

Damit wird deutlich, welche Ziele mit der geschlossenen Venerologischen Station verfolgt wurden. Auf der rechtlichen Grundlage der „Verordnung zur Verhütung und Bekämpfung von Geschlechtskrankheiten“ sollten die Mädchen und Frauen isoliert und erzogen werden. Deutlich formuliert wurde, dass so „Bürger“ erzogen werden sollten, welche die Gesetze des Staates achten. Es ging hier also in erster Linie um die Erziehung zum sozialistischen Bürger bzw. zur „sozialistischen Persönlichkeit“" 195 - wie auch in anderen Einrichtungen der DDR. ${ }^{196}$ Grundlagen dieser Erziehungsziele waren, in der Lesart der

193 BArch Best. DQ 1. Nr. 4228, unpag. Hausordnung (Anm. 24), S. 6.

194 BArch Best. DQ 1. Nr. 4228, unpag. Hausordnung (Anm. 24), S. 1.

195 Eckardt P (2006) Erziehung zur sozialistischen Persönlichkeit. Erziehung in der DDR. In: Thieme J, Beyler G, Klein B (Hrsg.) Geschlossene Heimunterbringung im Kontext sozialistischer Erziehung in der DDR. 13-22. Initiativgruppe Geschlossener Jugendwerkhof Torgau Torgau; Zimmermann V (2008) „Den neuen Menschen auf eine neue Weise schaffen“. Die Umerziehung von sozial fehlentwickelten und straffälligen Jugendlichen in der DDR (1945-1990). In: Barkleit G, Kwiatkowski-Celofiga T (Hrsg.) Verfolgte Schüler - gebrochene Biographien. Zum Erziehungs- und Bildungssystem der DDR. 113-120. Sächsische Landeszentrale für politische Bildung Dresden.

196 Gatzemann A (2008) Die Erziehung zum „neuen“ Menschen im Jugendwerkhof Torgau. Ein Beitrag zum kulturellen Gedächtnis. Lit Berlin, Münster, S. 35; Kaczmarek S (2008) Dir werd' ich schon helfen! Zur Erziehung in den Jugendwerkhöfen der DDR. In: Barkleit G, Kwiatkowski-Celofiga T (Hrsg.) Verfolgte Schüler - gebrochene Biographien. Zum Erziehungs- und Bildungssystem der DDR. 121-135. Sächsische Landeszentrale für politische Bildung Dresden. 
SED, der Marxismus-Leninismus sowie die wissenschaftlichen Einsichten und Erfahrungen aus dem Klassenkampf. Vor diesem Hintergrund wurde eine Erziehung zur „wissenschaftlich fundierten, unverrückbaren Klassenposition“ und die Parteinahme für den Sozialismus angestrebt. Die Erziehung zum neuen sozialistischen Menschen war nicht nur auf Haftanstalten oder Jugendwerkhöfe beschränkt, sondern setzte im Vorschulalter ein und durchzog alle Formen des einheitlich organisierten Erziehungssystems. Die im Erziehungsprozess vermittelten Wertorientierungen und Verhaltensweisen erfüllten ihre Funktion nur dann, wenn sie mit den Zielen von Partei und Staat in Übereinstimmung lagen. ${ }^{197}$ In der konkreten Ausformulierung der Hausordnung der geschlossenen Venerologischen Station wurde unter einer sozialistischen Persönlichkeit diejenige Person verstanden, die „eine gute Arbeitsdisziplin“ zeige und sich nach „den Prinzipien des sozialistischen Zusammenlebens der Bürger unseres Staates“ verhalte. ${ }^{198}$ Dieses Erziehungsprogramm wurde im Alltag der geschlossenen Venerologischen Station mithilfe verschiedener Formen der Disziplinierung - striktes Zeitregime, „Arbeitstherapie“, Belobigungen und harte Strafen - im Alltag konsequent umgesetzt (Kap. 4.6).

Erst an zweiter Stelle tauchte in der Hausordnung der geschlossenen Venerologischen Station Halle (Saale) die medizinische Funktion der Einrichtung, die „Erkennung bzw. Ausheilung ihrer Volkskrankheit“"199 auf. Wie gering diese medizinische Funktion gegenüber der pädagogischen gewertet wurde, verdeutlich die Präambel. Hier war festgeschrieben, dass die Zeit auf der Station nicht nur zur Erkennung und Ausheilung von Geschlechtskrankheiten genutzt werden sollte, sondern zur Vorbereitung auf das weitere Leben unter den genannten Bedingungen der sozialistischen Staats- und Gesellschaftsordnung diente. ${ }^{200}$ Indem die pädagogische Funktion der geschlossenen Venerologischen Station betont wurde, knüpfte die Hausordnung unter anderem an die im August 1951 erarbeitete Vorlage der Stadtverwaltung Halle (Saale) zum weiteren Umgang mit Geschlechtskranken bzw. „asozialen“ Personen an. Darin hatte sich die Stadtverwaltung von Halle (Saale) für eine Erziehung der gefährdeten Mädchen und Frauen nach dem Vorbild des sowjetischen Pädagogen Makarenko entschieden. ${ }^{201}$ In seinem Pädagogischen Poem ${ }^{202}$ hatte Makarenko die Kollektiverziehung mit dem Ziel verknüpft, eine sozialistische Persönlichkeit mithilfe von Disziplin zu formen. Mit der Hausordnung der geschlossenen Venerologischen Station in Halle (Saale) wurden die Anfang der 1950er Jahre diskutierten pädagogischen Rahmenbedingungen umgesetzt. Für die Wirksamkeit der Erziehungspläne waren das Einhalten aller Ordnungsregeln innerhalb der geschlossenen Venerologischen Station und die

197 Gatzemann: Die Erziehung zum „neuen“ Menschen im Jugendwerkhof Torgau (Anm. 196).

198 BArch Best. DQ 1. Nr. 4228, unpag. Hausordnung (Anm. 24), S. 1.

199 BArch Best. DQ 1. Nr. 4228, unpag. Hausordnung (Anm. 24), S. 1.

200 BArch Best. DQ 1. Nr. 4228, unpag. Hausordnung (Anm. 24), S. 1.

201 StAH: A 2.23 Jugend- und Fürsorgeamt Nr. 27. Bd. 4. Ausführungen von Kolln (Anm. 154).

202 Makarenko: Ein pädagogisches Poem (Anm. 156). 
bedingungslose Befolgung von Anweisungen unbedingte Notwendigkeiten, wie es in der Hausordnung weiter heißt. ${ }^{203}$

Im Anschluss an die Präambel folgen im zweiten Teil der Hausordnung die Regeln für die Aufnahme in die geschlossene Station. „Alle Ausweispapiere, alle Wertsachen wie Uhren, Ringe und ebenso Geldbeträge über DM 5,-- sowie alle privaten Bekleidungsstücke sind bei der Aufnahme der aufnehmenden Krankenschwester abzugeben. Diese Gegenstände werden in der Verwaltung bzw. im Effektenraum verwahrt. Bei Abgang werden alle registrierten Gegenstände zurückgegeben. "204 Nachdem die Zwangseingewiesenen alle privaten Gegenstände abgegeben hatten, sollten sie sich waschen und die Anstaltskleidung anziehen. Anschließend erfolgte ein Einweisungsgespräch, in dem die Mädchen und Frauen angeben sollten, warum sie auf die geschlossene Venerologische Station gekommen waren. Weiterhin wurden sie mit der Hausordnung vertraut gemacht und darüber informiert, welcher Alltag sie auf der Station erwartete. Dieser Alltag folgte, laut der Hausordnung, einem strengen Zeitregime. Unpünktlichkeit würde sofort bestraft werden. ${ }^{205}$ Vor allem die Prozedur der Einweisung wurde in der täglichen Routine umgesetzt. Dies zeigen die Aussagen verschiedener Zeitzeuginnen deutlich (Kap. 4.4).

Im dritten Teil der Hausordnung, den Verhaltensregeln auf dem Zimmer und auf der Station, ist zu lesen, dass für jedes Krankenzimmer eine Stubenälteste bestimmt werden sollte. Deren Anordnungen war unbedingt Folge zu leisten. Für Ordnung und Sauberkeit in den Krankenzimmern seien alle Patientinnen gleichsam verantwortlich. „Die Mahlzeiten werden im gemeinsamen Aufenthalts- und Speiseraum eingenommen." Es folgt eine Reihe von Verboten wie die Aufbewahrung von Lebensmitteln und Toilettenartikeln in einem Fach des Arzneischranks oder die Benutzung der Betten am Tag - mit Ausnahme der Mittagsruhe oder der besonderen Genehmigung eines Arztes oder der Stationsschwester. Jegliche Art von Ausgelassenheit oder Unruhe war streng untersagt. Weiterhin war es den Mädchen und Frauen verboten, „Sitzgelegenheiten, Betten oder Fensterbänke zu besteigen, um aus dem Fenster zu sehen. Speisereste oder andere Dinge aus dem Fenster zu werfen. (...) Singen, Lärmen, Pfeifen, Tanzen, Schlägereien oder laute Unterhaltungen in dem Krankenzimmer oder auf dem Krankenflur zu führen. (...) Schundliteratur zu lesen bzw. zu verbreiten. (...) Das Schminken während der Dauer der Behandlung. (...) Das Rauchen ab 19.30 Uhr. (...) Zänkereien und Schlägereien (...). Keiner darf einer anderen Patientin die Erkrankung zum Vorwurf machen. (...) Mit anderen Krankenhausinsassen oder fremdem Personal illegal in Verbindung zu treten und sich aus dem Fenster oder durch die Tür mit ihnen zu unterhalten. (...) Ohne Erlaubnis ein anderes Krankenzimmer zu betreten. (...)

203 BArch Best. DQ 1. Nr. 4228, unpag. Hausordnung (Anm. 24), S. 1.

204 BArch Best. DQ 1. Nr. 4228, unpag. Hausordnung (Anm. 24), S. 1, Kursivierung im Original.

205 BArch Best. DQ 1. Nr. 4228, unpag. Hausordnung (Anm. 24), S. 1 . 
Gegenstände, Wertsachen, Geldbeträge über DM 5.- bei sich zu behalten. "206 Wer gegen diese Verbote verstieß, musste mit empfindlichen Strafen rechnen, die entweder von den Schwestern oder den Stubenältesten überwacht und ausgeführt wurden. Die Stubenältesten, die laut Hausordnung für die Überwachung dieser Pflichten und Verbote zuständig waren, wurden in den Interviews immer wieder genannt. Sie überwachten aber nicht nur die einzelnen Vorschriften und Reglementierungen, sondern waren Teil des täglichen Terrors. Sie arbeiteten mit dem medizinisch-pflegerischen Personal zusammen und waren an Misshandlungen direkt beteilig (Kap. 4.7).

Neben dem Verhalten auf dem Krankenzimmer waren in der Hausordnung Regeln für die sogenannte „Arbeitstherapie“ festgeschrieben. Darunter wurden vor allem Reinigungstätigkeiten verstanden: „Jede arbeitsfähige Patientin ist zur Arbeit einzusetzen und zur Arbeitstherapie verpflichtet. Zu Reinigungsarbeiten der Krankenzimmer bzw. Krankenhausräume wird jede Patientin der geschlossenen Station ohne Anspruch auf Entlohnung herangezogen. Auf dem Wege von und zur Arbeitsstelle ist jede Unterhaltung untersagt. Die Patientinnen der geschlossenen Station dürfen den ihnen zugewiesenen Arbeitsplatz nicht selbständig verlassen. Den Anweisungen des Brigadiers bzw. Stubenältesten ist unbedingt Folge zu leisten. Der Brigadier bzw. Stubenälteste ist in Ausübung seiner Tätigkeit Vorgesetzter der Patientinnen der geschlossenen Station. "207 Hier zeigen sich deutliche Unterschiede zur Hausordnung der geschlossenen Venerologischen Station von Erfurt, vor allem was den Anspruch auf Entlohnung des Arbeitseinsatzes betrifft. Beim Verlassen des Arbeitsplatzes, etwa für die ärztliche Behandlung außerhalb der Poliklinik Mitte, sollten sich die Zwangseingewiesenen bei der diensthabenden Schwester der geschlossenen Station ab- bzw. zurückmelden. Nach Arbeitsschluss war der Arbeitsplatz sauber und aufgeräumt zu verlassen, das Reinigungsgerät bzw. Werkzeug abzugeben und die Arbeitskleidung mit auf die Station zu nehmen. ${ }^{208}$ Schließlich gab es Verhaltensregeln für den Besuch kultureller Veranstaltungen: „Vom Heraustreten auf den Stationsflur bis zum Wiedereinrücken in das Krankenzimmer ist jede Unterhaltung untersagt. An- und Abmarsch zu Kulturveranstaltungen hat in disziplinierter Weise zu erfolgen. Verstösse gegen diese Anordnung haben einen sofortigen Ausschluss von den Kulturveranstaltungen und evtl. Disziplinarmassnahmen zur Folge."209 Ob solche kulturelle Veranstaltungen tatsächlich besucht wurden, bleibt offen. Keine der Zeitzeuginnen erwähnt Kulturveranstaltungen im Zusammenhang mit Halle (Saale). Dagegen sind für die geschlossene Venerologische Station in Leipzig-Thonberg Vorträge und Kulturabende belegt (Kap. 5.2). ${ }^{210}$

206 BArch Best. DQ 1. Nr. 4228, unpag. Hausordnung (Anm. 24), S. 2 f.

207 BArch Best. DQ 1. Nr. 4228, unpag. Hausordnung (Anm. 24), S. 4.

208 BArch Best. DQ 1. Nr. 4228, unpag. Hausordnung (Anm. 24), S. 4.

209 BArch Best. DQ 1. Nr. 4228, unpag. Hausordnung (Anm. 24), S. 3.

210 StAL: StVuR Nr. 7093. An den Dezernats-Verwaltungsleiter. Bericht über meinen Besuch im Thonbergheim. Leipzig, der 19. November 1951, Bl. 18. 
In einem vierten Teil der Hausordnung der geschlossenen Venerologischen Station werden die Rechte der Zwangseingewiesenen beschrieben. Sie durften ihren Angehörigen schreiben: „Der Postverkehr unterliegt keiner Einschränkung, jedoch müssen alle Postsachen ordnungsgemäss frankiert werden.“ Weiterer Kontakt mit Angehörigen war strikt untersagt: „Besuch darf während der Beobachtungs- bzw. Behandlungszeit nicht empfangen werden.“ Weitergehende Rechte bezogen sich auf das Beschwerderecht der Mädchen und Frauen: „Jede Patientin hat das Recht, sich in privater und strafrechtlicher Angelegenheit dem Stationsarzt vormelden zu lassen. In dringenden Fällen ist eine Vormeldung zu jeder Zeit möglich. Die Pat[ientin] hat das Recht, Beschwerde zu führen in Bezug auf Behandlung, Verpflegung, ärztliche Betreuung usw. Beschwerden müssen schriftlich innerhalb von 3 Tagen erfolgen. Gemeinsame Beschwerden mehrerer Patientinnen sind unzulässig. Beschwerden sind in der Regel an den Krankenhausleiter zu richten. Die Patientin hat jedoch auch das Recht, die Beschwerde direkt an den Rat der Stadt, Abt[eilung] Gesundheits- und Sozialwesen, zu richten. Die Patientin hat das Recht, über die Entscheidung in Beschwerdesachen in Kenntnis gesetzt zu werden. Das Beschwerderecht besteht auch gegenüber ausgesprochenen Hausstrafen. " 211 Theoretisch bestand also die Möglichkeit, gegen die Behandlungs- und Erziehungsmethoden auf der geschlossenen Venerologischen Station in Halle (Saale) vorzugehen. Die Aussagen der Zeitzeuginnen zeichnen jedoch ein anderes Bild. Niemand sprach darüber, ernsthaft gegen die eigene, oft schmerzhafte und demütigende Behandlung vorgegangen zu sein. Ein Opponieren oder Formen des Widerstands sind für die geschlossene Venerologische Station in Halle (Saale) kaum überliefert. Vereinzelt wehrten sich die Zwangseingewiesenen gegen Behandlungen. Für diesen Widerstand wurden sie von den Pflegerinnen unter Zuhilfenahme der Stubenältesten hart bestraft. Dazu wurden alle in der Hausordnung beschriebenen Disziplinarmaßnahmen genutzt. Ein Opponieren durch Angehörige der zwangseingewiesenen Mädchen und Frauen oder durch das medizinisch-pflegerische Personal ist nicht überliefert.

Der letzte Teil der Hausordnung der geschlossenen Venerologischen Station beinhaltete die stets angedrohten Disziplinarmaßnahmen. In diesem Teil war geregelt, dass die Zwangseingewiesenen „der Disziplinargewalt des Krankenhausleiters“ unterlagen. „Disziplinarmassnahmen dienen der Erziehung sowie der Aufrechterhaltung der disziplinären Ordnung in der geschlossenen Station. Disziplinarmassnahmen bestehen nicht nur in der Bestrafung für Vergehen gegen die Hausordnung und Disziplin, sondern können gleichzeitig Belobigungen bei guter Führung und Arbeitsleistungen sein. " Unter den angedeuteten Belobigungen wurden die „Erteilung zusätzlicher Raucherlaubnis mit Rauchware aus Haushaltsmitteln (...), Löschung einer früher ausgesprochenen Hausstrafe und Aufhebung der damit verbundenen Massnahmen“

211 BArch Best. DQ 1. Nr. 4228, unpag. Hausordnung (Anm. 24), S. 5, Kursivierung im Original. 
sowie „Schriftliche Belobigungen“ verstanden. ${ }^{212}$ Einige Zeitzeuginnen berichten, dass es Privilegierte gegeben habe, die besser behandelt worden seien als andere. ${ }^{213}$ Im Gegensatz dazu wurden „Erziehungsmassnahmen“ in der Hausordnung aufgeführt. Diese bestanden aus zusätzlicher „Arbeitstherapie“, „Nachtruhe ausserhalb des Bettes auf dem Hocker, Verbot des Besuches von Kulturveranstaltungen und Abstrichsperre“. ${ }^{214}$

Vor allem die Nachtruhe auf einem Hocker und die Abstrichsperre waren häufig eingesetzte Mittel. Wer mit der Nachtruhe auf dem Hocker bestraft wurde, durfte nicht in seinem Bett übernachten, sondern sollte auf einem Holzhocker schlafen, der in einem gesonderten Raum stand. ${ }^{215}$ Die Abstrichsperre wiederum folgte einer anderen Logik. Bevor eine Zwangseingewiesene entlassen wurde, sollte sie eine bestimmte Anzahl von negativen Abstrichen vorweisen, „also ohne Gonokokken“, wie sich ein Famulant der Station erinnert: „Es können 20 oder 30 gewesen sein und dann konnten sie wieder entlassen werden. Als Strafe gab es dann auch eine Abstrichverweigerung. Vom Abstrich für ein oder zwei Tage ausgeschlossen, das hieß, die blieben länger. “216 Entsprechend verlängerte sich der Aufenthalt auf der geschlossenen Venerologischen Station mindestens um die Zeit der Abstrichsperre.

Diese Hausordnung übermittelte Münx am 4. Mai 1963 der Generalstaatsanwaltschaft der DDR. ${ }^{217}$ In einem dazugehörigen Begleitschreiben führte Münx aus, dass er als Bezirks-Dermato-Venerologe und Krankenhausleiter bereits viele Beschwerden von Zwangseingewiesenen der geschlossenen Station erhalten und bearbeitet habe. „Unsere bisherigen Erziehungsmaßnahmen wegen Verstößen gegen die Krankenhausordnung (z.B. Hockerschlafen) waren Kritiken ausgesetzt. Bemerken möchte ich hierzu, daß unsere geschlossene Station nicht derartig von der Umwelt abgeschlossen ist, wie zum Beispiel die entsprechende Station in Leipzig-Thonberg. Ebenfalls fehlen alle Voraussetzungen bewachungstechnischer und ähnlicher Art in unserem Hause, d.h. in einem offenen Krankenhaus müssen wir recht und schlecht mit diesem bestimmten Personenkreis, zumeist asozial, fertig werden. " ${ }^{218}$ Dass seit Gründung der geschlossenen Venerologischen Station die Eingangstür verschlossen war, wie aus den Interviews mit den Zeitzeugen hervorgeht, verschweigt Münx in seinem Schreiben.

In den folgenden 19 Jahren hatte die Hausordnung der geschlossenen Venerologischen Station in Halle (Saale) Bestand. Ihre wichtigste Funktion, die Er-

212 BArch Best. DQ 1. Nr. 4228, unpag. Hausordnung (Anm. 24), S. 5 f.

213 Interview mit Frau HPA (Anm. 170).

214 BArch Best. DQ 1. Nr. 4228, unpag. Hausordnung (Anm. 24), S. 6.

215 Interview mit Frau HPA (Anm. 170).

216 Interview mit Herrn HZF (Anm. 180).

217 BArch Best. DQ 1. Nr. 4228, unpag. Stadtkrankenhaus Poliklinik Mitte an Generalstaatsanwalt der Deutschen Demokratischen Republik, Halle (Saale), den 4. Mai 1963.

218 BArch Best. DQ 1. Nr. 4228, unpag. Stadtkrankenhaus Poliklinik Mitte (Anm. 217). 
ziehung zur „sozialistischen Persönlichkeit“, war gleich am Beginn der Hausordnung verankert. Erst dann wurde in der Präambel die medizinische Versorgung aufgeführt. Weiterhin wurden die Isolierung der Zwangseingewiesenen sowie Disziplinarmaßnahmen thematisiert. Die Zwangseingewiesenen waren zur Arbeit verpflichtet und konnten durch Disziplinarmaßnahmen für Verstöße gegen die Hausordnung bestraft werden. Diese Regeln wurden konsequent angewandt, um mit den als „zumeist asozial“ bezeichneten Frauen zurechtzukommen, wie der Leiter der Station in seinem Schreiben an die Generalstaatsanwaltschaft der DDR festhält. ${ }^{219}$ In der Entstehung der Hausordnung und der konkreten Ausgestaltung wird deutlich, dass die politisierte Medizin in den 1950er und 196oer Jahren selbstständig handelte und zur Durchsetzung der eigenen Wertvorstellungen die Rahmenbedingungen bestimmte.

219 BArch Best. DQ 1. Nr. 4228, unpag. Stadtkrankenhaus Poliklinik Mitte (Anm. 217). 
4 Die geschlossene Venerologische Station der Poliklinik Mitte in Halle (Saale)

Stadtkrankonhaus

Pollkinik Mitte

Halle (s) den 23.Apsil 9963

Halle/S. C2, KL. Kausstr. 16

Tol. 25539,22741

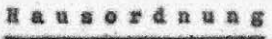

Fix die Patientinnen fer geschlossenen GeschlechtskrankenTravenatation is Stadticrankanhaus Hit to lialle (B) KLeine Klausstr. 16.

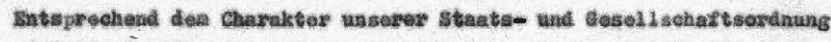
sind alo in die cesthlossene sration eirgewlesenen Pabiontinnen auf grund der Verordinung zur Bokbingfung dor Geschlechtakrankhei th voli 23.2.1961 voribergehend won der Geselisehert faollert, Daxch crtieherische BInvinicung muss exreicht verdes, dass diese Btrger nach Ihrex Krankenhausentlassung dle Gesetze unseros staates achten, elae gute Arbel bsdisgiplin selgen und sioh in threm Verhalten in unserey Geseliachaft won ton Prinziplon des sozialtstischen Busabaen-

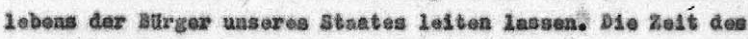
Aurenthaltes in der geschlossenen station dient der gricenaug bzv. Aushellung threr Volkakrankhelt sowle der Vorberaitung auf inr waiteres haben untor den genainten neuen Bedisguagen sovie untex strengeter Beachtung dar oben angeruhrten Verovinuag. Doahalb sind die Mtnhaltung a.lan Ordnungeregeln innerialb dex geschlossenen Station und Ale bedingungalose Bafolgung mithdileher Aavel sungen des Sohwertompersonals unbelisgte Notwendigkeiten. sio dienen der Aufrechterhaltung der Oxdaung und gevihrieloten elnom reibungstosen Tagesablaur?

\section{Aefaehees}

Alle Auswolsgaptere, alde Vertsachen wie Uhren, Ringe und ebenso

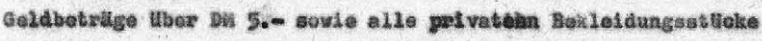
sind bel der Aufnahase der aufnehaenden Iranksnachuestar abrugeben. Diese Gegenstande verden in dor Yervaltung bav, in Efrektenraus verubhts. Bein Abgang werdea alle regletriezten Gegenstilnde surickgegebea. Fur alcht registrierte Sachen wire kolne Verantwortung

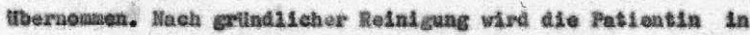


ein entsprechendes grankenbett alngewtesen. Jedes hat sieh on alo

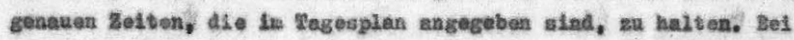
nteht pinkulteher Hinhaltung der Krankeahausordnung dux od elgene Schuld vivd jede Fatientin gur Perantwortung sezeged. Die Patiantinen alud warkichtet, ther Uxachen, die su thres

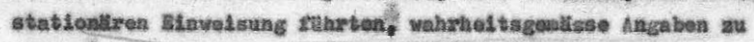
nachens?

\section{Bizene Sechens}

Die Patientinzen werden ungozogon, A.h. alle pxivaten Bokjeidungastlicke

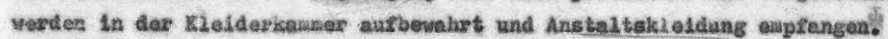

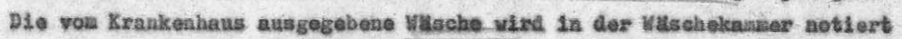

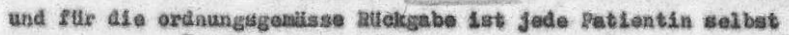
verantworthieh. Jeden Sonnabend 1st natschetausoh. Stritilehe Aastultsvăsche wire durch des Krankenhaus gewaschen.

\section{Yorpelesunge}

Die elngoplante uad varabrelchte Henge an bebonanitbeln ist aus

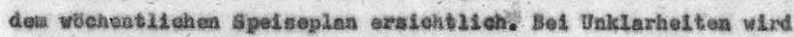
durch die diensttuende Obersutwester Austanft ertellt.

Yerbalten der MatientInnas 4 In Rrenkicongtmpers

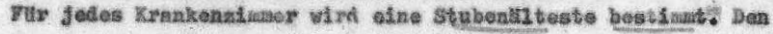
Anondmungar der stubenaltesten iat unbedingt Folge at laiaten. Fo Ordnung and Bauberkett in Krankensiaser aInd allo Patientinnea

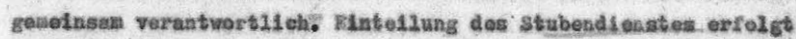
dureh die stubenliteste.

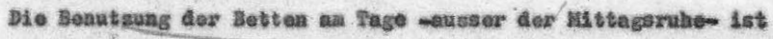

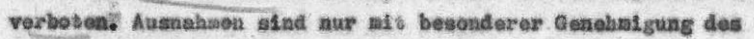
Arztes oder der Stationssuhvester gastactet. Bel angeordaetiox. Bestruhe bat sich ase Patientin enthleidet iss Bett zu legen.

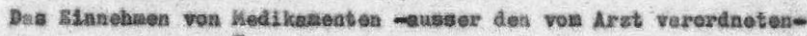
Ist as unterlassen.

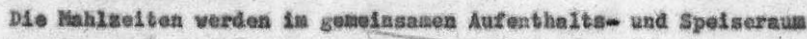
elingenomsen.

Me Patlentinaen sind sur plieglichaten Bohadiung der thaen

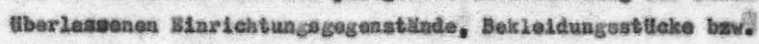

Fortsetzung von Abb. 12 Hausordnung der geschlossenen Venerologischen Station in Halle (Saale) vom 23. April 1963 
4 Die geschlossene Venerologische Station der Poliklinik Mitte in Halle (Saale)

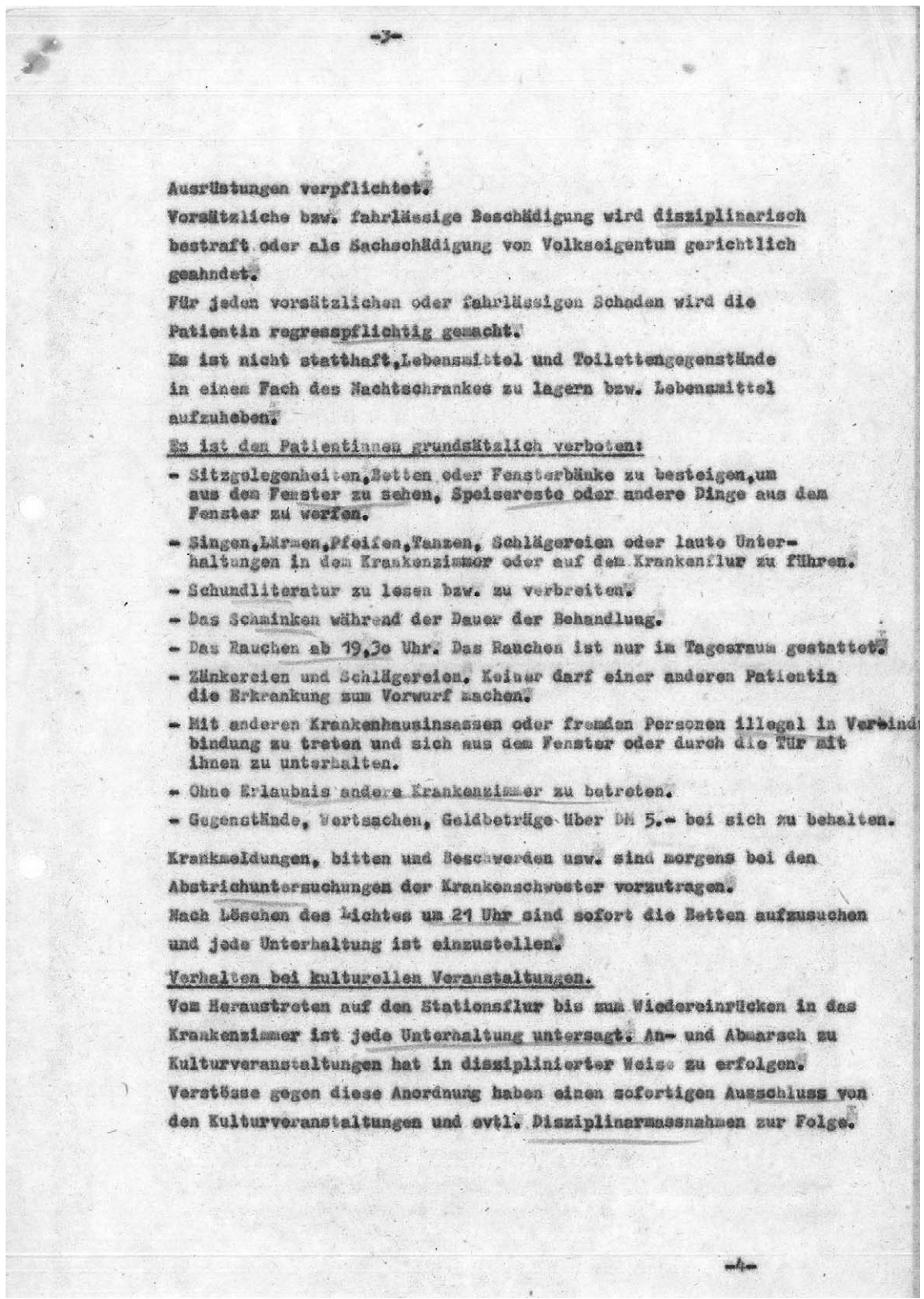

Fortsetzung von Abb. 12 Hausordnung der geschlossenen Venerologischen Station in Halle (Saale) vom 23. April 1963 


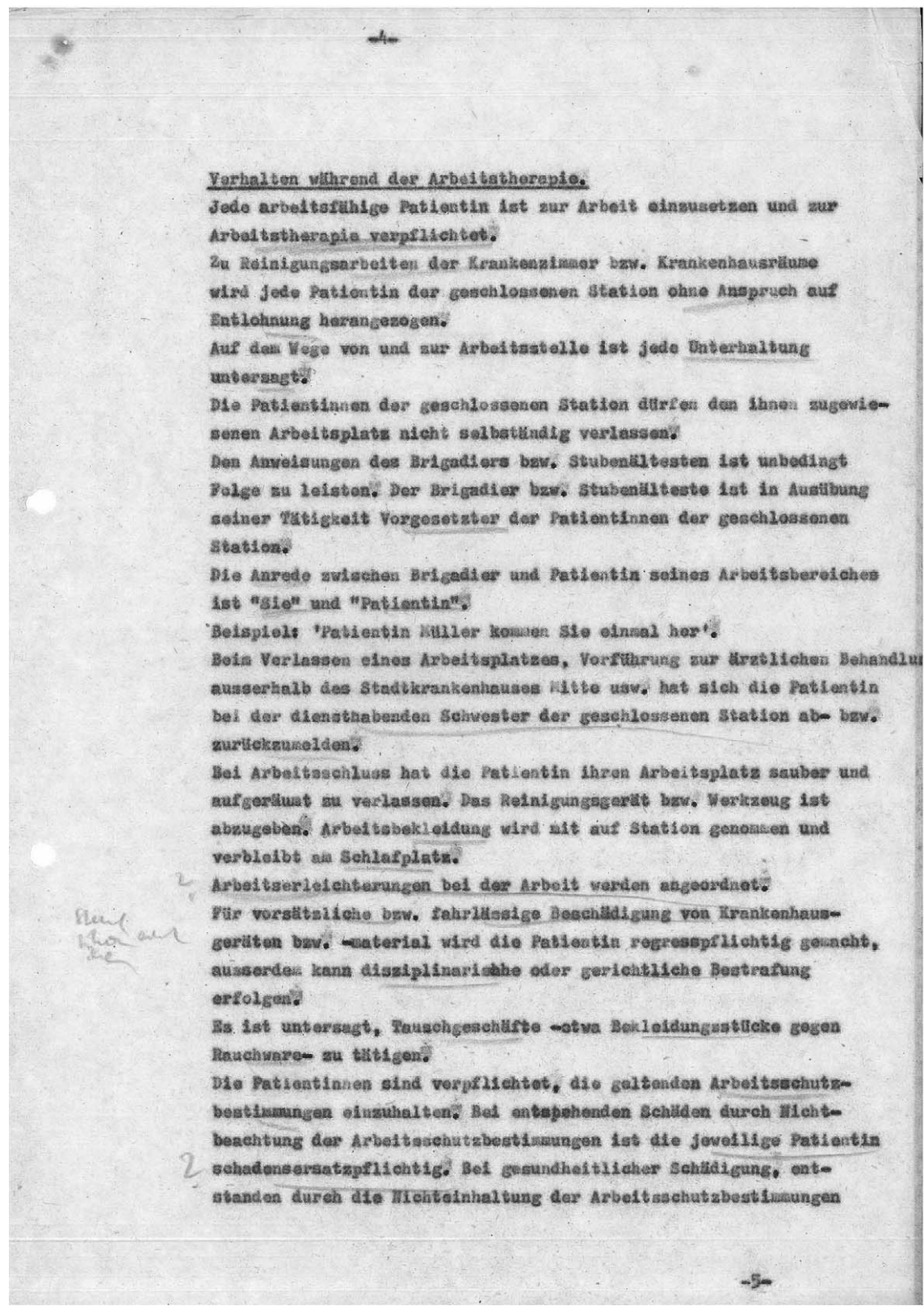

Fortsetzung von Abb. 12 Hausordnung der geschlossenen Venerologischen Station in Halle (Saale) vom 23. April 1963 
4 Die geschlossene Venerologische Station der Poliklinik Mitte in Halle (Saale)

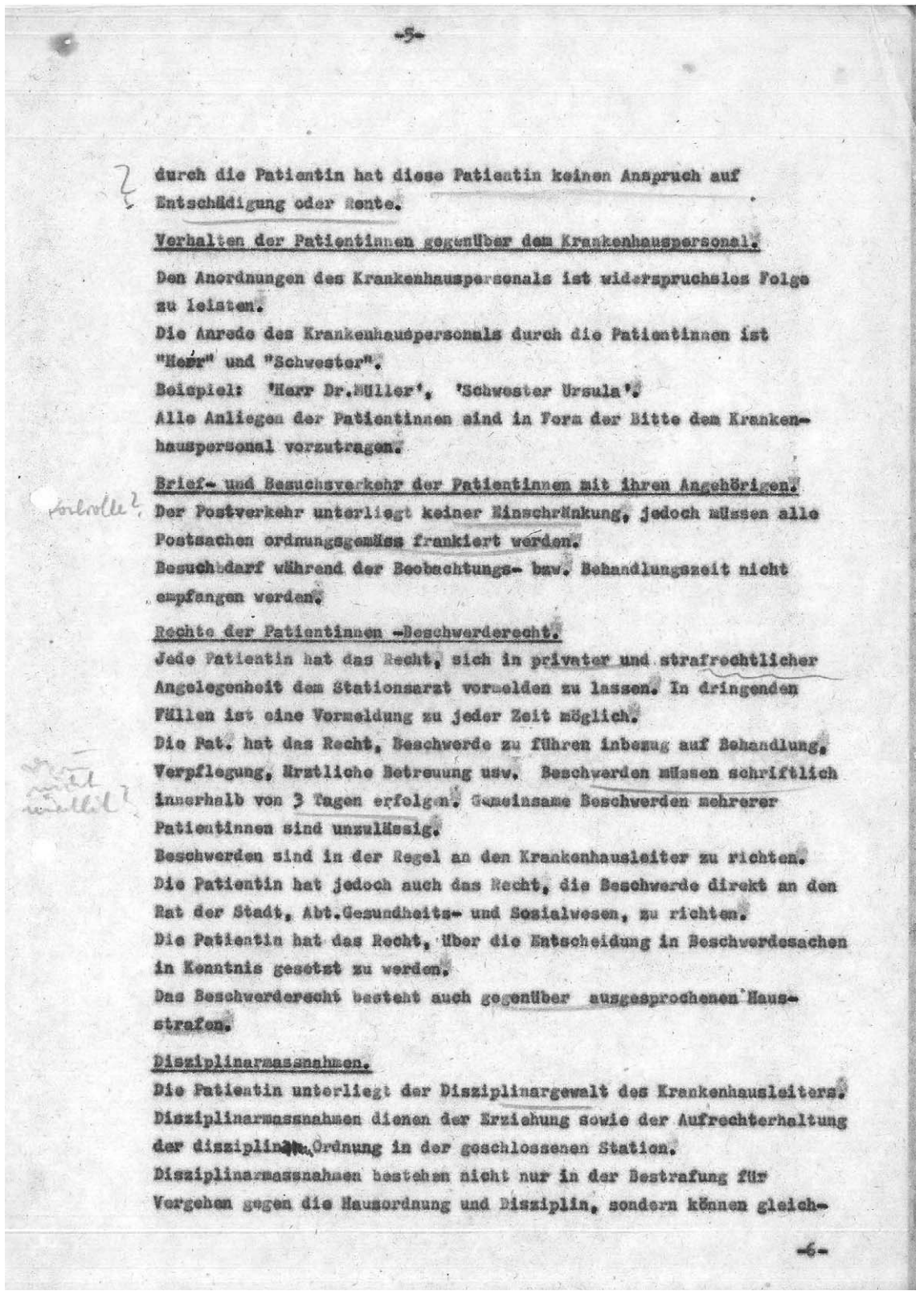

Fortsetzung von Abb. 12 Hausordnung der geschlossenen Venerologischen Station in Halle (Saale) vom 23. April 1963 
sattig Belobi gragen bel guter Furwas und Axbeltelelatungen acln. Bor Rrankenhausiedter kann ia Rahach goiner Disziplinargovalt Lolgendes verilgen:

Beloblaninen:

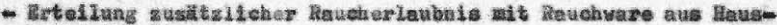
haltasatioln

- bësehung Aner frihar susgesprochenen Hausstrafe und Aurhebung der tasit verbundenen Vasanahwen

- sehriftiche Beiobi gungen.

Exzlebungsisessualuaren:

- zusbtrLiche irbet tatherapie

inchtruhe ausserhat b des Buttes ane das Hockar

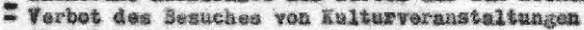

- Abatrichaperre.

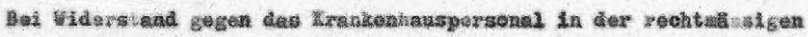

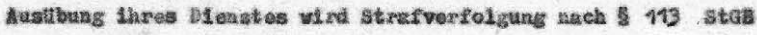
elageleitet.

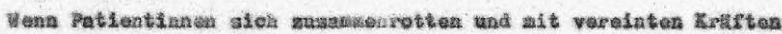

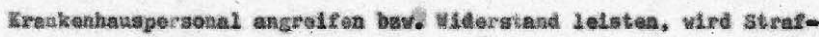
verfolgun vech of 122 staB aingelertet.

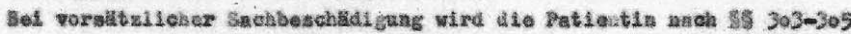

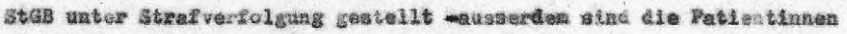
schatonsersatzgit 1 ebtig.

Bei butwedchen won dor geschiosatera station vird Strafvertolgung:

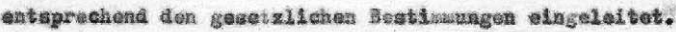

$$
\begin{aligned}
& \text { Qfluinx. } \\
& \text { Medizinairat Dr. G. Monx } \\
& \text { Aratichor Direktor }
\end{aligned}
$$

Fortsetzung von Abb. 12 Hausordnung der geschlossenen Venerologischen Station in Halle (Saale) vom 23. April 1963 


\subsection{Das medizinisch-pflegerische Personal}

Die Biographien von zwei Mitarbeitern der Poliklinik Mitte bzw. der geschlossenen Venerologischen Station in Halle (Saale) sind mit der Gründung bzw. mit dem Ende der Station verbunden. Gerd Münx wurde bei Cründung der Poliklinik Mitte der Ärztliche Direktor und leitete mehrere Jahre die geschlossene Venerologische Station. ${ }^{220}$ Manfred Narwutsch wurde Anfang der 1980er Jahre Leiter der Hautabteilung der Poliklinik Mitte und war an der Auflösung der dortigen geschlossenen Venerologischen Station beteiligt. ${ }^{221}$ Die Biographien der beiden Ärzte haben wir exemplarisch rekonstruiert, da beide Personen in ihrer Wirkungszeit für einen bestimmten Umgang mit den Zwangseingewiesenen stehen. Beide Ärzte waren Kinder ihrer Zeit und stehen damit auch für zwei unterschiedliche Generationen, die durch die beiden deutschen Diktaturen des 20. Jahrhunderts geprägt wurden.

Gerd Münx wurde am 6. März 1918 in Ammendorf (Saalkreis) als Sohn eines selbstständigen Kaufmanns geboren und evangelisch getauft. Er besuchte das Reformrealgymnasium in Halle (Saale) bis zur Obersekunda und machte 1938 das Abitur in Köthen (Anhalt) auf der Oberrealschule. ${ }^{222}$ Nach dem Abitur musste er von 1939 bis 1940 zum Reichsarbeitsdienst und zum Wehrdienst. ${ }^{223}$ Im Januar 1940 begann er das Studium der Humanmedizin an der Martin-Luther-Universität Halle-Wittenberg. Nach einem Trimester und einem einsemestrigen Physikum bestand er im Herbst 1942 die notwendigen Prüfungen. Das erste klinische Semester verbrachte Münx in Halle (Saale), um anschließend vier Jahre an der Julius-Maximilians-Universität in Würzburg zu studieren. ${ }^{224}$ Im Anschluss wirkte er ab 1944 als Feldarzt der Reserve. ${ }^{225}$ Nach erlangter Notapprobation, am 23. März 1945 in Würzburg, war er als kriegsgefangener Unterarzt in verschiedenen Kriegsgefangenen-Lazaretten tätig. Im Jahr 1946 legte Münx in Halle (Saale) sein medizinisches Staatsexamen ab. Ein Jahr später wurde er mit der Arbeit Die Behandlung der Placenta praevia an der Würzburger Universitäts-Frauenklinik in der Zeit vom 1. Januar 1941 bis zum 31. Dezember 1943 unter besonderer Berücksichtigung der Kopfschwartenzange an der Medizinischen Fakultät der Martin-Luther-Universität Halle-Wittenberg promoviert. ${ }^{226}$ Ende der $1940 e r$

220 Interview mit Frau HZA (Anm. 163).

221 Archiv der Diakonie: Hautklinik ab Apr. 98 - Neue Mappe, Gefäßchirurgie, IST. Lebenslauf Dr. med. Manfred Narwutsch.

222 Münx G (1946) Die Behandlung der Placenta praevia an der Würzburger Universitäts-Frauenklinik in der Zeit vom 1. Januar 1941 bis zum 31. Dezember 1943 unter besonderer Berücksichtigung der Kopfschwartenzange. Med. Diss., Halle (Saale) 1946, S. 61 (Lebenslauf).

223 Auskunft der Deutschen Dienststelle für die Benachrichtigung der nächsten Angehörigen von Gefallenen der ehemaligen Wehrmacht, 27. Mai 2013.

224 Münx: Die Behandlung der Placenta praevia (Anm. 222).

225 Auskunft der Deutsche Dienststelle (Anm. 223).

226 Münx: Die Behandlung der Placenta praevia (Anm. 222). 
Jahre fand Münx beim Gesundheitsamt in Halle (Saale) eine Anstellung. ${ }^{227} 1952$ war seine Dienststelle in der Kleinen Klausstraße 16. Dort arbeitete er in der Beobachtungs- und Fürsorgestelle für Geschlechtskranke, aus der 1961 die geschlossene Venerologische Station hervorging. ${ }^{228}$

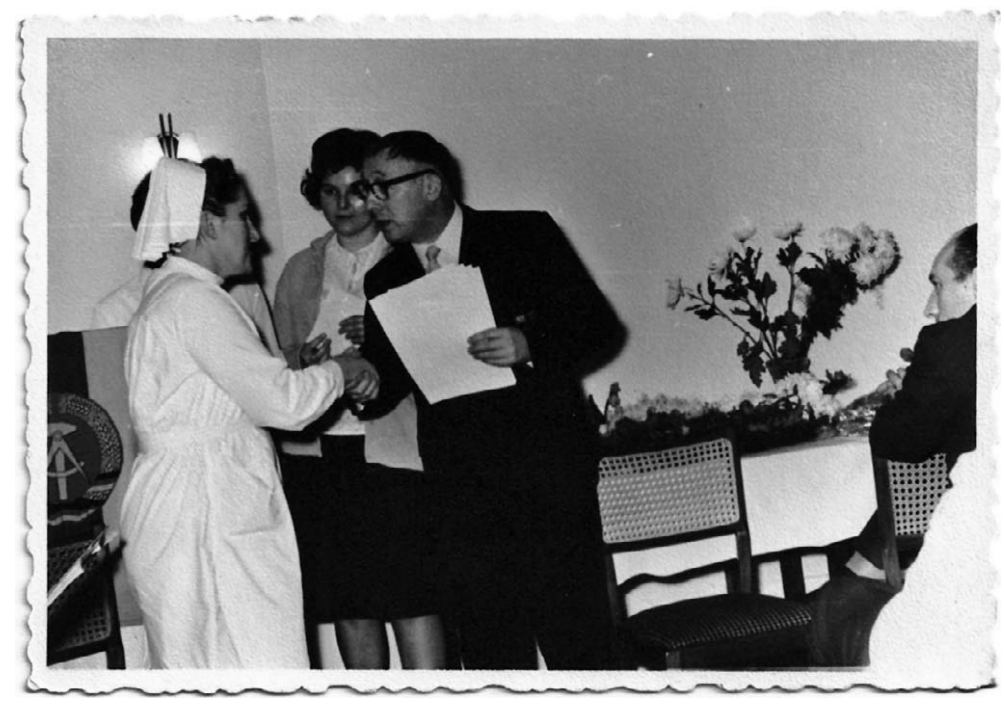

Abb. 13 Gerd Münx und eine Pflegerin der Poliklinik Mitte in Halle (Saale) (um 1970)

Von Zeitzeugen wird Gerd Münx als eine tyrannische Person beschrieben. Ein Famulant der geschlossenen Venerologischen Station erinnert sich: Münx ,verhielt sich uns Famulanten gegenüber sehr kollegial, war aber nichtakademischem Personal gegenüber ausgesprochen ruppig, kommandierend und kurz angebunden “. ${ }^{229}$ Eine Schwester der Station beschreibt die Wirkung von Münx: $\mathrm{Er}$, hatte ja so Tyrannenzüge und wenn der im Anmarsch war, ist doch jeder in irgendein Loch gekrochen, bloß um dem nicht zu begegnen. Aber das muss in den 8oer Jahren gewesen sein “. ${ }^{230}$ Ein ähnliches Bild zeichnet eine Mitarbeiterin der geschlossenen Venerologischen Station: „Also, wir waren immer froh, wenn er zu Mittag um eins gegangen ist. Er hat immer von um eins bis halb vier seine Mittagsruhe zu Hause gemacht (...) da waren wir froh, dass der weg war. “" ${ }_{331}$

Besonders das Verhalten des Arztes Gerd Münx gegenüber Zwangseingewiesenen war von Missachtung und Geringschätzung geprägt, wie ein Famulant der

227 StAH: A 2.23 Jugend- und Fürsorgeamt Nr. 27. Bd. 4. Besprechung am 19. April 51 der Abt. Sozialwesen - Gefährdetenfürsorge -, Halle (Saale), den 19. April 1951.

228 StAH: A 2.13 Finanzen Nr. 559 Bd. 1 (1943-1953). Ausbau der Kleinen Klausstraße 16 als Geschlechtskranken-Fürsorgestelle.

229 Fragebogen von Herrn HZG, eingetroffen am 24. Februar 2014.

230 Interview mit Frau HZD (Anm. 169).

231 Interview mit Frau HZE (Anm. 174). 
geschlossenen Venerologischen Station beschreibt: „Patientinnen wurden von ihm wie Menschen zweiter Klasse behandelt. Mit ,Sie‘ und Familiennamen angesprochen, keine Maßnahme mit den Betreffenden besprochen, keine Zusage abgewartet. " ${ }^{232}$ Vor allem die Ignoranz gegenüber den Rechten der Zwangseingewiesenen blieb einer Mitarbeiterin der geschlossenen Venerologischen Station im Gedächtnis: Er „war der Meinung ,Schweigepflicht, hier brauchen wir doch überhaupt keine Schweigepflicht einzuhalten, das ist der Abschaum der Bevölkerung. Da muss man keine Schweigepflicht einhalten'، "233 Den Schwestern wiederum verbot Münx persönliche Kontakte oder ein Gespräch am Rande mit den Zwangseingewiesenen: „Er hat gesagt, alle Geschlechtskranken lügen und wir haben uns nicht mit denen zu unterhalten und schon gar nicht, die irgendwie zu bedauern oder denen gut zuzureden auch wenn sie geweint hatten wegen ihren Kindern. " ${ }^{234}$ Eine Insassin wiederum berichtet, dass Münx sich mit ihr unterhalten und ihr suggeriert habe, dass sie die Behandlung auf der geschlossenen Venerologischen Station „verdient habe“. ${ }^{235}$

Im Gegensatz zum Lebenslauf von Gerd Münx stehen der Name Manfred Narwutsch und seine Biographie für das Ende der geschlossenen Venerologischen Station in der Poliklinik Mitte und den Neuanfang in der Hautklinik am Harz. Narwutsch wurde am 12. Februar 1937 in Fürstenberg an der Havel geboren. 1956 legte er sein Abitur in Neubrandenburg ab und nahm noch im selben Jahr das Studium der Humanmedizin an der Militärmedizinischen Sektion der Ernst-Moritz-Arndt-Universität in Greifswald auf. ${ }^{236} 1962$ schloss er das Studium der Medizin ab und wurde im selben Jahr mit der Arbeit Die Wirkung aminosaurer Nickel-Salze auf den Kohlehydratstoffwechsel promoviert. ${ }^{237}$ Es folgte eine einjährige Assistenzzeit im Bezirkskrankenhaus Dresden. 1963 erhielt er die ärztliche Approbation und wurde anschließend in einem Truppenteil der Nationalen Volksarmee (NVA) eingesetzt. 1964 wurde Manfred Narwutsch Bezirksmilitärarzt des Bezirks Halle (Saale). Parallel dazu absolvierte er eine Facharztausbildung an der Hautklinik der Martin-Luther-Universität Halle-Wittenberg, die er 1968 als Facharzt für Dermatologie und Venerologie abschloss. Nach einer 25jährigen Dienstzeit bei der NVA wurde er 1981 mit dem Dienstgrad Oberstleutnant in die Reserve versetzt und übernahm noch im selben Jahr die Leitung der dermatologischen Abteilung des Bezirkskrankenhauses Halle (Saale). ${ }^{238}$ 1986 wurde er stellvertretender Ärztlicher Direktor des Bezirkskrankenhauses Halle (Saale). Im Zuge der Übernahme der Hautklinik am Harz durch das Evan-

232 Fragebogen von Herrn HZG (Anm. 229).

233 Interview mit Frau HZD (Anm. 169).

234 Interview mit Frau HZE (Anm. 174).

235 Interview mit Frau HPB, geführt von Florian Steger und Maximilian Schochow, Halle (Saale), den 30. Januar 2014.

236 Archiv der Diakonie: Hautklinik ab Apr. 98 - Neue Mappe, Gefäßchirurgie, IST. Lebenslauf (Anm. 221).

237 Narwutsch M (1962) Die Wirkung aminosaurer Nickel-Salze auf den Kohlehydratstoffwechsel. Med. Diss., Greifswald.

238 Archiv der Diakonie: Hautklinik ab Apr. 98 - Neue Mappe, Gefäßchirurgie, IST. Lebenslauf (Anm. 221). 
gelische Diakoniewerk Halle (Saale) beendete Narwutsch seine Tätigkeit als Chefarzt und trat 1992 in den Ruhestand. ${ }^{239}$ In den Erinnerungen der Zwangseingewiesenen der geschlossenen Venerologischen Station taucht Manfred Narwutsch kaum auf. Die Mitarbeiter wiederum beschreiben ihn als einen ehrlichen Menschen: Manfred Narwutsch „war zu den Mädchen immer fair. Der ist nachmittags dann immer irgendwann gekommen, um fünf, und hat in der Ambulanz Sprechstunde gemacht (...). Ja, aber der war immer fair, eigentlich. Der hat echt wirklich nichts den Mädels getan. “240 In der Poliklinik Mitte sei Narwutsch, der in der Ambulanz tätig war, kaum mit der geschlossenen Station in Berührung gekommen, bis er die Leitung der dermatologischen Abteilung übernahm. ${ }^{241}$

Zwei weitere Ärzte waren zumindest zeitweise auf der geschlossenen Venerologischen Station tätig: die Dermatologin Rosemarie Drunkenmölle und der Psychologe Cottfried Rudolf. Eine Schwester erinnert sich: Frau Drunkenmölle war „Fachärztin für Haut und die hat ja ganz eng mit dieser V-Station zusammengearbeitet. Die Ambulanz war ja vis-à-vis von der Eingangstür zu dieser Station und die hat ja auch diese Patienten auch untersucht, also die musste doch anordnen nach Abstrich, ob da eine Gonorrhoe vorliegt und die musste doch auch therapieren. Die hat doch auch angeordnet (...), wer in welchem Maß Penicilline bekommt oder nicht. " 242 Eine weitere Mitarbeiterin der Station beschreibt Rosemarie Drunkenmölle als eine herzliche Frau: „Eine ganz liebe, die das echt nicht begriffen hat, was sich da abspielt und die dagegen Sturm gelaufen ist. Das war eigentlich eine sehr liebe Person, die Hautärztin war und keine Gefängniswärterin und keine, die Leute züchtigt. Die war Hautärztin, also wie sich das gehört. Den Beruf als Arzt hat die ausgeübt. " ${ }^{243}$ Auch die ehemaligen Zwangseingewiesenen beschreiben sie als eine Ärztin, die sich verständnisvoll und fürsorgend für sie eingesetzt habe: „Auf alle Fälle war das eine verständnisvolle Gynäkologin. " ${ }^{244}$ Letztlich war Rosemarie Drunkenmölle an der Entmachtung von Münx im Jahr 1981 beteiligt. ${ }^{245}$

Des Weiteren war auf der geschlossenen Venerologischen Station der Psychologe Gottfried Rudolf tätig. Als Psychologe sollte er mit den zwangseingewiesenen Mädchen und Frauen zum einen "psychologische Gespräche führen“. ${ }^{246}$ Zum anderen erhob er aber auch die Anamnesen von den Mädchen und Frauen und führte das Einweisungsgespräch. „Wenn die neu reinkamen, musste man ja wissen, wieso sie da reingekommen waren. " Darüber hinausgehende Funktionen hatte Rudolf nicht: „Der war genug beschäftigt mit Patienten

239 Hecht M (1992) Rote SED-Vergangenheit: Arzt muß in den Ruhestand gehen. Bild, 17. Oktober 1992.

240 Interview mit Frau HZE (Anm. 174).

241 Interview mit Frau HZE (Anm. 174).

242 Interview mit Frau HZB (Anm. 164).

243 Interview mit Frau HZE (Anm. 174).

244 Interview mit Frau HPC, geführt von Florian Steger und Maximilian Schochow, Halle (Saale), den 29. Januar 2014.

245 Interview mit Frau HZE (Anm. 174).

246 Interview mit Frau HZE (Anm. 174). 
außerhalb. Als Psychologe hat man ja doch viel zu tun, auch alles andere und auf anderen Gebieten. Eigentlich ambulant hatte der seine Sprechzeiten." ${ }^{247}$ Ende der 1970er Jahre verließ Rudolf Halle (Saale) und wurde 1979 mit der Arbeit Zur Diagnostik asozialitätsrelevanter Einstellungen an der Humboldt-Universität zu Berlin promoviert. ${ }^{248}$ In seiner Dissertation untersuchte Rudolf zwei Vergleichsgruppen: Die erste Cruppe bestand aus Probanden der Abteilung für innere Angelegenheit - sogenannte rechtskräftig verurteile „asoziale Personen“. ${ }^{249}$ Die zweite Gruppe bildeten Probanden aus der geschlossenen Abteilung für Venerologie des Bezirkskrankenhauses Halle (Saale) -,,Arbeits- und Schulbummelanten mit sogenanntem promiskuitiven Verhalten" . ${ }^{250}$ Demnach griff Rudolf zur Erlangung seiner Doktorwürde auf Probanden aus der geschlossenen Venerologischen Station zurück: „Von den 175 venerologischen Patientinnen waren 59 Jugendliche, die restlichen 116 Volljährige. Das Durchschnittsalter betrug 20,4 Jahre. Die jüngste Patientin war 12 Jahre, die älteste 42 Jahre. " ${ }_{251}$ Nur wenige Jahre später legte er seine Habilitationsschrift unter dem Titel Der Psychologe als Sachverständiger im Strafverfahren ${ }^{252}$ an der HumboldtUniversität zu Berlin vor. Rudolf publizierte eine Reihe weiterer Arbeiten, in denen er die zwangseingewiesenen Frauen zum Gegenstand seiner Forschung machte. ${ }^{253}$ Dabei versuchte er vor allem nachzuweisen, dass zwangseingewiesene Frauen nahezu ausnahmslos „Arbeits- und Schulbummelanten“ sowie häufig Herumtreiberinnen seien, die durch Verwahrlosungserscheinungen und promiskes Verhalten auffielen. ${ }^{254}$

Darüber hinaus waren auf der geschlossenen Venerologischen Station Fürsorgerinnen tätig. Fürsorgerinnen und Fachärzte für Haut- und Geschlechtskrankheiten bildeten in der DDR, so auch in Halle (Saale), eine arbeitsteilige Einheit von Prophylaxe, Diagnostik und Therapie. Die Fürsorgerinnen im Gesundheitswesen hatten meist eine medizinisch-pflegerische Ausbildung und waren so spezialisiert für die Schwangerenfürsorge, die Diabetesfürsorge oder die Fürsorge bei Haut- und Geschlechtskrankheiten. In Halle (Saale) waren zwei Fürsorgerinnen sowohl in der Ambulanz als auch in der geschlossenen Venerologischen Station tätig. „Wir hatten zwei Fürsorgerinnen, aber die eine war für den stationären Bereich und eine ambulant. Die ambulante hat es ja gar nicht geschafft, da sind wir halt zusammen los, weil es auch unangenehm war. " Die Fürsorgerin hatte verschiedene Aufgaben auf der Station und außerhalb der Poliklinik Mitte - beispielsweise die Anamnese bei den zwangsein-

247 Interview mit Frau HZA (Anm. 163).

248 Rudolf G (1979) Zur Diagnostik asozialitätsrelevanter Einstellungen. Diss., Berlin.

249 Rudolf: Zur Diagnostik asozialitätsrelevanter Einstellungen (Anm. 248), S. 47.

250 Rudolf: Zur Diagnostik asozialitätsrelevanter Einstellungen (Anm. 248), S. 49.

251 Rudolf: Zur Diagnostik asozialitätsrelevanter Einstellungen (Anm. 248), S. 54.

252 Rudolf G (1984) Der Psychologe als Sachverständiger im Strafverfahren. Diss., Berlin.

253 Rudolf G (1976) Psychologische Befunde bei ambulanten venerologischen Patienten im Ballungsgebiet Halle. Dermatologische Monatsschrift 162, 215-220.

254 Rudolf G, Bruns H, Münx G (1978) Vergleichende psychologische und soziologische Untersuchungen an ambulanten und stationären venerologischen Patienten. Dermatologische Monatsschrift 164, 351-360. 
gewiesenen Mädchen und Frauen. Eine Fürsorgerin erinnert sich: „Na, wenn die jetzt neu da waren, die hatten sich beruhigt einigermaßen, da wurden die von uns dann praktisch abgefragt, Name, Adresse. (...) Wir haben denen auch erzählt, wenn sie nicht die Partner angeben, was dann passieren könnte, aber nicht unter Druck, sondern haben denen echt gesagt, das mit dem dunklen Raum eben, und ihnen passiert auch nichts, denen wird nicht gesagt, wer sie angegeben hat. (...) Und da haben wir dann die Anamnese gemacht mit denen und jetzt hier die ganzen Partner, Gesundheit, Größe, Gewicht, alles. “255 Auf Grundlage dieser Dokumentation wurden anschließend alle Personen angeschrieben und zur Untersuchung in die Poliklinik Mitte bestellt, die angegeben wurden. Wenn diese Personen sich nicht meldeten, dann wurden sie von den Fürsorgerinnen besucht oder von der Polizei zugeführt: „Wir mussten ja auch raus, die Mädels suchen und so eine Vorladung reinschreiben. Bei der dritten Vorladung, wenn sie da nicht gekommen sind, wurden sie dann zugeführt. " ${ }_{256}$

Die Pflegerinnen auf der geschlossenen Venerologischen Station hatten unter anderem folgende Aufgaben: „Die Nahrung zu verteilen, früh Spritzen zu geben, Abstriche zu machen. Man musste ja erst nachweisen, dass sie nun krank waren oder nicht krank waren. Und ja, zu beaufsichtigen, dass sie keinen Unsinn machten. “" ${ }^{257}$ Die Zeitzeuginnen erinnern sich vor allem an Schwester Dora. Viele der Zwangseingewiesenen nannten sie schlicht „Kurbeldora“. Gemeinsam mit Gerd Münx führte sie die täglichen gynäkologischen Untersuchungen durch. Eine Zwangseingewiesene erinnert sich: „Und naja, dann habe ich mich da hingelegt und da muss die wohl das dickste Röhrchen genommen haben, was es gibt, jedenfalls hatte ich das Gefühl. Das tat so weh und da habe ich da aufgeschrien und da hat die mir mit der Zange oder was die da in der Hand hatte, hat die mir auf den Oberschenkel gehauen." 259 Und nicht nur das Spekulum führte Schwester Dora besonders grob ein. Auf Anweisung von Münx sperrte sie Zwangseingewiesene ein, schlug sie und überwachte die Strafmaßnahmen: „Also, die Kurbeldora auf alle Fälle (...). Es waren ja nicht alle so brutal, ja, also hauptsächlich war ja das die Dora. " ${ }^{60} \mathrm{Nicht}$ nur die Patientinnen zeichnen ein erschreckendes Bild von Schwester Dora, sondern auch die Mitarbeiter beschreiben sie in den Interviews als unangenehme Kollegin, die sehr brutal war. Sie „hat die Mädchen geschlagen. Also, die hat sie wirklich geschlagen dann. (...) Schwester Dora, die war bösartig. Ja, ja, die hat sie geschlagen, die Mädchen. Die hat sie auch gleich gezerrt, und wenn die auf dem Stuhl nicht funktionierten, dann hat die zugepackt. “" ${ }^{261}$

255 Interview mit Frau HZE (Anm. 174).

256 Interview mit Frau HZE (Anm. 174).

257 Interview mit Frau HZA (Anm. 163).

258 Interview mit Frau HPD, geführt von Florian Steger und Maximilian Schochow, Halle (Saale), den 30. Januar 2014.

259 Interview mit Frau HPD (Anm. 258).

260 Interview mit Frau HPD (Anm. 258).

261 Interview mit Frau HZE (Anm. 174). 
Schließlich war die Poliklinik Mitte eine Ausbildungsstätte für Ärzte und Pflegerinnen. Somit kamen auch Famulanten und Pflegeschülerinnen auf die geschlossene Venerologische Station. Während die Schülerinnen eine mehrjährige Ausbildung absolvierten, waren die Famulanten nur „14 Tage lang “'262 auf der Station, nahmen die Anamnesen auf oder waren im Labor tätig. Ein Famulant, der Anfang der 1970er Jahre auf der geschlossenen Venerologischen Station tätig war, beschreibt seine Eindrücke wie folgt: „Der andere, wesentliche Teil der Famulatur bestand in einer Tätigkeit auf der venerologischen Station, wo junge, von der Trapo [Transportpolizei] oder anderen Organen vorzugsweise am Bahnhof aufgegriffene junge Frauen in einer geschlossenen Abteilung überwiegend wegen einer Gonorrhoe zwangsweise verwahrt und auch zwangsweise behandelt wurden. Uns Famuli oblag die Befragung der Insassinnen, die zur Preisgabe aller Sexualkontakte der vergangenen Monate gebracht werden sollten - die Hauptarbeit hatte hierbei ein anwesender Psychologe; uns dabeisitzenden Studenten kam zumeist die Rolle staunender $\mathrm{Zu}$ schauer und -hörer zu. Nach Ermittlung der Adressen der Kontaktpersonen wurden diese zumeist zu Hause aufgesucht und die Problematik wurde im Kreis der jeweiligen Familie erörtert. " ${ }^{263}$ Ein weiterer Famulant erinnert sich an die Erhebung der Anamnesen und die Arbeit im Labor: „Wir hatten dann noch die Aufgabe, uns um die Laborarbeit zu kümmern, die Abstrichuntersuchung auf Tripper, gefärbte Präparate unter dem Mikroskop ansehen und dann durchmustern, ob wir Gonokokken finden. "264 Insgesamt begegnete das medizinisch-pflegerische Personal den Zwangseingewiesenen der geschlossenen Venerologischen Station in Halle (Saale) mit Missachtung und Geringschätzung.

\subsection{Die Einweisung in die Station}

In der „Verordnung zur Verhütung und Bekämpfung von Geschlechtskrankheiten" vom 23. Februar 1961 war die Einweisung in eine geschlossene Abteilung in den $\mathbb{\$} 20$ und 22 geregelt. Der $\mathbb{2 0}$ sah ein mehrstufiges Schema vor, an dessen Ende die Einweisung in eine geschlossene Abteilung möglich war. Dieses Verfahren, so geht es aus unseren Interviews hervor, wurde regelmäßig durch die Polizei unterlaufen. Die Mädchen und Frauen wurden von der Polizei direkt auf die geschlossene Station gebracht und vom verantwortlichen Arzt aufgenommen. Das rechtlich vorgegebene Verfahren sah drei Stufen vor: Wenn eine Person a) eine erforderliche ärztliche Anweisung nicht befolgte, b) sich der ärztlichen Untersuchung, Behandlung oder Nachuntersuchung entzog, c) Geschlechtsverkehr entgegen dem ärztlichen Verbot durchführte oder d) die Überweisung in ein Krankenhaus verweigerte, dann konnte der Rat des Kreises, Abteilung Gesundheits- und Sozialwesen, die Untersuchung oder Be-

262 Fragebogen von Herrn HZG (Anm. 229).

263 Fragebogen von Herrn HZH, eingetroffen am 21. April 2014.

264 Interview mit Herrn HZF (Anm. 180). 
handlung in einer bestimmten Behandlungsstelle oder den Nachweis der Untersuchung oder Behandlung durch einen berechtigten Arzt innerhalb einer festgesetzten Frist verlangen. Den Arzt konnte der Patient selbst wählen. Entzog sich die geschlechtskranke oder krankheitsverdächtige Person der angeordneten Untersuchung oder Behandlung entsprechend der ersten Stufe, so sollte die zweite Stufe in Kraft treten. In diesem Fall konnte die Person vom Rat des Kreises, Abteilung Gesundheits- und Sozialwesen, zur Untersuchung oder Behandlung stationär untergebracht werden. Sollte sie auch dieser Anordnung nicht nachkommen, wurde die dritte Stufe wirksam. Nun bestand die Möglichkeit, die Unterbringung in einer geschlossenen Abteilung für Geschlechtskranke zu verfügen. Der $\$ 24$ regelte die Einweisung in eine geschlossene Abteilung für dringend Krankheitsverdächtige. Auch hier sah die Verordnung zumindest ein zweistufiges Verfahren vor: Der Rat des Kreises, Abteilung Gesundheits- und Sozialwesen hatte die Möglichkeit, dringend krankheitsverdächtige Personen in einer staatlichen stationären Behandlungsstelle unterzubringen, so die erste Stufe der Anordnung zur Untersuchung und Behandlung. Die zweite Stufe wurde wirksam bei Nichtbefolgung oder bei Verdacht, dass dieser Maßnahme nicht Folge geleistet wurde. Dann wurde die Unterbringung in einer geschlossenen Abteilung für Geschlechtskranke veranlasst. ${ }^{265}$

Aus einem Interview mit einer Fürsorgerin geht hervor, wie die konkrete Umsetzung der „Verordnung zur Verhütung und Bekämpfung von Geschlechtskrankheiten“ in Halle (Saale) geregelt war: „Mitunter kam irgendein Mann in die Ambulanz und hat einen Tripper gehabt. So, der hat dann, was weiß ich, Müller, Meyer, Schulze angegeben. (...) Also, die wurden gemeldet durch Kontakte und diejenigen wurden dann angeschrieben. Die mussten kommen. Das war ja meldepflichtig. Das wurde ja sofort dem Kreisarzt gemeldet. Auch dieser Mann wurde halt gemeldet und man musste all seine Geschlechtspartner alle angeben. So, und wenn die nicht gekommen sind, so, wie gesagt mit Hausbesuchen und mit allen, und die sind wieder nicht gekommen, dann wurden die, wo sie auch waren, vom Arbeitsplatz oder irgendwo, wo sie sich befanden, wurden die abkassiert. (...) Wir sind dann in ganz Halle rumgekrochen und mussten die Leute zusammensuchen." ${ }^{266}$

Crundsätzlich waren alle Personen verpflichtet, die sich wegen einer Geschlechtskrankheit bei einem Arzt vorstellten, folgende Angaben zu machen: „Ob und wo eine vorherige Untersuchung und Behandlung stattfand, von wem er angesteckt worden sein kann bzw. wen er möglicherweise infiziert hat." ${ }^{267}$ Und weiter heißt es in dem Aufsatz Rechtsgrundlagen bei der Behandlung von Haut-

265 Verordnung zur Verhütung und Bekämpfung von Geschlechtskrankheiten (Anm. 23), S. $87 f$.

266 Interview mit Frau HZE (Anm. 174).

267 Richter G (1975) Rechtsgrundlagen bei der Behandlung von Haut- und Geschlechtskrankheiten. In: Burkhardt G, Reimann W (Hrsg.) Aufklärungs- und Schweigepflicht des Arztes und seiner Mitarbeiter. Medizinisch-juristische Grundlagen. 54-57. Steinkopff Dresden. 
und Geschlechtskrankheiten: „Hier ist Kavaliersdiskretion nicht vorgesehen und auch nicht am Platze. Verletzt der Patient diese seine Aufklärungspflicht, so können daraus namentliche Meldungen und Ordnungsstrafen bis zu $500 \mathrm{M}$ resultieren, denn ein derartiges Verhalten wird expressis verbis einer Nichtbefolgung der ärztlichen Untersuchungs- und Behandlungsanordnung gleichgesetzt. " ${ }^{268}$ Diese Aufklärungspflicht sei Voraussetzung für eine zügige und vollständige Infektionsquellenforschung, die anschließend unter anderem von den Fürsorgerinnen für Haut- und Geschlechtskrankheiten durchgeführt wurden.

Waren die Geschlechtspartner identifiziert, wurden sie angeschrieben oder persönlich aufgesucht. Häufig wollten die Frauen nicht freiwillig mitkommen. ,[W]ir haben mit denen gesprochen, wenn sie zu Hause waren, dass sie doch kommen sollen und wir durften ja auch nicht sagen, wer sie angegeben hat. Das durften wir nicht sagen und teilweise sind sie gekommen, und wenn sie dann nicht gekommen sind, hat Münx dann die stationäre Einweisung praktisch geschrieben. Dann mussten wir in die Schmerstraße zum Kreisarzt. Der hat gar nicht erst draufgeguckt, alles unterschrieben. Es war ja immerhin Freiheitsberaubung eigentlich, aber nur eigentlich." ${ }^{269}$ Waren die denunzierten Frauen nicht anzutreffen, dann erhielten sie ein Schreiben, das vom Kreisarzt unterzeichnet war:

„Rat der Stadt Halle (Saale) Abt. Gesundheit - und Sozialwesen, Halle, den ... Frau/Fräulein ...

Auf Grund eingegangener Berichte sind Sie dringend verdächtig häufig wechselnden Geschlechtsverkehr auszuüben und somit Geschlechtskrankheiten weiter zu verbreiten.

Unter Bezugnahme auf $\$ 3 / 3 b$ der Verordnung zur Verhütung und Bekämpfung der Geschlechtskrankheiten vom 23.2.1961 wird Ihnen aufgegeben, ab sofort bis auf weiteres alle 8 Tage14 Tage - 4 Wochen in der Poliklinik Mitte/Süd, Abt. für Haut- und Geschlechtskrankheiten, innerhalb der jeweiligen Sprechstundenzeiten auf Geschlechtskrankheiten sich untersuchen zu lassen.

Kommen Sie dieser Aufforderung nicht nach, so wird zu ihrer Durchführung unmittelbarer Zwang (polizeiliche Zuführung) angewandt werden.

Ein Rechtsmittel ist gemäss der Verordnung zur Bekämpfung und Verhütung von Geschlechtskrankheiten vom 23.2.1961 gegen diese Verfügung nicht gegeben.

Der Kreisarzt i.A.

Erhalten am: ..." ${ }^{270}$

268 Richter: Rechtsgrundlagen bei der Behandlung von Haut- und Geschlechtskrankheiten (Anm. 267).

269 Interview mit Frau HZE (Anm. 174).

270 BArch Best. DQ 1. Nr. 4228, unpag. Ref. Volkskrankheiten Rat des Bezirkes Halle an Min. f. Gesundheitswesen z.H. Hauptreferent Dr. med. L., Halle (Saale), den 11. April 1961. 
Eine Zeitzeugin erinnert sich, dass sie von der Hautklinik einen Brief bekam, in dem sie zur Untersuchung in der Klinik aufgefordert wurde. Dort sollte sie angeben, mit wie vielen Männern sie im letzten halben Jahr intime Beziehungen gehabt hatte. „Da konnte ich aber, wie gesagt, nur den einen Freund da benennen. Und da wurde ich untersucht, das war aber in Ordnung. Aber ich sollte 14 Tage später, sollte ich da nochmal zu der Untersuchung kommen, weil es wohl hieß, es kann sein, dass da noch etwas anderes gewesen ist oder das sich das später entwickelt (...) und da bin ich nicht hingegangen“. Wenige Tage nach dem eigentlichen Termin nahm sie dennoch die Nachuntersuchung wahr: „(...) und dann war ich dort und dann hieß es gleich: ,Sie kommen gleich mal mit hoch und wir müssen das noch einmal überprüfen. 'Und dann ging das los. (...) Ich habe gedacht, das ist eine normale Krankenstation, wie so in einem Krankenhaus. “271

Eine zweite Variante der Einweisung wird in einem Schreiben vom 11. April 1961 an das Ministerium für Gesundheitswesen deutlich. Demnach bestimmte ein wöchentlich tagendes Gremium, welche Personen als HwG-Personen galten und sich zur Untersuchung und Behandlung melden sollten: „HwGPersonen werden bei uns in Halle (S) regelmäßig am ersten Mittwoch eines jeden Monats - 10.00 Uhr - , aufgesetzt bzw. abgesetzt‘. Hierzu findet eine Aktivsitzung statt, an der teilnehmen: von den einzelnen Stadtbezirken Vertreter der Abteilungen Sozialwesen, Jugendhilfe, Mutter und Kind, Inneres, Volkspolizei Abt. S, Volkspolizei Abt. K, Volkspolizei Abt. Fahndung, Stadtstaatsanwaltschaft, Divisionsarzt der NVA, Standortarzt der NVA, einzelne Abschnittsbevollmächtigte, Kreisarzt, Kreis-Dermato-Venerologe, Abteilungsarzt der GK-Stationen [Stationen für Geschlechtskrankheiten], Fürsorgerinnen der GK-Fürsorge. Dieser Personenkreis, der sich nur aus Vertretern staatlicher Dienststellen zusammensetzt, berät und beschließt, ob die betreffenden Personen auf die HwG-Liste aufgesetzt bzw. von dieser abgesetzt werden. Dies wird anschließend in jedem einzelnen Fall von den entsprechenden Vertretern der zuständigen Stadtbezirke unterschriftlich bestätigt, sodass der Kreisarzt, der zumeist an diesen Sitzungen teilnimmt, hierbei ein entsprechendes Protokoll erhält." ${ }^{272}$

Entsprechend \$ 27 der „Verordnung zur Verhütung und Bekämpfung von Geschlechtskrankheiten“, welcher die polizeiliche Amtshilfe bzw. eine Unterstützung durch die Organe der Deutschen Volkspolizei bei der Zuführung von geschlechtskranken oder krankheitsverdächtigen Personen regelte, wurden in Halle (Saale) Polizisten mit dieser HwG-Liste ausgestattet. Auf dieser Grundlage sollten sie die Anordnung zur Behandlung oder Untersuchung durchsetzen. Ein Polizist aus Halle (Saale) erinnert sich: „Ich war normaler Streifenpolizist und ich war auf dem Hauptbahnhof am Anfang. Ich habe 60 im Juli

271 Interview mit Frau HPB (Anm. 235).

272 BArch Best. DQ 1. Nr. 4228, unpag. Ref. Volkskrankheiten (Anm. 270). 
angefangen und es gab eine Liste. Im Wartesaal trieben sich junge Mädchen rum, die Kontakt suchten zu Reisenden, Nutten sagten wir (...). Und die suchten Kontakt und wir hatten eine Liste (...), wo die alle draufstanden, wenn die erwischt wurden, dann wurden die in die Poli Mitte gebracht (...). Ich habe auch ein oder zwei Mal welche dort so abgeliefert." Die aktuellen HwG-Listen hingen „bei uns auf dem Polizeirevier“. Bei der Identifizierung der verdächtigen Mädchen und Frauen auf dem Hauptbahnhof gingen die Polizisten nach eigenem Ermessen vor: „(...) wenn man ständig da ist, dann sieht man, wer oft da ist und wie sie sich ranmachen". Ein weiterer Ort, an dem die Polizei zugriff, war die Ernst-Kamieth-Straße. Dort „war so ein kleiner Park, dahinter war eine Tischlerei, ein Zaun und da standen Bänke und dort haben die immer ihre Geschäfte gemacht und die Polizei, ich weiß nicht, ob es dienstlich war, (...) die standen dann dahinter und haben die dann beobachtet. Der eine hat sogar mit dem Polizeistock mal einen Schlüpfer über den Zaun gehoben.“ Die aufgegriffenen Mädchen und Frauen seien meist ohne Widerstand mitgekommen. „Zu Fuß sind wir gegangen“, erinnert sich ein Polizist. „Wir haben geklingelt, kam eine Schwester, ,Ach, unser Sonnenschein ist wieder da', sagte sie, das weiß ich noch, und dann haben die die mitgenommen. Also, es waren keine Engel. Es sind welche gewesen, die suchten Kontakt zu Reisenden. Ich weiß auch nicht, ob die sich dafür bezahlen ließen, also nehme ich an." ${ }^{273}$

Diese kurze Passage aus einem Zeitzeugeninterview macht deutlich, dass gegen die rechtlichen Bestimmungen der „Verordnung zur Verhütung und Bekämpfung von Geschlechtskrankheiten " regelmäßig verstoßen wurde. Die Mädchen und Frauen auf der sogenannten HwG-Liste sollten eigentlich nicht zur Poliklinik Mitte gebracht werden, sondern waren aufgefordert, sich in der Poliklinik Mitte oder der Poliklinik Süd innerhalb einer bestimmten Frist zu melden, wie aus dem Formular und dem zweistufigen Schema für dringend Krankheitsverdächtige hervorgeht. Aber nicht nur aus den Aussagen beteiligter Polizisten wird deutlich, wie gesetzeswidrig die Einweisungspraxis in Halle (Saale) umgesetzt wurde. Die Mädchen und Frauen wurden von den Polizisten unter völliger Missachtung der in der Verordnung aufgeführten Bestimmungen direkt auf die geschlossene Station gebracht.

Wenn die Polizisten mit den Mädchen und Frauen dastanden, erinnert sich eine Oberschwester, „und die aus dem Verkehr ziehen wollten als Ordnungshüter und nicht wussten, wie sie sie nun unterbrachten, dann kamen Sie eben mal auf unsere Station. (...) Die auffällig waren durch Alkohol oder sonst wie mal auf der Wiese und wenn irgendwelche Großveranstaltung war, weiß ich nicht, was das nun für Mädchen waren. Sie hatten nicht immer alle positive Befunde." 274 Obwohl es keinerlei rechtliche Crundlage für diese Einweisungen gab, mussten „mehrere Abstriche gemacht werden und wenn die negativ wa-

273 Interview mit Herrn HZI, geführt von Florian Steger und Maximilian Schochow, Halle (Saale), den 30. Januar 2014. 274 Interview mit Frau HZA (Anm. 163). 
ren, dann konnten sie gehen, aber dass musste wohl dreimal oder was weiß ich wie oft gemacht werden und da kann es schon sein, dass sie da eine Woche oder vierzehn Tage oder drei Wochen hier bleiben mussten. " ${ }^{275}$ Viele Mädchen und Frauen wurden täglichen medizinischen Behandlungen und Torturen auf der geschlossenen Venerologischen Station ausgesetzt, obwohl sie keine Geschlechtskrankheit hatten. Sie wurden auf die Station zwangseingewiesen, weil die Polizei überfordert war oder unliebsame „Störenfriede“ schnellstmöglich ruhiggestellt werden sollten.

Auch das folgende Beispiel belegt die Verstöße gegen die „Verordnung zur Verhütung und Bekämpfung von Geschlechtskrankheiten“. So beschreibt eine Zeitzeugin, wie sie im Sommer 1976 mit einer Freundin durch die DDR getrampt ist und von der Polizei aufgegriffen wurde. Die beiden Freundinnen wurden zu ihren Eltern gebracht. Anschließend nahmen sie wieder ihre Ausbildung auf. Im Ausbildungsbetrieb „wurde gesagt: ,Da sind zwei Männer. Die sind vom Polizeipräsidium. 'Aber die hatten keine Uniform an, sondern waren in Zivil gewesen. (...) , Du sollst mit denen zum Polizeirevier gehen und du würdest danach wieder zu deiner Arbeitsstelle kommen', hat der Chef gesagt und die Männer auch. (...) So, und dann musste ich zum Polizeirevier auf dem Hallmarkt und ja, da kam das da alles so. ,Was habt ihr gemacht?‘ und eben die Vernehmung und so alles so weiter und sofort. ,Du kannst doch zugeben, dass ihr euch prostituiert habt, ihr wart doch in Leipzig. ' Und da habe ich gesagt: ,Wir haben uns nicht prostituiert, wir haben dort in der Gaststätte einen Kellner kennengelernt und der war homosexuell gewesen und der hat uns mit in seine Wohnung in Leipzig mitgenommen, weil wir so lange in der Gaststätte gesessen hatten (...). ' Ich hatte so ein komisches Gefühl (...) und dann haben sie mich hier in die Tripperburg gebracht." ${ }^{276}$ Der Verdacht der „Rumtreiberei“, oft in Kombination mit dem Vorwurf der Prostitution, war ein häufiger Vorwand, unter dem Mädchen und Frauen in die geschlossene Venerologische Station in Halle (Saale) eingeliefert wurden.

Es gab aber auch Frauen, die im Rahmen der rechtlichen Bestimmungen der „Verordnung zur Verhütung und Bekämpfung von Geschlechtskrankheiten“ in die geschlossene Venerologische Station in Halle (Saale) kamen. Gründe für die Einweisung waren das Fernbleiben von einer angeordneten ärztlichen Untersuchung, einer Behandlung oder Nachuntersuchung sowie die Ausübung des Geschlechtsverkehrs oder geschlechtsverkehrsähnlicher Handlungen mit Dritten, obwohl diese Handlungen von ärztlicher Seite verboten wurden. Eine Zeitzeugin berichtet, die mehrfach auf die geschlossene Venerologische Station in Halle (Saale) und schließlich ins Gefängnis kam, weil sie das Verbot, Geschlechtsverkehr oder geschlechtsverkehrsähnliche Handlungen mit anderen Personen auszuüben, nicht beachtet hatte: „Das ist gar nicht mal 
so einfach, wenn man weggeht, wenn man tanzen geht. Ja und dann spielte auch immer noch ein bisschen der Alkohol mit eine Rolle, weil man da ja auch ein bisschen Alkohol trinkt, wenn man weggeht. (...) Ich war dann mit meiner Freundin weg. Die sagt: ,Ach komm, die wissen das nicht, die finden das nicht raus, wir nehmen einfach einen mit', wie das eben so ist als junges Mädchen, ja. (...) Und da habe ich eben die Verbotszeiten nicht eingehalten, habe dann wieder einen Mann gehabt, weil ich mich von meiner Freundin auch bequatschen lassen " habe. Drei Tage später wurde im Rahmen einer gynäkologischen Nachuntersuchung festgestellt, dass die Zeitzeugin Geschlechtsverkehr hatte. „Ja, ich war vorher mal auf der Station, das erste Mal, weil ich das Verbot nicht eingehalten hatte. Ja, und da das dann wieder passiert war, wo die mich da untersucht hatten, wo die da die Spermien gefunden hatten (...), da hatten die mich verurteilt, ich soll ins Gefängnis als Strafe."277

In den Interviews werden weitere Begebenheiten geschildert, in deren Folge Mädchen und Frauen zwangsweise auf der geschlossenen Venerologischen Station untergebracht wurden. Eine Zeitzeugin beschreibt, dass sogar Eltern ihre Kinder direkt auf die geschlossene Venerologische Station brachten, wenn sie mit ihnen überfordert waren: „Auch teilweise 12, 13. Und auch ein so junges Mädchen, also das, da haben wir damals nur schlucken müssen, also ich konnte das gar nicht begreifen (...). Die Kleine hatte immer wieder gesagt: ,Ich hatte noch gar kein Mann gehabt.' Die Mutter hat praktisch die Kleine angezählt. Die kam zu uns. Die hat jämmerlich geweint. Oder 12, wie alt die war, ein junges Mädchen, schöne lange Haare und hat wirklich im Untersuchungszimmer ganz doll geweint, dass sie noch nie einen Mann hatte und es stimmte sicher auch, weil sie da drinnen gelandet ist. " ${ }^{278}$

Neben der Einweisung von Kindern und Jugendlichen durch ihre Erziehungsberechtigten berichten einige Frauen, dass sie von staatlichen Institutionen eingewiesen wurden - beispielsweise von Heimen oder Jugendwerkhöfen. Eine Zeitzeugin, die mit 15 Jahren im Heim wohnte, hatte mit ihrer Freundin zwei Gastarbeiter aus Ungarn kennengelernt. Die beiden Mädchen trafen sich mit den Gastarbeitern trotz Ausgangssperre: „Die haben im Hochhaus da gewohnt und dann haben die gekocht für uns und dann haben wir was getrunken, wie das so ist, haben wir da geschlafen, so, und am nächsten Früh, da war dann das Malheur da: Wir nicht im Heim. Das gab es ja nicht, so etwas. Dann trauten wir uns nicht zurück und dann haben wir gesagt: ,Dann bleiben wir hier. Das war erstens mal einfacher so für uns, ja, aber das Gewissen, ja, das schlechte Gewissen. Wir hatten ja immer Angst, weil wir ja nun nicht im Heim waren, ja und es sind dann zwei Tage schon vergangen und am dritten Tag (...) da klingelt, da klingelt es und da steht die Polizei vor der Tür. (...) Ich denke mal vom Heim aus, ja, dass andere Mädels vielleicht, die wussten ja,

277 Interview mit Frau HPE, geführt von Florian Steger und Maximilian Schochow, Halle (Saale), den 9. Januar 2014. 278 Interview mit Frau HZE (Anm. 174). 
dass wir mit den Ungarn zusammen waren. Das waren ja nicht erst ein oder zwei Tage. Wir waren ja schon ein bisschen länger mit denen zusammen, aber wir haben ja nie zusammen geschlafen oder so." ${ }^{279}$

Die Konsequenz und die Härte bei den Einweisungen werden noch einmal deutlich durch die Tatsache infrage gestellt, dass etwa 70\% der zwangseingewiesenen Frauen keine Geschlechtskrankheit hatten. Die Frauen wurden bereits an dieser Stelle in doppelter Weise zu Opfern. Zum einen durch die anonyme Denunziation, gegen die sie letztlich machtlos waren. Zum anderen durch das Herausreißen aus dem persönlichen Umkreis und dem Arbeitsumfeld und die Überführung in die Isolation der geschlossenen Einrichtung. Alleinstehenden Frauen wurden die Kinder weggenommen und in Heime gebracht. Die Frauen wurden direkt vom Arbeitsplatz geholt und auf die geschlossene Venerologische Station eingewiesen. „Es war ja immerhin sehr, sehr peinlich dann, weil sie ja nun da arbeiteten und da kommt Polizei und nimmt einen mit." "280

\subsection{Die (medizinische) Behandlung}

Wie aus den Interviews hervorgeht, fielen die Aufnahme und die medizinische wie soziale Behandlung in der geschlossenen Venerologischen Station in gewisser Weise zusammen, da Anamnese und medizinische Untersuchung teil der Aufnahme waren. Dies geht auch aus der Hausordnung der geschlossenen Venerologischen Station in Halle (Saale) hervor. Die in der Hausordnung beschriebene Prozedur der Aufnahme auf die Station sah vor, dass sämtliche persönliche Gegenstände abgenommen wurden, die Zwangseingewiesenen sich waschen und die Anstaltskleidung anziehen sollten. Anschließend folgte laut Hausordnung die Anamnese. ${ }^{281}$ Aus Interviews mit Zeitzeuginnen geht hervor, dass sich an die Anamnese, die von Famulanten, Pflegerinnen und dem Psychologen Rudolf durchgeführt wurde, die erste gynäkologische Untersuchung anschloss. Diese wurde vom Leiter der Station und von den Pflegerinnen vorgenommen. Die Zwangseingewiesenen wurden weder im Vorfeld über die medizinische Behandlung aufgeklärt noch wurde eine Einwilligung eingeholt. Die gynäkologischen Untersuchungen selbst waren mit physischen Schmerzen und psychischer Erniedrigung verbunden.

Eine Frau, die im Frühjahr 1965 vom Durchgangsheim Goldberg in Halle (Saale) in die geschlossene Venerologischen Station eingewiesen wurde, beschreibt die Einweisung: „Ich war damals 15 Jahre alt und wusste nicht, was mir geschieht. (...) Das Erste, was sehr unangenehm war, ich bin da reingekommen, wir mussten uns alles ausziehen. Wir standen praktisch nackig im Behand-

279 Interview mit Frau HPD (Anm. 258).

280 Interview mit Frau HZE (Anm. 174).

281 BArch Best. DQ 1. Nr. 4228, unpag. Hausordnung (Anm. 24), S. 1. 
lungszimmer, wurden untersucht auf brutalste Weise. Ich hatte damals lange Haare, die wurden mir abgeschnitten. (...) Wir haben dann Kopftücher bekommen, jeder ein Schlüpfer, solche komischen Latschen und ein ellenlangen grauen alten Kittel und den mussten wir anziehen. (...) Dann wurde ich in so einen Schlafsaal geführt, da wurde mein Bett und dann wurde die Wäsche da draufgeknallt und ich musste dann das Bett beziehen und eine Stunde später war wieder eine Untersuchung und dann habe [ich] eine Spritze bekommen und dann bin ich schon auf dem Weg zum Zimmer zusammengebrochen, sodass mich die anderen Patienten ins Bett reinlegen sollten und das durften die nicht, also wurde ein Schlaflager unten auf der Erde gemacht mit einer Decke und einem Kissen und ich habe dann Schüttelfrost gehabt, mir wurde übel, habe gebrochen, ich konnte meine Beine nicht mehr bewegen. Das war alles wie gelähmt. " ${ }^{282}$ Diese Beschreibung steht exemplarisch für viele Aussagen von Frauen, die in die geschlossene Venerologische Station eingewiesen worden sind. In den Beschreibungen der zwangseingewiesenen Frauen fallen stets folgende Punkte auf: das Ablegen jeglicher persönlicher Kleidung, das Durchsuchen sämtlicher persönlicher Gegenstände, die Konfiszierung von Geld, das Duschen, das Rasieren der Haare am gesamten Körper, das Ankleiden mit grauen Anstaltskitteln sowie die schmerzhaften gynäkologischen Untersuchungen. Die Raucherinnen konnten ein paar Zigaretten mitnehmen. ${ }^{283}$

Eine Frau, die 1976 wegen „Herumtreiberei“ in die geschlossene Venerologische Station in Halle (Saale) zwangseingewiesen wurde, erinnert sich deutlich an die medizinische Erstuntersuchung: ,Jedenfalls sollte ich mich ausziehen und sollte auf den Untersuchungsstuhl. Ja und da wurde ich eben untersucht, also, ich sollte mich ausziehen. Ich hatte eine Angst, ich habe gedacht: ,Was ist das hier?' Ja und da kann ich mich daran erinnern, das war, als er mich untersucht hat, das war wie so ein Glasrohr, was in die Scheide eingedreht wurde, und auf einmal, ich hatte solche Schmerzen gehabt und der hat einen, erst einmal hat er einen nur beschimpft (...) und da hatte ich geblutet und dann merkte ich, dass das alles nass war. (...) jeden Tag, mussten wir auf den Stuhl, jeden Tag aufs Neue, immer in einer Reihe so anstellen und man hat das gemacht, weil man wusste, man möchte irgendwann wieder mal hier rauskommen, wenn man das nicht gemacht hatte, wäre man ja nicht rausgekommen. " ${ }^{284}$

Weitere Zeitzeuginnen beschreiben vor allem die Kommunikation zwischen den Zwangseingewiesenen und dem behandelnden Arzt: „Dann nahm er ein dickes langes Glasrohr und rammte es tief in meinem Unterleib rein. Ich schrie vor lauter Schmerzen. Er meinte ,Stell dich nicht so an, so jungfräulich ist 
hier niemand mehr'. Als er fertig war, lief das Blut aus der Scheide. Dann untersuchte er noch meinen Kopf nach Läusen ab." ${ }^{285}$ Statt die Mädchen und Frauen über die Untersuchung und die anschließenden Diagnoseverfahren aufzuklären, wurden sie zwangsuntersucht. Dieses Vorgehen stand im klaren Widerspruch zu den rechtlichen Grundlagen bei der Behandlung von Hautund Geschlechtskrankheiten in der DDR: „Der Arzt hat den Patienten nicht nur über das Bestehen, sondern bereits über den Verdacht einer Geschlechtskrankheit aufzuklären, und zwar schriftlich, mit Gegenzeichnung des Patienten. D.h., der Patient erhält ein vorgedrucktes Belehrungsmerkblatt, in dem Untersuchungs- und Behandlungspflicht, die Pflicht zur Angabe möglicher Infektionsquellen und -gefährdeten, das Verbot, Geschlechtsverkehr auszuüben sowie Badeanstalten und Tanzgaststätten zu besuchen und zuletzt die Strafandrohung fixiert sind. "Jenseits der Aufklärungspflichten des behandelnden Arztes hatten auch die zwangseingewiesenen Mädchen und Frauen bestimmte Pflichten. Jede „muß auf dem beim Arzt verbleibenden Personalblatt quittieren, daß er diese Belehrung empfangen und verstanden hat bzw. nach Abschluß von Diagnose und Therapie das Entlassungsmerkblatt ausgehändigt bekam."“286

Nach Aussagen zwangseingewiesener Frauen wurden in Halle (Saale) solche Aufklärungsgespräche nicht geführt. Im Gegenteil, es wurde in die Integrität der Mädchen und Frauen ohne jegliche Kommunikation eingegriffen. Die Aussagen machen deutlich, wie brutal die Mädchen und Frauen untersucht wurden. Dabei wurde weder Rücksicht auf das Alter der Mädchen und Frauen genommen noch wurde geprüft, ob sie tatsächlich sexuelle Kontakte hatten. Nahezu alle Frauen berichten von den traumatischen Erfahrungen infolge der Erstuntersuchungen. Neben dem rauen Umgangston ist den Frauen vor allem die Untersuchung mit einem Glasrohr in Erinnerung geblieben. Das Glasrohr, welches meist eine Pflegerin den Zwangseingewiesenen für die Entnahme eines Abstriches einführte, hatte den Durchmesser eines 5-Mark-Stücks und war ungefähr 20 Zentimeter lang. ${ }^{287}$

Die gynäkologischen Untersuchungen wurden nicht nur bei der Aufnahme in die Station, im Rahmen der Erstuntersuchung durchgeführt, sondern waren Teil der täglichen Routine. Jede Zwangseingewiesene musste zwischen 20 und 30 Mal diese Untersuchung über sich ergehen lassen, bevor sie entlassen wurde. Diese tägliche Tortur beschreibt eine Frau wie folgt: „Und dann war dann so, am nächsten Früh mussten wir um 6 aufstehen, also schon eher. Um 6 mussten wir alle vor dem Behandlungszimmer stehen in Reih und Glied, wie bei der Armee. Dann durften wir nicht reden, mussten wir den Mund halten und dann musste jeder Einzelne dann rein und dann haben sie einen Abstrich

285 Fragebogen von Frau HPF, eingetroffen am 30. April 2014.

286 Richter: Rechtsgrundlagen bei der Behandlung (Anm. 267), S. $55 f$.

287 Interview mit Frau HPD (Anm. 258). 
gemacht (...), dann musste ich da hoch auf dem Stuhl und dann habe ich schon draußen, wo wir noch draußen gestanden haben, habe ich schon gehört, wie die eine gesagt hat ,Oh Kurbeldora ist wieder da. 'Und dann habe ich nachher im Nachhinein erfahren, dass die sehr brutal war, die Schwester, ja. Und naja, dann habe ich mich da hingelegt und da muss die wohl das dickste Röhrchen genommen haben, was es gibt, jedenfalls hatte ich das Gefühl, das tat so weh und da habe ich da aufgeschrien (...) Da hatten die dann einen Abstrich gemacht und dann konnte ich wieder gehen, raus da, ja. (...) Und dann bin ich dann da raus und dann habe ich so geblutet, ich habe gedacht, ich habe meine Regel, ja, so derb war das, aber wahrscheinlich durch der ihre Brutalität, ja. Und das war jeden Früh, vier Wochen, jeden Früh. “" ${ }^{288}$

Der Nachweis von Geschlechtskrankheiten verlief über diese Abstriche und die anschließende Identifizierung der Erreger. Hierzu wurden die Abstriche mit „Methylenblau und nach Gram gefärbt und auf Leukozyten und Gonokokken untersucht“. ${ }^{289}$ Eine zweite Methode zum Nachweis von Infektionen waren die sogenannten Provokationsmaßnahmen. Dazu wurden fieberauslösende Mittel injiziert. Eine Zeitzeugin beschreibt diese Form der Nachweisführung: „Da wurde dann so ein Mädel reingeholt, mit barfuß, ohne Schuhe und Glatze und dem Kittel. Die musste dann auf den Stuhl hopfen und da stand diese rothaarige Dame daneben (...) und der Gerd Münx machte da seine Untersuchung. Gynäkologische Untersuchungen waren ja das. Und dann wurde die gespritzt (...) So und da habe ich dann erst einmal erfahren, dass sie Fieberspritzen gekriegt hatten. Das die, wenn die so einen Tripper oder Syphilis irgendwas hatten, dass das rauskommt. Durch das Fieber würde das wohl rauskommen. So, manche hatten dann eben dermaßen Fieber gehabt, dass die völlig eben flach lagen, teilweise 42, 41 und die lagen da halt und es wurde halt auch nichts unternommen. “ ${ }^{290}$ Die Spritzen wurden von den Schwestern in den Oberschenkel oder das Gesäß injiziert. Dazu wurden die Mädchen und Frauen von den Pflegerinnen und den Stubenältesten festgehalten. ${ }^{291}$

Die so behandelten Frauen bekamen Fieber und Schüttelfrost oder waren von Kopfschmerzen und Übelkeit geplagt. Eine Frau beschreibt die Wirkung einer solchen Spritze: „Zuerst friert man, ja. Sie haben Ihren Körper nicht mehr unter Kontrolle, so zittern Sie ja, dann ist schlecht, dann muss man rausbrechen, Durchfall, Kopfschmerzen, Kopfschmerzen. Da kann man sich vorstellen, wie welche, wenn die Migräne haben, wenn die alles dunkel machen müssen oder so, ja. “" ${ }^{292}$ Eine Pflegerin beschreibt die Wirkung der Fieberspritzen: „Die sahen auch ziemlich mitgenommen aus. Das muss den Patienten

288 Interview mit Frau HPD (Anm. 258).

289 Gertler: Systematische Dermatologie und Grenzgebiete (Anm. 20), S. 1246.

290 Interview mit Frau HZE (Anm. 174).

291 Interview mit Frau HPG, geführt von Florian Steger und Maximilian Schochow, Halle (Saale), den 11. Dezember 2013.

292 Interview mit Frau HPG (Anm. 291). 
ziemlich zu schaffen gemacht haben, weil da hatten auch alle davor Angst, diese Klienten, weil das muss sehr unangenehm sein, diese Fieberspritzen, aber was das jetzt zur Therapie zu bedeuten hat, das konnte ich nie rausfinden. Oder ob das eine Strafmaßnahme ist, dass es denen schlecht geht, das kann auch sein. " ${ }^{293}$

Die fieberauslösenden Mittel hatten eine doppelte Funktion: Sie waren Teil der Therapie und dienten gleichzeitig als Strafmaßnahme. So zumindest interpretierten es vor allem die Zwangseingewiesenen. „Wer dort nicht gespurt hat, hieß es dann gleich, er kriegt eine Spritze, und zwar nannten die das Bomben. (...) Und jeder, der neu reinkam, wurde von den anderen Mädchen, die schon da waren, wurde schon gewarnt. ,Also, horch zu', sagten sie mir dann auch, ja. ,Du musst hier das machen, was die Schwestern sagen, wenn du das nicht machst, hast du darunter zu leiden, weil dann kriegst du vielleicht eine Bombe und das ist gefährlich, ja.' Man denkt sich ja nichts dabei, eine Bombe. Also, es ist so, man hat eigentlich überhaupt keine Ahnung, was die da überhaupt machen. Und dann war halt auch ein Mädchen, die kriegte die Bombe und wir haben die wirklich mit allen möglichen Decken zugedeckt. Die hat solchen starken Schüttelfrost gehabt, ja, und hohes Fieber dann, ja. Durch die Spritzen, dass haben die uns ja auch erklärt, wenn wir nicht hören, kriegen wir diese Spritze, ja, und davon bekommt man Fieber und Schüttelfrost, ja. “"294

Die Funktion der Spritzen beschreibt ein Famulant, der im Frühjahr 1961 auf der geschlossenen Venerologischen Station tätig war: „Diese Fieberspritzen galten als Provokationstest, um eventuell versteckte Gonokokken zu mobilisieren und bei der Abstrichkontrolle dann leichter zu finden. Ob das berechtigt war, ob die Methode überhaupt was brachte, das weiß ich nicht." 295 Ein anderer Famulant erinnert sich an das eingesetzte Präparat. Demnach hieß das Fieber auslösende Mittel „Pyrexal (oder so ähnlich)““.296 Die Präparate Pyrexal und Vaccigon waren in der DDR Teil der Standardtherapie, wie eine Hautärztin in einem Interview bestätigt. ${ }^{297}$ Diese Präparate wurden, wie aus dem Artikel Der Pyrexal-Provokationstest in der Diagnostik der chronischen Pyelonephritis 298 hervorgeht, zum Triggern von Infektionskrankheiten, beispielsweise einer Gonorrhoe-Infektion oder einer Pyelonephritis eingesetzt.

Provokationsmaßnahmen wurden noch in den 1970er Jahren als geeignetes Mittel zur Diagnose empfohlen. So ist in Gertlers Systematischer Dermatologie nachzulesen, dass Provokationsmaßnahmen „entweder diagnostischen Zwecken

293 Interview mit Frau HPD (Anm. 258).

294 Interview mit Frau LPA, geführt von Florian Steger und Maximilian Schochow, Halle (Saale), den 11. Dezember 2013.

295 Interview mit Herrn HZF (Anm. 180).

296 Fragebogen von Herrn HZG (Anm. 229).

297 Interview mit Frau HZ), geführt von Florian Steger und Maximilian Schochow, Halle (Saale), den 11. Februar 2014.

298 Schirmeister J, Karachonsiti H, Willmann H, Kiefer H (1964) Der Pyrexal-Provokationstest in der Diagnostik der chronischen Pyelonephritis. Gynäkologisch-geburtshilfliche Rundschau 1, 74-77. 
oder zur Sicherung des Behandlungserfolgs [dienen]. Durch das Setzen verschiedenartiger Reize sollen die in der Tiefe der Schleimhaut der Harnröhre und der Drüsenausführungsgänge befindlichen Gonokokken an die Oberfläche gebracht werden.“ “299 Analog zu den Empfehlungen im „Bericht über den 6. Pflichtkursus" aus dem Jahr 1946 werden im Gertler unterschiedliche Provokationsmethoden angegeben: biologische, mechanische, thermische oder chemische. Und weiter heißt es: „Unter den üblichen 3-5 Provokationsmaßnahmen muß mindestens eine biologische sein. Nach jeder biologischen Provokationsmaßnahme werden an den 3-4 darauffolgenden Tagen Abstriche vorgenommen. " ${ }^{000} \mathrm{Als}$ biologische Provokationsmaßnahme galt die intramuskuläre Injektion von Gonokokkenvakzinen. Stieg die Körpertemperatur über 38 Grad Celsius, dann sollte dieselbe Dosis nach vier Tagen noch einmal verabreicht werden. Alternativ werden im Gertler „Pyrifer“ intravenös aber auch die Anwendung von entfetteter Milch empfohlen. Als mechanische Provokationsmaßnahme wird im Gertler die Massage genannt. Als physikalische Provokationen werden Kurzwellendurchflutungen im Beckenbereich angegeben. Im Fall der chemischen Provokation wird die Spülung der Harnröhre mit 1- bis 2-prozentiger Silbernitratlösung oder Lugolscher Lösung empfohlen. ${ }^{301}$

Nicht nur Gertler empfahl diese Vorgehensweise bei Provokationen. Auch das Ministerium für Gesundheitswesen der DDR argumentierte in seinen „Empfehlungen zur Behandlung von Geschlechtskranken“ in eine ähnliche Richtung. Die Provokationsmaßnahmen bei Frauen sollten biologisch, physikalisch oder chemisch durchgeführt werden. Die biologische Provokation sollte „mit pyrogenen Substanzen: Pyramide oder Gonokokken-Vakzine“ durchgeführt werden. Für die physikalische Provokation wurde eine „Diathermiebehandlung der Adnexe (2o Min. Kurzwelle)“ empfohlen. Schließlich könnten auch örtliche chemische Provokationsmaßnahmen helfen. Hierzu sollte verdünnte Lugolsche Lösung in die Harnröhre bzw. in die Cervix gebracht werden. Nach jeder einzelnen Provokation waren in den folgenden Tagen Abstriche zu nehmen. Des Weiteren wurde „mindestens ein Abstrich während der Menstruation (am besten am zweiten Tag)“ empfohlen. Zuletzt sollten nach der „Beendigung der Provokationsuntersuchungen (...) die Kranken in wöchentlichen Abständen insgesamt viermal" nachuntersucht werden. ${ }^{302}$ Diese Nachuntersuchungen, die auch die Zwangseingewiesenen in den Interviews beschreiben, wurden nach der Entlassung aus der geschlossenen Venerologischen Station von der Fürsorgestelle durchgeführt. ${ }^{303}$

Die noch in den 197oer Jahren praktizierten Provokationsmaßnahmen wurden bereits Mitte der 1940er Jahre im „Bericht über den 6. Pflichtkursus“ propa-

299 Gertler: Systematische Dermatologie und Grenzgebiete (Anm. 20), S. 1246.

300 Gertler: Systematische Dermatologie und Grenzgebiete (Anm. 20), S. 1246.

301 Gertler: Systematische Dermatologie und Grenzgebiete (Anm. 20), S. 1247, 1253.

302 BArch Best. DQ 1. Nr. 4228, unpag. Empfehlungen (Anm. 108).

303 Interview mit Frau LPA (Anm. 294). 
giert. Die Ausführungen dort ähnelten sich stark mit den Maßnahmen in den 197oer Jahren - bis hin zur Empfehlung, fettarme Milch für die Provokation zu verwenden. Lediglich ein gravierender Unterschied fällt auf: Während die Provokationsmaßnahmen in den 1940er Jahren noch Teil der Therapie waren, wurden sie in den 1970er Jahren nur noch zur Diagnose und Absicherung der Behandlung vorgeschlagen. Dennoch wird aus den Empfehlungen von Gertler und vom Ministerium für Gesundheitswesen der DDR deutlich, dass der Einsatz der Fieberspritzen an vielen medizinischen Einrichtungen der DDR zum Standardprogramm gehörte. Die Nebenwirkungen der Spritzen werden übereinstimmend sowohl von den Zwangseingewiesenen als auch von den Mitarbeitern der geschlossenen Venerologischen Station als heftig und äußerst schmerzhaft für die Mädchen und Frauen beschrieben. Lediglich über die Funktion der Spritzen gibt es widersprüchliche Aussagen. Während das medizinisch-pflegerische Personal eine klare diagnostische Funktion benennt, wissen die zwangsbehandelten Frauen oft nicht, warum sie überhaupt die Spritzen verabreicht bekamen. Viele interpretierten die Provokationsmaßnahmen als Teil eines Strafsystems. Die Zwangseingewiesenen wurden nicht über Ziel und Wirkung der Provokationen aufgeklärt. Auch vor diesem Hintergrund verstanden sie die Eingriffe als Strafe.

Die Geschlechtskrankheiten wurden in Halle (Saale) mit Penicillin behandelt. Eine Zeitzeugin berichtet, dass Penicillin zur Behandlung der Conorrhoe standardmäßig eingesetzt wurde. Diese Therapie wurde in Halle (Saale) vom leitenden Arzt angeordnet. Er untersuchte die Frauen, entschied nach dem Abstrich, ob eine Gonorrhoe vorliegt und welche die geeignete Therapie sei - wer also „in welchem Maß Penicilline bekommt oder nicht“. ${ }^{304}$ Damit entsprach die therapeutische Behandlung den „Empfehlungen zur Behandlung von Geschlechtskrankheiten“. Darin heißt es: „(1) Die unkomplizierte Gonorrhoe wird bei Männern und Frauen in gleicher Weise behandelt mit a) wässerigem Depot-Penicillin 1 x 80o.ooo E[inheiten] oder b) öligem Depot-Penicillin $1 \mathrm{x}$ 600.000 E. Ein Versagen dieser Behandlung läßt auf das Vorliegen von Komplikationen schließen und erfordert stationäre Behandlung. "Auch die Syphilis sollte mit wässerigem „Depot-Penicillin 4.00o.ooo E zweimal täglich in Abständen von 12 Stunden“ oder mit öligem „Depot-Penicillin 60o.ooo E in Abständen von 24 Stunden“ "behandelt werden. ${ }^{305}$ Im Gertler heißt es zur Therapie: „Im akuten Stadium, um zugleich Penizillinasebildner in der Begleitflora zu erfassen: eine i.m. Injektion von $4 \mathrm{ME}$ wäßrigem Depotpenizillin. Danach mindestens 12 Std. Bettruhe. (...) Penizillin kann bei Unverträglichkeit durch andere Antibiotika ersetzt werden. "306 Weitere Therapien, wie sie im „Bericht über den 6. Pflichtkursus“ aus dem Jahr 1946 noch angeführt wurden, finden sich bei Gertler nicht mehr.

304 Interview mit Frau HZB (Anm. 164).

305 BArch Best. DQ 1. Nr. 4228, unpag. Empfehlungen (Anm. 108).

306 Gertler: Systematische Dermatologie und Grenzgebiete (Anm. 20), S. 1247, 1253. 


\subsection{Alltägliche Erziehung}

Vor dem Hintergrund des medizinischen Wissens und der Standardtherapie mit Penicillin stellt sich die Frage, warum die zwangseingewiesenen Frauen bis zu sechs Wochen auf der geschlossenen Venerologischen Station bleiben mussten. Ein ehemaliger Arzt der Hautklinik Dresden-Friedrichstadt, den wir in einem Interview zu diesem langen Behandlungszeitraum befragten, konnte sich diese Dauer nicht erklären: „Also fünf, sechs Wochen verstehe ich nicht. Es möge Einzelfälle geben, wo immer wieder zwischendurch mal ein Abstrich dabei ist, wo Zweifel sind, wo man nicht die Möglichkeiten, also in den Goer Jahren, Anfang der 7oer Jahre, die Gonokokken zu kultivieren. Das war ausgesprochen schwierig. Die sind so anspruchsvoll und wir hatten in der DDR die entsprechenden Nährmedien nicht zur Verfügung, um die Kulturen, jetzt routinemäßig, durchführen zu können. PCR gab es eh nicht und andere Möglichkeiten eben auch nicht. Serologisch war das auch nicht machbar, sodass es schon mal in ganz seltenen Einzelfällen schwierig sein konnte eine klare Diagnose rein morphologisch, mikromorphologisch zu stellen. (...) Also das ist dann schon klar, aber wie gesagt, eine ärztliche Indikation für eine so lange Diagnostik ist sehr, sehr selten gewesen und ich kann mir nicht vorstellen, dass dann diese seltenen Fälle gepaart mit Unbotmäßigkeit der Patienten dann alle in Halle gelandet sind. "307 Nach der Standardtherapie mit Penicillin waren die Geschlechtskrankheiten innerhalb weniger Tage kuriert. Die Provokationsmaßnahmen zum Behandlungserfolg und die Nachuntersuchungen lagen theoretisch in der Verantwortung der nachgestellten Fürsorgeeinrichtung. Dennoch wurden die Frauen über mehrere Wochen festgehalten und von der Außenwelt isoliert. In der Präambel der Hausordnung von Halle (Saale) war die Erziehungsfunktion der Station festgelegt: „Durch erzieherische Einwirkung muss erreicht werden, dass diese Bürger nach ihrer Krankenhausentlassung die Gesetze unseres Staates achten, eine gute Arbeitsdisziplin zeigen und sich in ihrem Verhalten in unserer Gesellschaft von den Prinzipien des sozialistischen Zusammenlebens der Bürger unseres Staates leiten lassen. “308 Im Mittelpunkt des Erziehungsprogramms stand die sogenannte „Arbeitstherapie“, die in den täglichen Ablauf auf der Station integriert war. Teil dieser „Arbeitstherapie“ war das Reinigen der geschlossenen Venerologischen Station sowie der Poliklinik Mitte. Eine genauere Rekonstruktion des alltäglichen Erziehungsprogramms auf der geschlossenen Venerologischen Station ist auf Crundlage der Zeitzeugeninterviews möglich.

Die Zwangseingewiesenen mussten täglich vor 6 Uhr aufstehen. ${ }^{309}$ Nach dem Aufstehen wurden die täglichen gynäkologischen Untersuchungen durchgeführt: „Um 6 mussten wir alle vor dem Behandlungszimmer stehen in Reih

307 Interview mit Herrn DAA, geführt von Florian Steger und Maximilian Schochow, Dresden, den 9. Juli 2015.

308 BArch Best. DQ 1. Nr. 4228, unpag. Hausordnung (Anm. 24), S. 1.

309 Interview mit Frau HPG (Anm. 291). 
und Glied, wie bei der Armee. " ${ }^{110}$ Im Anschluss an die Untersuchungen gab es um 8 Uhr Frühstück. ${ }^{31}$ Das Frühstück wurde vom Pflegepersonal vorbereitet. Es gab Brot, Butter, Wurst und Marmelade. ${ }^{312}$ Die Pflegerinnen verteilten das Essen und beaufsichtigten während des Frühstücks die zwangseingewiesenen Mädchen und Frauen. ${ }^{313}$ Nach dem Frühstück durften die Raucherinnen eine Zigarette rauchen: „Es gab 3 Zigaretten, Frühstück, Mittag, Abend.“314 Anschließend waren die Zwangseingewiesenen sich selbst überlassen oder mussten zur „Arbeitstherapie“.

Wie in der Hausordnung vorgesehen, waren die Mädchen und Frauen zur sogenannten „Arbeitstherapie“ verpflichtet. Diese bestand hauptsächlich im Putzen der geschlossenen Venerologischen Station bzw. der Poliklinik Mitte. Bei der Zuteilung der Dienste gab es Unterschiede: „Da waren wir die Jüngsten und da mussten wir nichts machen (...), manche, die mussten dann runter und mussten dann Behandlungsräume und so etwas sauber machen, ja."315 Über die Motive für die unterschiedliche Vergabe der Aufgaben können die Zeuginnen nur mutmaßen: „Aber das waren dann Ausgesuchte. Also wir auf alle Fälle nicht. Erstens, weil wir wahrscheinlich das erste Mal da drinnen waren und viel zu jung auch. "316 Neben dem Alter als Kriterium für die Zuteilung von Arbeit führten andere die Fluchtgefahr als mögliches Kriterium an. Diejenigen, die unter dem Verdacht standen fliehen zu wollen, wurden eingesperrt. Eine Schwesternschülerin erinnert sich, dass jede Station ,ein oder zwei zugeteilt [bekam], die dann sauber gemacht hat und die in der Küche abgewaschen hat. Und nachmittags war ja dann nur eine da, die abgewaschen hat. Und die mussten aber zu einer bestimmten Zeit, ich glaube, dass weiß ich eben nicht ganz genau, ob es 19 Uhr war, mussten die wieder drüben sein. Also am Lattenzaun mussten man die persönlich abgeben (...). Und die hatten Angst, dass sie ihre Arbeit nicht schaffen bis zur Zeit und wenn es 5 Minuten oder 10 Minuten später war, die hatten solche Angst, denn ich habe es selbst erlebt, man schloss die Tür auf und dahinter stand schon, wie im Knast quasi, die Zimmerälteste, die Älteste, die dort, wenn die Schwestern am Nachmittag Feierabend hatten, hatte dort eine der Patienten das Sagen. Und die stand schon wie ein schnaufender Stier hinter diesem Zaun, hinter dem Bretterverschlag. " 317

Wer nicht putzen musste, wurde in der Wäscherei beschäftigt: „Die haben vielleicht immer gedacht, wenn wir mal da in der Wäschekammer Wäsche waschen mussten oder dies oder jenes, sauber machen, Toiletten putzen und

310 Interview mit Frau HPD (Anm. 258).

311 Fragebogen von Frau HPF (Anm. 285).

312 Interview mit Frau HZA (Anm. 163).

313 Interview mit Frau HZA (Anm. 163).

314 Interview mit Frau HPB (Anm. 235).

315 Interview mit Frau HPD (Anm. 258).

316 Interview mit Frau HPD (Anm. 258).

317 Interview mit Frau HZD (Anm. 169). 
was weiß ich (...), die können uns ärgern, ja. Aber für uns war es ehrlich gesagt eine Abwechslung, obwohl es nicht schön war, aber trotzdem, ja. “"118 Teile der sogenannten „Arbeitstherapie“ wurden also nicht von allen Zwangseingewiesenen als Schikane empfunden, sondern als Ablenkung. Weitere Arbeiten waren kleinere Hilfstätigkeiten für die Pflegerinnen: „Da mussten wir immer so Zellstoff schneiden und so etwas machen und andere Sachen, Tabletten einordnen oder so etwas hier machen. (...) Das war praktisch wie so ein kleines Gefängnis. “319 Neben dem Schneiden des Zellstoffs unterstützten die Zwangseingewiesenen das Personal bei der Essenverteilung: „Und das Essen kam quasi von der Poliklinik Süd und da mussten die Essenkübel immer nach oben getragen werden auf die Station. " 320

Wenn die Mädchen und Frauen außerhalb der Poliklinik Mitte als Reinigungskräfte eingesetzt wurden, bekamen sie „normale“ Kleidung. „Die hatten alle blaue Kittel an, die Patientinnen, wie die Reinigungskräfte (...). Die wurden beaufsichtigt, mussten abgeholt werden gegen Quittung und mussten auch wiedergebracht werden und dann wurden Räume überall gereinigt durch die Patientinnen, aber nur diejenigen, wo wir sicher waren, dass sie also nicht abhauten, denn wenn sie von Halle waren, kannten sie ja das Terrain und waren dann manchmal auch verschwunden, aber das möchte ich meinen, ganz, ganz selten. Kann ich mich nicht daran erinnern. Sie waren also immer wieder da. Wurden mit dem Auto in die Außenstellen gefahren. Wir hatten ja 22 davon über ganz Halle weg und da machten die auch sauber und wurden wieder abgeholt und kamen dann wieder, wurden dann wieder verschlossen, eingeschlossen. “" ${ }^{321}$ Die Mädchen und Frauen, welche in den Außenstellen arbeiteten, erhielten neben anderer Kleidung auch eine andere Medikation: „Und das war bald tagtäglich, außer wenn wir putzen gehen mussten im Krankenhaus, da wurden keine Tabletten und keine Säfte verabreicht, weil da Publikumsverkehr war. Und da haben wir auch andere Kittel bekommen. "322 Es scheint, als sollte das Bild einer normalen Station, in der nichts Unrechtes geschah und es den Mädchen und Frauen gut ging, nach außen aufrechterhalten werden.

Wer nicht im Rahmen der „Arbeitstherapie“ beschäftigt war, wurde am Vormittag von zwei Pflegerinnen der geschlossenen Venerologischen Station überwacht. Über die Möglichkeiten, sich mit Lesen, Spielen etc. abzulenken, gibt es widersprüchliche Aussagen. Einige Zwangseingewiesene berichten, dass man auf der Station nichts hätte machen können. ${ }^{323}$ Andere erzählen, dass sie lesen konnten: „Zu lesen gab es was und Spiele, Mensch ärgere dich nicht." ${ }^{224}$

318 Interview mit Frau HPG (Anm. 291).

319 Interview mit Frau HPE (Anm. 277).

320 Interview mit Frau HZD (Anm. 169).

321 Interview mit Frau HZA (Anm. 163).

322 Interview mit Frau HPA (Anm. 170).

323 Interview mit Frau HPG (Anm. 291).

324 Interview mit Frau HPD (Anm. 258). 
Vor allem aber überwog die Langeweile: „Den ganzen Tag, vier Wochen lang, gammelten wir rum. “ 325 Es muss aber auch gewisse Freiräume gegeben haben. Zeitzeuginnen berichten von Ereignissen, welche durch die Hausordnung eigentlich sanktioniert waren - beispielsweise das Schminken: ${ }^{226}$ „Da saßen welche, die hatten sich die Haare aufgedreht. Zeitungspapier, Lockenwickler aus Zeitungspapier, dann würfelten welche am Tisch. So einen Würfel hab ich auch noch nie gesehen, da sage ich, ,Was habt denn ihr hier?' ,Das ist ein Würfel', da wurde Brot mit Zahnpasta gekaut. (...) Und die hatten sich ja alle aufgehübscht." 327

Zwischen 12 und 12.30 Uhr gab es Mittagessen. ${ }^{328}$ Anschließend überwachten die Stubenältesten die geschlossene Venerologische Station. ${ }^{229}$ Den Spätdienst übernahm dann wieder das medizinisch-pflegerische Personal und sorgte für die Verteilung des Abendessens und überwachte anschließend die Nachtruhe. „Ich glaube, 20 Uhr war Nachtruhe angesagt. Wer sich nicht daran gehalten hat, musste stundenlang im Flur stehen, ohne sich anzulehnen oder sich zu bewegen. Das ging so immer zwei bis vier Stunden." $33^{\circ}$ Dieser Tagesablauf bestimmte den Alltag auf der geschlossenen Venerologischen Station. Einige ehemalige zwangseingewiesene Frauen berichten, dass sie bis zu sechs Wochen auf der Station in Halle (Saale) waren.

Vor allem in den Nachmittagsstunden herrschte auf der geschlossenen Station Langeweile. Die Langeweile und die Isolation waren für die Zwangseingewiesenen belastend: „Nein, da durfte keiner rein. Ich sage doch, es durfte nie jemand kommen und etwas abgeben oder wie oder was oder mal nachfragen. Wir waren total abgeschnitten die drei Wochen." 331 Ob die sogenannte „Arbeitstherapie“ von den Zwangseingewiesenen tatsächlich als eine Abwechslung empfunden wurde oder nicht, kann letztlich nicht beantwortet werden. Das persönliche Empfinden in Bezug auf die Arbeiten variierte zwischen dem Gefühl der Bestrafung und dem willkommener Abwechslung. Sicher ist aber, dass alle Arbeiten auf der geschlossenen Station und in den Abteilungen der Poliklinik Mitte vom medizinisch-pflegerischen Personal als Teil der „Arbeitstherapie“ verstanden wurden. Im Rahmen dieser Therapie wurden vor allem zwei Erziehungsziele verfolgt: Strukturierung des Tagesablaufs und tägliche Beschäftigung. Täglich mussten die Zwangseingewiesenen vor 6 Uhr aufstehen und pünktlich um 6 Uhr zur gynäkologischen Untersuchung antreten. Pünktlich um 8 Uhr gab es Frühstück und anschließend folgte die „Arbeitstherapie“. Um 12 Uhr wurde zu Mittag gegessen, um 20 Uhr gab es

325 Fragebogen von Frau HPF (Anm. 285).

326 BArch Best. DQ 1. Nr. 4228, unpag. Hausordnung (Anm. 24), S. 1-5.

327 Interview mit Frau HZD (Anm. 169).

328 Fragebogen von Frau HPF (Anm. 285).

329 Interview mit Frau HZD (Anm. 169).

330 Fragebogen von Frau HPF (Anm. 285).

331 Interview mit Frau HPG (Anm. 291). 
Abendbrot und um 21 Uhr war Nachtruhe. An diese Struktur sollten die Mädchen und Frauen tagtäglich herangeführt werden, damit sie auch jenseits der geschlossenen Station einen Rhythmus in ihren Tagesablauf bringen konnten. Neben der Struktur war die Arbeit Teil des Erziehungsprogramms. Bei den Tätigkeiten ging es primär nicht um die Tätigkeit an sich. Vielmehr sollten sich die Mädchen und Frauen generell mit dem Arbeiten auseinandersetzen. Insofern war es letztlich gleichgültig, ob die Zwangseingewiesenen die Stationen putzten, die Wäsche wuschen oder andere Hilfstätigkeiten erledigten. Im Vordergrund stand die tägliche, pünktlich zu beginnende Arbeit.

Auch nach der Entlassung aus der geschlossenen Venerologischen Station waren die Mädchen und Frauen in eine vorgegebene Struktur der Überwachung integriert. Für einen gewissen Zeitraum mussten sie sich in der zentralen Fürsorgestation melden, um die Nachuntersuchungen einzuhalten. In Halle (Saale) gab es „eine Hauptfürsorgestelle in der Leipziger Straße. (...) Und die hatten eigentlich die kompletten Unterlagen, auch einschließlich Syphilispatienten. "In der zentralen Fürsorgestelle wurden die Mädchen und Frauen unter anderem regelmäßig gynäkologisch untersucht. „Die wurden ja, wenn sie entlassen wurden, (...) der Nachkontrolle unterzogen. Das gab es auch noch. Tripper- und auch Syphilisnachkontrolle. So und das lief über die Hauptfürsorgestelle (...) und wenn die da wieder nicht zur Nachkontrolle gegangen sind, landeten die wieder auf Station. Also das nahm kein Ende." 332 Die zentrale Fürsorgestelle kam einer Überführung der geschlossenen Venerologischen Station in den Alltag vieler Mädchen und Frauen gleich. Hier mussten sie sich stets zur Nachkontrolle einfinden und wurden bei Zuwiderhandlung sofort durch die Polizei in die geschlossene Venerologische Station eingewiesen.

\subsection{Der Terror im Terror}

Die geschlossene Venerologische Station in Halle (Saale) war hierarchisch strukturiert. Der Ärztliche Direktor der Poliklinik Mitte und Leiter der geschlossenen Venerologischen Station stand an der Spitze. Unten waren die jungen Mädchen, die von den Stubenältesten drangsaliert wurden. Diese Hierarchie wurde durch einen Terror im Terror erzeugt und aufrechterhalten. Dieser Terror war im Kleinen wie im Großen zu finden und zog sich wie ein roter Faden durch die Geschichte der geschlossenen Venerologischen Station. Die Zeitzeugenberichte belegen die Kontinuität der Gewalt. Dieser Terror hatte viele Gesichter und verfehlte seine Wirkung fast nie.

Eines der Gesichter war der Leiter der geschlossenen Station Gerd Münx. Seine ärztlichen Kollegen bezeichneten ihn zwar als tyrannisch, dennoch war er gegenüber dem medizinischen Personal kollegial und höflich. ${ }^{33}$ Mit dem Pfle-

332 Interview mit Frau HZE (Anm. 174).

333 Fragebogen von Herrn HZG (Anm. 229). 
gepersonal ging Münx nicht nur tyrannisch und ruppig, sondern auch unpersönlich um. „Das war der Herrscher. Der hat alles gemanagt dort. Der war eigentlich nur Schreibtischmensch." 334 Die Zwangseingewiesenen behandelte Münx abwertend und herablassend: „Er sagte aber, die Frauen, die hier sind, das ist, wie gesagt, der Abschaum. Der hat nur vom Abschaum gesprochen. " ${ }_{335}$ Dritten gegenüber bezeichnete Münx die Zwangseingewiesenen als „Nutten“. Gerd Münx setzte konsequent die Hausordnung durch und bestrafte die Zwangseingewiesenen mit Disziplinarmaßnahmen, welche in der Hausordnung festgelegt waren. Auch Teile des medizinischen Personals betrachteten die Zwangseingewiesenen als „Abschaum“. In den Interviews mit den Polizisten und ehemaligen Angestellten der Station werden die Zwangseingewiesenen mitunter noch heute in dieser Form diffamiert. ${ }^{336}$ Eine differenziertere Haltung den Zwangseingewiesenen gegenüber hatten viele Famulanten, wie in den Interviews deutlich wird. Doch auch sie nahmen häufig eine paternalistische Perspektive ein, wenn sie die Mädchen und Frauen beispielsweise als ,arme Würstchen “ bezeichneten, denen geholfen werden musste. ${ }^{337}$

Das Pflegepersonal handelte ähnlich unpersönlich, entindividualisierend und entwertend, wenn sie mit den Zwangseingewiesenen zusammen waren: „,Das war ja schon einmal bisschen Dreck und Abschaum', sagen die Schwestern. " ${ }^{33^{8}}$ Möglicherweise wurde diese abschätzige Haltung auch dadurch verstärkt, dass das medizinische Personal die strenge Hausordnung sowie die Internalisierung durchsetzen musste. Aus der Sicht des medizinisch-pflegerischen Personals hatten viele der Zwangseingewiesenen Geschlechtskrankheiten mutwillig verbreitet. Um dies künftig zu verhindern, mussten sie entsprechend medizinisch versorgt, aber vor allem pädagogisch unterwiesen werden. Bei den (medizinischen) Untersuchungen und Behandlungen wurden die Mädchen und Frauen misshandelt und ihnen wurden absichtlich Schmerzen zugefügt. Gleichzeitig wurden die Zwangseingewiesenen durch ein System von Belohnungen (beispielsweise Zuteilung von Zigaretten) und Bestrafungen (Nachtruhe auf dem Hocker) gefügig gemacht. „Eine milde Strafe war Autowaschen unten im Hof. Da ist so ein Bild, da stehen Autos im Hof und da wurden die delegiert zum Autowaschen. Das war nun was ganz Mildes." 339 Eine drastischere Strafe war die sogenannte Abstrichsperre, die auch in der Hausordnung aufgeführt war. ${ }^{340}$ Demzufolge waren neben den sogenannten „Arbeitstherapien“ auch Teile der medizinischen Versorgung Bestandteil des Erziehungs- und Disziplinierungssystems.

334 Interview mit Frau HZE (Anm. 174).

335 Interview mit Frau HZD (Anm. 169).

336 Interview mit Frau HZ) (Anm. 297).

337 Interview mit Herrn HZF (Anm. 180).

338 Interview mit Frau HZD (Anm. 169).

339 Interview mit Herrn HZF (Anm. 180).

340 BArch Best. DQ 1. Nr. 4228, unpag. Hausordnung (Anm. 24), S. 6. 
Nicht zuletzt war auch das Verhältnis der Zwangseingewiesenen untereinander hierarchisch organisiert. Dieser vertikalen Struktur wurde bereits durch die Hausordnung und die Implementierung der Stubenältesten Vorschub geleistet. „Als Neuling musste man immer, so lange, bis wieder eine Neue kam, für die Älteste Insassin den Butler machen. (...) Wie ein Hund an ihrer Seite. Man durfte nicht von ihrer Seite weichen. Das war die reinste Schikane und Erpressung. Aus Angst vor Strafen traute man sich nicht, beim Arzt oder Schwester zu beschweren. " ${ }^{341}$ Die Stubenältesten teilten die Innen- und die Außendienste ein, unterstützten das medizinisch-pflegerische Personal bei den (medizinischen) Behandlungen oder überwachten die Disziplinarmaßnahmen. Sie kooperierten regelrecht mit dem medizinisch-pflegerischen Personal und erlangten so eigene Vorteile - beispielsweise zusätzliche Raucherlaubnis oder Zigaretten. ${ }^{342}$ Eine Pflegerin erinnert sich: „Zigaretten wurden verteilt für gute Arbeit. “" ${ }^{43}$ Auch jenseits der Regularien der Hausordnung gab es Mittel zur Belobigung und zur Privilegierung: „Die haben eben drei Scheiben Wurst gekriegt, die anderen haben eine gekriegt oder nachmittags eine Schnitte mit Marmelade und die anderen haben nur so einen Malzkaffee da gekriegt." 344

Jenseits konkreter Personen waren es die Praktiken im Allgemeinen, die vom Terror zeugten. Allein die Einweisung in die geschlossene Venerologische Station war mit Zwang verbunden: „Die sind ja zwangseingeliefert. Da war ja keiner dabei, der freiwillig mit seiner Tasche kam und hat gesagt: ,Guten Tag, ich würde jetzt hier mal ein paar Wochen stationär mich aufnehmen lassen.' So war es ja nicht. Die wurden ja alle mit der Polizei gebracht. " ${ }^{345}$ Die anschließende Prozedur der Aufnahme, das Entkleiden, die Abgabe von allen privaten Gegenständen und die Aushändigung von Stationskleidung erinnert die Zeitzeugen stark an die Aufnahme in ein Gefängnis. „Ja, komplett ausziehen. Da gab es eine Kleiderkammer (...) und da lagen dann die Sachen drin, unter Verschluss. Also, die hätten gar nicht abhauen können, die wären im Kittel gewesen. " ${ }^{346}$ Einer Zeitzeugin ist die Prozedur der Reinigung der neu aufgenommenen Mädchen und Frauen als besonders demütigend in Erinnerung geblieben: „Die wurden mit einem Eimer kaltem Wasser begossen und die anderen haben mit dem Schrubber, mit dem Stiel, die sauber, versucht zu säubern. Also das haben auch die Mädels erzählt. (...) Ich sage mal, hier waren vielleicht der Faktor des Demütigens vorrangig, denn wie kann ich denn jemanden mit einem Schrubber, mit dem Stiel, also. Das hat doch etwas mit Demut zu tun. " ${ }^{347}$ Aus der Sicht der Zwangseingewiesenen war das Abschneiden der Haa-

\footnotetext{
341 Fragebogen von Frau HPF (Anm. 285).

342 BArch Best. DQ 1. Nr. 4228, unpag. Hausordnung (Anm. 24), S. 6.

343 Interview mit Frau HZA (Anm. 163).

344 Interview mit Frau HZE (Anm. 174).

345 Interview mit Frau HZD (Anm. 169).

346 Interview mit Frau HZE (Anm. 174).

347 Interview mit Frau HZD (Anm. 169).
} 
re bei Aufnahme in die geschlossene Venerologische Station eine besonders demütigende Prozedur: „Ja, weil die uns nicht so behandelt haben, wie als wenn wir jetzt draußen richtig normal zum Arzt gehen würden, die Haare abgeschnitten. " ${ }^{348}$ Und nicht nur beim Abschneiden der Haare erhielt das Personal Unterstützung von den Stubenältesten, sondern auch bei den Intimrasuren: „Ja, mit festhalten dann und es gab ja meistens dann Schläge, wenn die sich gewehrt hatten, dann gab es Schläge. Das war an der Tagesordnung. Dass die sich untereinander auch geprügelt haben auf der Station. "349

Die Stubenältesten waren bei diesen Prozeduren der Aufnahme - dem Entkleiden, dem Waschen oder dem Rasieren - stets beteiligt. Sie überwachten gemeinsam mit den Schwestern alle Vorgänge. Viele Gewaltakte wurden auch an die Stubenältesten delegiert, wie in zahlreichen Aussagen ehemaliger Zwangseingewiesener und Mitarbeiter der geschlossenen Station deutlich wird. War Münx unter anderem der Meinung, eine Zwangseingewiesene verstoße gegen die Disziplin, dann hat ,er die anderen aufgehetzt: ,Werft ihr eine Decke drüber und haut drauf, haut drauf.' Das mit der Decke vielleicht deshalb, dass man nicht namentlich festmachen kann, wer da geschlagen hat. Auch wieder so eine Tarnung, denn wenn die sich beschwert hätten, sie sind geprügelt worden, ja wer hat sie denn geprügelt. Ohne Namensangabe war nichts zu machen. “"350 Und wenn die Stubenältesten nicht allein handelten, so waren sie zumindest an den meisten körperlichen Gewaltakten unmittelbar beteiligt.

Zum Terror auf der Station gehörten auch die gynäkologischen Untersuchungen. Diese wurden einerseits im Rahmen der Aufnahme auf die Station durchgeführt. Ein Beispiel soll noch einmal verdeutlichen, wie menschenunwürdig diese Untersuchungen waren. Eine Zeitzeugin schildert die Erstuntersuchung eines 12jährigen Mädchens: „Und da hat der Gerd Münx die auch auf den Stuhl gezottelt und da zu dieser Frau Siebeneichner, zu dieser alten Schrulle gesagt: ,Hier! Untersuchen!' So und die hat dann wahnsinnig geblutet die Kleine und da hat er gesagt, so nun hattest du einen Mann gehabt. Das konnten wir nicht begreifen. Die haben die praktisch da drinnen entjungfert. “" 351 Mit der ersten Untersuchung wurden die Mädchen und Frauen verbal attakiert, es wurde in ihre körperliche Integrität eingegriffen und ihnen absichtlich Schmerz zugefügt. Die Aussage der Zeitzeugin verdeutlicht zudem, dass Mädchen und junge Frauen auf der Station defloriert wurden. Und nicht nur während der Erstuntersuchung kam es zu gewalttätigen und traumatisierenden Übergriffen. Auch die tagtäglichen gynäkologischen Untersuchungen waren entwürdigend, schmerzvoll und traumatisierend. Noch einmal soll die Zeitzeugin zu Wort kommen: „Also, untersucht wurde, kann man sagen, eigentlich brutal. Die

348 Interview mit Frau HPE (Anm. 277).

349 Interview mit Frau HZE (Anm. 174).

350 Interview mit Herrn HZF (Anm. 180).

351 Interview mit Frau HZE (Anm. 174). 
wurden da reingezerrt. Da war teilweise auch die Stubenälteste dabei. Wenn die widerwillig war, da musste die die mit reinzerren. Die stand dann auch dabei und hat sie gleich mit eingesackt. Da wurden die auf dem Stuhl da hochgezottelt, und es waren ja teilweise sehr junge Mädels dabei; auch 12, 13 Jahre auch dabei. Und die wurden dann festgehalten oder war auch irgendwie so ein Lederdings am Bein. Das war damals, glaube ich, überhaupt an den Gynstühlen, dass man nicht runterrutscht. Also, waren solche Schalen waren das, gibt es ja heute gar nicht mehr. Aber, und wenn die widerwillig wurden, wurden halt die Riemen zugemacht. Ich glaube, bei der OP wird das auch gemacht oder wurde, dass man nicht runterrutscht. So und da wurde das halt zugemacht und da ging es richtig zur Sache. Also brutal ging es vor. Es wurden Abstriche gemacht, mit solchen Glasröhrchen da rein, plupp und rumgekratzt drinnen. Und die Weiber haben natürlich da, das tut ja weh. Das ist ja ganz klar. “352

Die Stubenältesten wurden nicht nur im Zusammenhang mit den gynäkologischen Untersuchungen eingesetzt, um die anderen Zwangseingewiesenen zu disziplinieren. Sie übernahmen auch die Überwachung und Ausführung der Strafmaßnahmen wie das Schlafen auf einem Hocker, das Isolieren und Einsperren oder Essen- und Schlafentzug. Eine Zeitzeugin berichtet darüber sehr ausführlich: „Da gab es ja da die Stubenälteste, die hat sie dann verdroschen oder kein Essen. Und im schlimmsten Fall war dann das Bad. Da gab's ja auf der Station so ein Bad, nannte sich das. Da war so eine Badewanne drin und so ein weißer Hocker aus Holz und ansonsten nur Fliesen, gar nichts, kein Spiegel, gar nichts, kein Tageslicht, nichts und da mussten die dann drinnen bleiben. Da wurde auch das Licht ausgeschaltet. Da saßen die dann zwei, drei Tage dann, mit nackigen Füßen, ohne Schuhe. Da saßen die dann halt ein paar Tage, bis sie sich eben bewusst waren, was sie Böses getan hatten. "353 Eine weitere Strafe, die in der Hausordnung genannte Nachtruhe außerhalb des Bettes auf dem Hocker, 354 wurde laut der Zeitzeugen regelmäßig angewandt. Eine Zwangseingewiesene, die 48 Stunden in Isolation verbringen musste, berichtet: „Also es war katastrophal. Ich hatte 48 Stunden in den Toilettentrakt eingesperrt, ohne Essen, ohne Trinken, nichts, ein vergittertes Fenster war davor und dann habe ich gebrochen, weil ich wieder Säfte und Tabletten einnehmen musste." ${ }^{355}$ Die Strafe der Nachtruhe auf einem Hocker wurde von sehr vielen Zeitzeuginnen beschrieben. Entsprechend ist zu vermuten, dass diese Strafe auf der geschlossenen Station häufig angewandt wurde.

Gemeinsam mit anderen Zwangseingewiesenen bildeten die Stubenältesten Erziehungskollektive, um einzelne Mädchen oder Frauen zu bestrafen. Die Situationsbeschreibung einer Frau, die 1965 in der geschlossenen Venerologischen Station von Halle (Saale) war, verdeutlicht diese Vorgänge: „Und das

352 Interview mit Frau HZE (Anm. 174).

353 Interview mit Frau HZE (Anm. 174).

354 BArch Best. DQ 1. Nr. 4228, unpag. Hausordnung (Anm. 24), S. 6.

355 Interview mit Frau HPA (Anm. 170). 
weiß ich noch, ich habe den Untersuchungsstuhl gesehen so verschwommen und wie ich dann wieder zu mir kam, war ich am Arm tätowiert und zwar war das ein großes T wie Theodor, ein $\mathrm{H}$ wie Heinrich, ein A wie Anton, ein X und eine 56 und ich hörte ganz weit vom Hintergrund, dass die gesagt haben, ja die Nummer ist mit eintätowiert. (...) Ich habe mir das dann nach Jahren in der Universitätsklinik Leipzig rausmachen lassen, aber man sieht die Narbe an der Hand ist alles noch da. " 356 Solche Übergriffe waren offenkundig keine Seltenheit. Sie wurden von mehreren Zwangseingewiesenen in einer Gruppe durchgeführt und hatten das Ziel, die Opfer zu disziplinieren. „Ich war nicht die Einzige, die tätowiert worden ist. “357

Die Frauen drangsalierten sich nicht nur gegenseitig, sondern griffen in bestimmten Situationen auch das medizinisch-pflegerische Personal an. Vor allem ein Übergriff, der anschließend von der Staatsanwaltschaft bearbeitet wurde, blieb vielen Zeitzeugen in Erinnerung. Den Anlass für den Übergriff beschreibt eine Oberschwester wie folgt: „Eine Schwester, das war keine Hilfsschwester, das war eine Krankenschwester. Aber die hat auch gedacht, sie sei der König oder die Prinzessin über die Anderen. Das haben sie sich nicht bieten lassen. Sie wollten als normale Patienten geachtet werden und behandelt werden. Und wer das machte, das klappte. Der hatte keine Schwierigkeiten mit denen, aber wehe dem, man degradierte sie irgendwie oder diskriminierte sie, dann waren sie zickig. " "358 Eine andere Zeitzeugin begründete die Übergriffe mit der Raublust der Zwangseingewiesenen: „Da war eine Nachtschwester, die war immer da nachts und die war erst auch nicht hinter Gittern. Und die Schwester, die saß vorne in ihrem Schwesternzimmer und nachts haben ja die Mädels eigentlich geschlafen. So und da die auch keine Zigaretten und nichts hatten, brauchten sie ja, es wurde ja alles weggenommen. Die hatten ja gar nichts mehr, also ein Kamm und eine Zahnbürste. Da haben sie die Nachtschwester sich zur Brust genommen und haben die wohl zusammengeschlagen dann. Wollten von der Geld und Zigaretten haben. "359 Schließlich der gleiche Überfall aus der Perspektive der betroffenen Pflegerin, die von den Zwangseingewiesenen überwältigt wurde: ,Ja und dann so um Mitternacht war es halt so, dass plötzlich alle von hinten vor kamen aus ihren Schlafräumen und mich bedrängten und bedrohten und eine Frau, ich weiß jetzt gar nicht, ob es eine Ältere oder eine Jüngere war, schlug mir eine mit Wasser gefüllte Flasche über den Kopf. Andere traten auf mich ein, eher in den Unterleibbereich, also ziemlich brutal. So ein ganzer Pulk von diesen Frauen. Ich wusste überhaupt gar nicht, was los war, habe aber sofort gewusst, was die wollten, nämlich meinen Schlüsselbund und habe den einfach dann auch aus meiner Kitteltasche herausgezogen und habe den freiwillig abgegeben und

356 Interview mit Frau HPA (Anm. 170).

357 Interview mit Frau HPA (Anm. 170).

358 Interview mit Frau HZA (Anm. 163).

359 Interview mit Frau HZE (Anm. 174). 
dann ging das alles recht schnell. Die Tür haben die aufgeschlossen, alle Türen und dann waren die fort. " ${ }^{60}$ Die geflohenen Zwangseingewiesenen wurden von der Polizei auf der Straße wieder aufgegriffen. Die Pflegerin war mit einer schweren Gehirnerschütterung sechs Wochen krank zu Hause. Danach musste sie auf der gleichen Station weiterarbeiten. „Man hatte dann inzwischen ein Gitter angebracht, was die Nachtschwester dann trennte von dem Dienstzimmer und den Schlafräumen dieser Klienten. "361 Dieser Überfall, der Anfang der 1980er Jahre stattfand, prägte sich tief in das Gedächtnis der Zeitzeugen ein. Einerseits, da der Überfall bauliche Veränderungen nach sich zog. Andererseits hatte der Überfall Konsequenzen für alle, die auf der geschlossenen Venerologischen Station arbeiteten. Nun mussten sämtliche Mitarbeiter Nachtdienste übernehmen - egal ob Sachbearbeiterin oder medizinisch-pflegerisches Personal. Die Nachtwachen wurden nun zu zweit abgehalten. ${ }^{362}$

Die Folgen des täglichen Terrors waren unmittelbar oder zeigten sich erst Jahre später in Form von Traumatisierungen. Frauen, die bis zur ersten gynäkologischen Untersuchung auf der geschlossenen Venerologischen Station noch keinen Geschlechtsverkehr hatten, wurden meist durch das Einführen des Glasröhrchens defloriert. Einige ehemalige Zwangseingewiesene berichten von starken Blutungen infolge des Erstabstrichs. Viele beschreiben zudem, dass sie die Prozedur der Abstrichentnahme als Bestrafung empfanden. Aufgrund der Behandlung mit den Provokationsmitteln klagten viele Zwangseingewiesene über Übelkeit, Durchfall, Erbrechen, Müdigkeit, Kopfschmerzen, langanhaltende Lähmungen und Schüttelfrost. Möglicherweise war sogar der Tod einer Zwangseingewiesenen die Folge der Provokationsuntersuchung. ${ }^{363}$

Darüber hinaus beschreibt der überwiegende Teil der ehemaligen Zwangseingewiesenen Spätfolgen, die sich in Form von Traumatisierungen manifestieren. Genannt werden in diesem Zusammenhang eine allgemeine Angst vor gynäkologischen Untersuchungen und Ärzten. Bis heute leiden viele Frauen unter Schlafstörungen, sexueller Unlust und Inkontinenz. Aus zahlreichen Biographien spricht eine gewisse Unfähigkeit, stabile und langanhaltende Partnerschaften einzugehen. Auch diese Beziehungsunfähigkeit könnte eine Folge des Aufenthalts auf der geschlossenen Venerologischen Station sein. Eine ehemalige Zwangseingewiesene berichtet aus ihrem Leben und von den gescheiterten Beziehungen: „Ja, ich lebe heute immer noch frei und ledig, außer ich habe eben jetzt zur Zeit, ich war mal 20 Jahre alleine, da hatte ich mal die Faxen dicke von die Männer, weil ich ja nicht geheiratet habe, ich wollte aber vielleicht auch gar nicht so. Ja ich wollte schon vielleicht mal heiraten, das kann man jetzt schlecht sagen, aber einmal kann man ja schon einmal heiraten, ja, wenn es dann nicht klappt, dann heiratet man meistens

360 Interview mit Frau HZB (Anm. 164).

361 Interview mit Frau HZB (Anm. 164).

362 Interview mit Frau HZE (Anm. 174).

363 Interview mit Frau LPA (Anm. 294). 
nicht noch einmal, aber es war nicht so der Richtige da, obwohl ich 6 Kinder habe und die sind nicht alle von einem Mann, ja, war auch nicht der Richtige, so das hat alles nicht so richtig hingehauen, wie man sich das vorgestellt hat und da hat man gedacht, ehe man da heiraten tut, da bleibst du lieber ledig, ja. Da waren die immer mal gekommen zu Besuch, wegen der Kinder und so, das hat sich nachher, ist nachher auseinander hat sich das gelebt, da sind die nachher nicht mehr gekommen, weil die ja nun immer größer werden, die Kinder, dann kommen die nachher später nicht mehr so und naja, da bin ich eben bis heute nicht verheiratet, ja. Mein letztes Kind, habe ich ja schon gesagt, ist jetzt 24, den sein Vater ist vor 4 Jahren verstorben. Da überlegen Sie sich mal, das erste Kind, das ist jetzt 48, das ist der gleiche Vater, wie das erste Kind und trotzdem nicht geheiratet, ja. " ${ }^{664}$ Dabei ist die problematische Bindungsfähigkeit mit einem Partner aber auch der Umgang mit den eigenen Kindern ein Hinweis auf Traumatisierungen (Kap. 9).

Seit den ersten Berichten über den Terror auf der geschlossenen Venerologischen Station wird gleichzeitig der Widerstand dagegen thematisiert, wie die Ereignisse von 1961 und 1962 in Halle (Saale) verdeutlichen, die zur Einführung einer verbindlichen Hausordnung führten (Kap. 4.2). Dieses Beispiel zeigt, dass die Zwangseingewiesenen zumindest in den Anfangsjahren der geschlossenen Venerologischen Station in Halle (Saale) die Möglichkeit des Opponierens hatten, was jedoch weniger alltäglich war als der Terror. Die Cründe hierfür sind vielfältig. Sie reichen von der Ignoranz gegenüber den Demütigungen bis hin zur Legitimation der Gewalt. Die folgende Aussage eines Famulanten steht stellvertretend für viele Mitarbeiter der geschlossenen Venerologischen Station: „(...) ich habe mir auf die Zunge gebissen." ${ }^{65}$ Mit dieser Aussage wird deutlich, dass sich Teile des medizinisch-pflegerischen Personals der Missstände auf der geschlossenen Venerologischen Station bewusst waren. Das Wissen um den Terror führte bei den Mitarbeitern aber nicht zur Opposition, sondern wurde verdrängt. Andere Mitarbeiter verdrängten die tägliche Gewalt und die Erniedrigungen nicht, sondern legitimierten sie sogar, wie aus den Aussagen einer Hautärztin deutlich wird: „Das war sozusagen der Abschaum und das Letzte vom Letzten. (...) Es war das Unterste. Sie haben also sich, erst einmal haben sie Geschlechtskrankheiten verbreitet (...). Die Frauen sind gegen, die haben sich das selber zuzuschreiben gehabt." Sie habe die Missstände zwar gesehen, sei davon sogar schockiert gewesen und habe Mitleid empfunden, doch opponiert habe sie nie, da sie keine Zwangseingewiesene erlebt habe, ,die also sagt, ich bin hier eingesperrt worden und ich habe gar nichts gemacht und ich bin schuldlos und so weiter". ${ }^{366}$ Die Zwangseingewiesenen waren aus der Sicht der Hautärztin selbst schuld an ihrer Situation und hätten selbst nie gegen ihre Behandlung aufbegehrt.

364 Interview mit Frau HPE (Anm. 277).

365 Interview mit Herrn HZF (Anm. 180)

366 Interview mit Frau HZI (Anm. 297). 
Ein Widersetzen gegen die Internierung oder die Behandlung der Mädchen und Frauen vonseiten der Eltern, der Angehörigen oder Bekannten ist nicht überliefert. Vielmehr wird beschrieben, dass Eltern ihre Töchter in der geschlossenen Venerologischen Station abgaben, weil das eigene Kind zu Hause nicht mehr funktioniere und sich herumgetrieben hätte. ${ }^{367}$ Zurückhaltend war nicht nur der unmittelbare familiäre Kreis. Auch von den Zwangseingewiesenen selbst oder der Bevölkerung von Halle (Saale) ist ein Opponieren nicht bekannt. Viele Bewohner von Halle (Saale) wussten um die geschlossene Venerologische Station durch ihre Besuche der Poliklinik Mitte. Ein Patient der Poliklinik Mitte, der Misshandlungen an Zwangseingewiesenen beobachtet hatte, kann heute seine damalige Zurückhaltung nicht mehr nachvollziehen: „Ich habe mich immer für die Schwachen eingesetzt. Also, es war schon ein Drang in mir, den Laden dort auch zusammenzuschreien. Ich weiß nicht, was mich davon abgehalten hat. Das kann ich heute nicht mehr nachvollziehen, wahrscheinlich der Schock, weil ich so was bis dato nicht erlebt habe. " ${ }^{68}$ Einige Mitarbeiter suchten Wege des indirekten Widerstands und kündigten ihre Arbeit. Gegenüber Gerd Münx begründeten sie ihre Kündigung zum Beispiel so: „, Ich mache das nicht mehr mit und ich will das nicht, weil, ich bin ein Mensch (...).' Und er hat gesagt: , Ist in Ordnung und dann gehen sie halt nicht mehr mit zu den Untersuchungen und dann bleiben Sie eben hier und kriegen eine Gehaltserhöhung. ' Da habe ich, was weiß ich, 10 Ostmark mehr gekriegt und er hat nur gesagt, er wäre sehr traurig auch und ich soll es mir nochmal überlegen und wir können darüber reden. Und da hat eigentlich meine Freundin auch gesagt: ,Komm bleib hier!' Und dann bin ich dort geblieben, ja. Und ab dem Zeitpunkt sind wir gegen den vorgegangen." ${ }^{69}$

\subsection{Das Ministerium für Staatssicherheit und die Schließung der Station}

Das Ministerium für Staatssicherheit war über die Vorgänge auf der geschlossenen Venerologischen Station der Poliklinik Mitte in Halle (Saale) informiert. Sowohl die Zwangseingewiesenen als auch die Mitarbeiter bestätigen in den Interviews, dass offizielle Mitarbeiter des Ministeriums für Staatssicherheit regelmäßig die geschlossene Venerologische Station in Halle (Saale) aufsuchten. Eine Mitarbeiterin erinnert sich: ,Ja, wir haben auch ganz genau gewusst, wenn der von der Stasi da war, was wir dem erzählen und was wir dem nicht erzählen. Das haben wir schon gewusst. " ${ }^{370}$ Dass die Mitarbeiter des Ministeriums für Staatssicherheit relativ regelmäßig auf der Station waren, geht aus einem Interview mit einer der Zwangseingewiesenen hervor: „Es waren Zivil-

367 Interview mit Frau HZD (Anm. 169).

368 Interview mit Herrn HZC (Anm. 165).

369 Interview mit Frau HZE (Anm. 174).

370 Interview mit Frau HZE (Anm. 174). 
personen des Öfteren da. Mindestens dreimal in der Woche, aber nicht in Uniform oder sonst was. Aber die haben immer mit den hübscheren Frauen haben die dort gesprochen und wenn die wiedergekommen waren, die hatten dann auch immer Zigaretten mit und Süßigkeiten mit und alles so was. “371

Die offiziellen Mitarbeiter des Ministeriums für Staatssicherheit gingen entweder direkt auf die Leiter der geschlossenen Venerologischen Station zu, wandten sich an die Mitarbeiter der Station oder an die Fürsorgerinnen: „Wir haben ja dann alle Fürsorgearbeit gemacht. Die sind auch zu uns und haben immer in die Akten geguckt. Da gab es ja Akten. Ich weiß nicht, wo die abgeblieben sind. Die müssten ja eigentlich auch noch irgendwo sein." "372 So wurde entweder bei einem Kaffee über die Zwangseingewiesenen gesprochen oder in den Patientenakten gelesen. Der Mitarbeiter vom Ministerium für Staatssicherheit, so eine ehemalige Mitarbeiterin der geschlossenen Venerologischen Station, „musste sich ja mit uns gut stellen, wenn er immer zu uns kam. Der war ja eigentlich auch unser Alter damals. Wir haben mit dem Kaffee getrunken und die Schwester Steffi und ich, wir beide waren ja ganz enge Freundinnen. Wir haben schon gewusst, was wir erzählen. Also, der hat von uns Sachen erfahren, aber sicher nicht solche Sachen, wo man jetzt sagen könnte und damit kann er was anfangen, ja. Das haben wir halt aufs Lustige mehr genommen. Und das wusste der auch, dass der von uns eigentlich - der ist meistens bloß zum Kaffeetrinken gekommen und hat gefragt, was es Neues gibt, hat die Unterlagen sich angeguckt und dann ist er wieder abgeschoben. " ${ }^{373}$

Die Zusammenarbeit zwischen den Mitarbeitern des Ministeriums für Staatssicherheit und den Zwangseingewiesenen gestaltete sich anders. Laut einiger Mitarbeiter der geschlossenen Venerologischen Station waren unter den Frauen auch Inoffizielle Mitarbeiterinnen (IMs) der Staatssicherheit. „Da gab es welche, entweder waren das so, na geheime Mitarbeiter oder was, ja. Die hatten da das Sagen, so eins, zwei Frauen und die haben einen dann auch verpetzt, wenn man dann auch mal ein bisschen laut war. “"374 Über dieses interne Netz an IMs erhielt das Ministerium für Staatssicherheit Informationen über die Zwangseingewiesenen, aber auch über das medizinisch-pflegerische Personal. Zudem waren die Mitarbeiter des Ministeriums für Staatssicherheit auch an Informationen über Personen außerhalb der geschlossenen Venerologischen Station interessiert, besonders an Reisenden aus dem „Nichtsozialistischen Wirtschaftsgebiet“ (NSW), die während der Leipziger Messe in Hotels in Leipzig und in Halle (Saale) wohnten. Frauen, denen entsprechende Kontakte nachgesagt wurden, waren für die Mitarbeiter des Ministeriums für Staatssicherheit von besonderem Interesse. Viele Zeitzeugen berichten, dass es gerade die großen Hotels waren, die als Rekrutierungsort für potenzielle

371 Interview mit Frau HPA (Anm. 170).

372 Interview mit Frau HZE (Anm. 174).

373 Interview mit Frau HZE (Anm. 174).

374 Interview mit Frau HPD (Anm. 258). 
Kandidatinnen dienten: „Entweder haben sie die überhaupt in diesem Interhotel oder Leipzig, Merkur - ich weiß nicht, ob das zu Ostzeiten schon Merkur hieß, wenn Messe war vor allen Dingen, sind die ausgeschwärmt. Ja, dass waren ja welche in Halle, die eigentlich bekannt waren, die das machen. (...) Halle war ja nicht so groß, wie Sie schon sagten, und da gab es eben die Frau, die und die. (...) Die sollten ja auch Sachen jetzt von diesen, die da die Frühjahrs- und Herbstmesse besuchten, dass waren ja alles Firmen und da sollte ja ein bisschen etwas rauskommen dabei, ja. Das haben ja die Herren auch teilweise dann gemacht, abends im Hotel erzählt, geplaudert, ein Gläschen Wein und da haben sie halt erzählt. Das war ja wichtig. “375

Wirkten diese Frauen nicht im Sinn des Ministeriums für Staatssicherheit, so eine Mitarbeiterin der geschlossenen Venerologischen Station, dann wurden sie in die Station zwangseingewiesen: „Wenn Messe war zum Beispiel, wurden die auch aus Leipzig angekarrt, die Frauen. Das waren welche, die halt mit solchen Männern zusammen waren. (...) Das waren solche Damen dann halt, die auf ältere Wessis angesetzt wurden. Die halt zur Messe dann da waren und die halt nicht funktioniert haben. Die haben sich zwar mit den Herren getroffen, aber dementsprechend nicht funktioniert und dementsprechend nicht die Nachrichten gegeben und die wurden dann halt einkassiert. Die sollten sich ja mit den Herren treffen, um etwas rauszukriegen. " ${ }^{376}$ Dieses Vorgehen verdeutlicht eine weitere Dimension der Brutalität der Systeme Staatssicherheit und geschlossene Venerologische Station. In der Station wurden Frauen für die Komplizenschaft mit dem Ministerium für Staatssicherheit gefügig gemacht. Dies funktionierte im Wesentlichen über ihre Erpressung. Das Ministerium für Staatssicherheit instrumentalisierte vor allem die Strafrechtsänderung aus dem Jahr 1968, in deren Folge die Prostitution in der DDR mit einer Freiheitsstrafe von bis zu fünf Jahren geahndet werden konnte. ${ }^{377}$ Dadurch waren Frauen, die wegen sexueller Dienstleistungen überführt wurden, leicht erpressbar. Entsprechend war es nach 1968 wesentlich einfacher für das Ministerium für Staatssicherheit, Frauen zur „nachrichtendienstlichen Zusammenarbeit" zu zwingen. ${ }^{378}$ Dennoch bleibt zu fragen, wie sich die Zusammenarbeit zwischen dem Ministerium für Staatssicherheit und der geschlossenen Venerologischen Station bei der Rekrutierung von Frauen gestaltete. Das Ministerium für Staatssicherheit hatte für solche Einsätze recht klare Vorstellungen von den zu gewinnenden Frauen, denn diese mussten Kontakt mit Personen aus dem nichtsozialistischen Ausland (NSA) aufnehmen können. Entsprechend sollten die Frauen Fremdsprachen beherrschen, gebildet sein und analytische Fähigkeiten besitzen. ${ }^{379}$

375 Interview mit Frau HZE (Anm. 174).

376 Interview mit Frau HZE (Anm. 174).

377 Falck: VEB Bordell. Geschichte der Prostitution (Anm. 71), S. 15.

378 Falck: VEB Bordell. Geschichte der Prostitution (Anm. 71), S. 15.

379 Falck: VEB Bordell. Geschichte der Prostitution (Anm. 71), S. 15. 
Sicher hingegen ist, dass das Ministerium für Staatssicherheit zumindest seit Frühjahr 1976 einen Arzt der Poliklinik Mitte als IM angeworben hatte. Aus den entsprechenden BStU-Unterlagen des Vorgangs „IM Schneider“ geht hervor, warum der Arzt im März 1976 für die Anwerbung zur Mitarbeit vorgeschlagen wurde: „Die Begründung der Eignung und Fähigkeiten des Kandidaten zur Lösung der Aufgaben des IMV erfolgt von der objektiven Seite durch: 1. Der Kandidat ist Angehöriger der med. Intelligenz und arbeitet in einem Schwerpunktbereich der Linie Gesundheitswesen. 2. Der Schwerpunktbereich ist in verschiedene Ambulanzen aufgeteilt, deren Zentrum das Haupthaus ist. Als Abteilungsleiter hat der Kandidat die Möglichkeit, vom Zentrum aus in allen Bereichen wirksam zu werden. 3. Durch Mitgliedschaft in der CDU ist der Kandidat für den großen Teil der Angehörigen des Bereiches vertrauenswürdig und genießt die Achtung der Ärzte und Schwestern des Bereiches. Insbesondere ist es ihm dadurch möglich, auch das Vertrauen negativ eingestellter Personen zu gewinnen. " Darüber hinaus eignete sich IM Schneider durch Kontakte zu „operativ interessanten Personen“ und seine „Verbindungen ins NSA“ “ ${ }^{800}$ Aus dem Schreiben geht auch hervor, wie sein erster Auftrag lautete: „Der IM erhält folgenden Auftrag: „1. Analyse seines Verbindungskreises auf dienstlicher und privater Ebene. 2. Analyse der derzeitig bestehenden begünstigenden Bedingungen im Bereich Mitte des BKH [Bezirkskrankenhaus], die zu Unzufriedenheiten unter den Mitarbeitern führen. 3. Aufstellung von Ärzten, bei denen die Möglichkeit eines ungesetzl[ichen] Verlassens der DDR auf Grund ihrer Einstellung besteht. " 381

Bereits im April 1976, einen Monat nach der Anwerbung, lagen erste Berichte des IM Schneider zum Bezirkskrankenhaus, der Poliklinik Mitte und dessen Ärztlichen Direktor Münx vor. So berichtet IM Schneider unter anderem, dass „im Bereich Mitte des BKH die Ablösung von Dr. Münx noch nicht vollzogen“ war. ${ }^{3{ }^{82}}$ Seit seiner Anwerbung berichtete der IM mindestens einmal monatlich über die Situation in der Poliklinik Mitte. Im Zentrum dieser Berichte war stets Gerd Münx. Gegen dessen Behandlungsmethoden hatten Mitte der 197oer Jahre mehrere Patientinnen Eingaben bei der Staatsanwaltschaft gemacht, „die jedoch ohne Erfolg blieben, da der M. vom damaligen Kreisarzt $\square$ gedeckt wurde“, ${ }^{383}$ wie IM Schneider kommentiert. Im August 1976 berichtete IM Schneider, dass im Februar desselben Jahres ein Disziplinarverfahren gegen Münx eingeleitet wurde, das nach wie vor nicht abgeschlossen gewesen sei: „Die Absetzung des Dr. M. sollte am o1. Juli 1976 erfolgen, aber er regiert nach

380 BStU Archiv der Außenstelle Halle. MfS BV Halle. KD Halle. VIII 616/76. Vorschlag zur Verpflichtung des Kandiaten, Bl. $000116 f$.

381 BStU Archiv der Außenstelle Halle. MfS BV Halle. KD Halle. VIII 616/76. Vorschlag (Anm. 380), Bl. 000119.

382 BStU Archiv der Außenstelle Halle. MfS BV Halle. KD Halle. VIII 616/76. Mündlicher Treffbericht. Halle, den 26. April 1976, Bl. 000117.

383 BStU Archiv der Außenstelle Halle. MfS BV Halle. KD Halle. VIII 616/76. Treffauswertung. Halle, den 25. Mai 1976, Bl. 000006, Schwärzung im Original. 
wie vor im Amt mit den alten Methoden." ${ }^{84}$ In den folgenden Monaten liefert der IM detaillierte Einschätzungen über die Leitungsarbeit, die medizinische Qualifikation und die privaten Verhältnisse von Münx. ${ }^{385}$

Vor allem ein Bericht vom 13. Oktober 1976 belegt, dass das Ministerium für Staatssicherheit von Zwangseinweisungen wusste, die gegen die rechtlichen Bestimmungen der DDR verstießen: „Münx weist also ungerechtfertigter Weise Mädchen auf die V-Station der Poliklinik Mitte ein. Diese Einweisungen entbehren jeglicher rechtlicher Crundlage. Er weiß genau, mit welchem Personenkreis er das machen kann, hat also ausgiebig Erfahrung. "386 In dem Bericht werden vier Fälle benannt, in denen Münx gegen die rechtlichen Bestimmungen verstoßen hat. So kommt der Arzt IM Schneider zu dem Schluss: „Es sollte hierbei noch erwähnt werden, daß die Diagnose von Münx bezüglich des Trippernachweises als äußerst fragwürdig anzusehen ist. Ich meine, bei einer solch schwerwiegenden ärztlichen Entscheidung, muß die Diagnose absolut sicher sein, bevor ich jemanden in die V-Station einweise. Für eine absolut sichere Diagnose jedoch, wird heutzutage eine Kultur verlangt. Denn an ein Mikrobiologisches Institut muß das Abstrichmaterial eingeschickt werden. Aber Münx allein behauptet, die Tripperdiagnose auf Grund eines Objektivträgerpräparates stellen zu können. “387

Im November 1976 verbreiteten sich in der Poliklinik Mitte die Gerüchte. Seit Februar 1976 war das Disziplinarverfahren gegen Münx anhängig und bisher war diesbezüglich nichts entschieden worden. Bereits im September 1976 hatten Mitarbeiter der Poliklinik Mitte spekuliert, dass Münx aufgrund seiner guten Kontakte zu Genossen des Volkspolizei-Kreisamts (VPKA), zu Staatsanwälten und vor allem zum Kreisarzt von Halle keine Konsequenzen aus dem laufenden Disziplinarverfahren zu befürchten habe. ${ }^{388} \mathrm{Im}$ November des Jahres wurde von einem ärztlichen Kollegen des IM Schneider behauptet, „daß in der Bezirksleitung SED Gruppensexveranstaltungen stattfinden und die dortigen Mädchen einige Herren angesteckt haben. Diese Herren hätten sich anschließend bei Münx in Behandlung begeben. “" ${ }^{89}$ Etwa um diese Zeit wurde das Zentralkomitee der SED aktiv. Die Vorgänge rund um das Disziplinarverfahren wurden geprüft und anschließend an die Bezirksleitung der SED in

384 BStU Archiv der Außenstelle Halle. MfS BV Halle. KD Halle. VIII 616/76. Mündlicher Bericht des IMV „Klaus Schneider". Halle, den 4. August 1976, Bl. 000015.

385 BStU Archiv der Außenstelle Halle. MfS BV Halle. KD Halle. VIII 616/76. Tonbandmitschnitt der mündlichen Berichterstattung des IMV „Klaus Schneider“. Halle, den 29. September 1976, Bl. 000020.

386 BStU Archiv der Außenstelle Halle. MfS BV Halle. KD Halle. VIII 616/76. Mündlicher Bericht des IMV „Klaus Schneider". Halle, den 13. Oktober 1976, Bl. 000035.

387 BStU Archiv der Außenstelle Halle. MfS BV Halle. KD Halle. VIII 616/76. Mündlicher Bericht (Anm. 386), Bl. 000036.

388 BStU Archiv der Außenstelle Halle. MfS BV Halle. KD Halle. VIII 616/76. Tonbandmitschnitt (Anm. 385), Bl. 000020.

389 BStU Archiv der Außenstelle Halle. MfS BV Halle. KD Halle. VIII 616/76. Mündlicher Bericht des IMV „Klaus Schneider“. Halle, den 17. November 1976, Bl. 000041. 
Halle (Saale) übergeben. Im Dezember 1976 nahmen Genossen der SED-Bezirksleitung Kontakt zur Poliklinik Mitte auf. Am 5. Januar 1977 endlich kam eine Genossin der SED-Bezirksleitung in die Poliklinik Mitte, „um sich an Ort und Stelle über den Gang der Dinge zu informieren“. ${ }^{390}$ Im Zeitraum zwischen Dezember 1976 und Januar 1977 musste Gerd Münx zumindest teilweise entmachtet worden sein, da IM Schneider am 12. Januar 1977 berichtet: „Es ist dazu zu sagen, daß seit Anfang Januar 1977, als Leiter der Poliklinik Mitte im Amt ist. "391 Gerd Münx war fortan Leiter der Hautabteilung mit der angeschlossenen Bettenstation und unterstand dem Ärztlichen Direktor für stationäre Betreuung. IM Schneider notiert einige Monate später einen weiteren Schritt zur Entmachtung von Münx. In einem undatierten „Treffbericht“ ist zu lesen: „Dr. Münx ist seit April 1977 als Chefarzt der Poli-Mitte abgelöst worden und betreut noch die geschlossene Station." 392

Obwohl Gerd Münx vor allem für seinen Umgang mit den Zwangseingewiesenen, für seine Einweisungspraktiken und Diagnosemethoden kritisiert wurde, blieb er weiterhin Leiter der geschlossenen Venerologischen Station. Statt ihn von dieser Tätigkeit zu entbinden und ihn in die Verwaltung zu versetzen, durfte er weiterhin mit den zwangseingewiesenen Mädchen und Frauen arbeiten. Diese Diskrepanz erklärt der Führungsoffizier des IM Schneider in einem undatierten Treffbericht, der im Jahr 1977 angefertigt worden sein muss, wie folgt: „Im allgemeinen wird die Station als Untersuchungs- und Haftanstalt mit verschärftem Charakter bezeichnet. Es kommt des öfteren zu brutalen Auseinandersetzungen innerhalb der Patienten die mitunter damit enden, daß die VP [Volkspolizei] geholt werden muss, um die Streitigkeiten zu schlichten. Durch Dr. M. werden Maßnahmen bei ,Aufsässigkeit‘ eingeleitet wie: Einzelunterkunft im Bad, wo sich die Patientinnen stundenlang auf kalten Fliesen aufhalten müssen, Anstiftung zur Selbsterziehung die dann damit endet, daß die ,Aufsässigen“ verprügelt werden. Mitunter müssen Patienten der geschlossenen Station in stationäre Behandlung gebracht werden, da sie Platzwunden o.ä. Verletzungen aufweisen. Dem IM ist bekannt, daß andere Stationen wie Berlin, Leipzig und Rostock ihre Patienten nach 30 oder maximal 40 Tagen entlassen. Ein Aufenthalt bei Dr. M. dauert in der Regel 6o-70 Tage. Eine nicht unerhebliche Anzahl von Einweisungen kommt aus den genannten Städten vor allem Leipzig die eine solche Maßnahme als Strafversetzung betrachten und die Meinung vertreten, daß auf der Station von Dr. M. noch ,Zucht und Ordnung' herrsche. “393

390 BStU Archiv der Außenstelle Halle. MfS BV Halle. KD Halle. VIII 616/76. Mündlicher Bericht des IMV „Klaus Schneider“. Halle, den 12. Januar 1977, Bl. 000050.

391 BStU Archiv der Außenstelle Halle. MfS BV Halle. KD Halle. VIII 616/76. Mündlicher Bericht (Anm. 390), Bl. 000050, Schwärzung im Original.

392 BStU Archiv der Außenstelle Halle. MfS BV Halle. KD Halle. VIII 616/76. Treffbericht, Bl. 000092.

393 BStU Archiv der Außenstelle Halle. MfS BV Halle. KD Halle. VIII 616/76. Treffbericht (Anm. 392), Bl. 000095. 
Diese Notiz lässt den Schluss zu, dass das Ministerium für Staatssicherheit wusste, dass Gerd Münx unter den Bezirks- und Kreisvenerologen für seinen Umgang mit den Zwangseingewiesenen bekannt war und die Überweisungen von „aufsässigen“ Mädchen und Frauen nach Halle (Saale) und in die dortige geschlossene Venerologische Station häufig auf andere geschlossene Stationen zurückgeführt werden können. Möglicherweise sind hier die Gründe dafür zu suchen, dass Münx noch weitere zwei Jahre in der geschlossenen Venerologischen Station tätig sein durfte, bis er endgültig versetzt wurde. Vom IM Schneider liegen aus dem Jahr 1977 keine weiteren Berichte zur Poliklinik Mitte vor. Auch im darauffolgenden Jahr steht die Poliklinik Mitte nicht im Mittelpunkt der Berichte des IM Schneider.

Ende 1978 überschlugen sich die Ereignisse auf der geschlossenen Venerologische Station, wie aus den Berichten vom IM Schneider hervorgeht. Erneut hatte es eine Anzeige gegen Gerd Münx gegeben und ein Disziplinarverfahren wurde gegen ihn eingeleitet. Den Crund für die Anzeige und das Disziplinarverfahren lieferte eine Begebenheit, die von vielen Zeitzeugen in den Interviews beschrieben wurde: Während einer Nachtwache fanden zwei Pflegerinnen eine Zwangseingewiesene mit starkem Husten im Bad eingeschlossen. Die Frau hatte bereits zwei Tage und Nächte isoliert im Bad verbracht. Am Abend des zweiten Tages hatte Frau Drunkenmölle Bereitschaft. Die Frau „saß im Bad, die war ja auch böse, saß mit nackigen Beinen und Kittel und war im Bad und hustete (...). Da hat die Frau Drunkenmölle gefragt, seit wann sie im Bad ist. Sie hat gesagt: ,Seit zwei Tagen.' ,Und Essen?' Sie kann nicht essen, ihr ist übel und sie muss immer husten und sie muss mal auf Toilette auch. Die mussten ja dann klopfen, dann durften sie mal auf Toilette gehen. Und da ist die Drunkenmölle mit auf die Toilette, weil sie sagt, sie hat so blutigen Auswurf. (...) Da hat sie am Abend noch in Dölau angerufen und da haben sie die abgeholt. Da hatte die eine offene TB [Tuberkulose] gehabt. “" ${ }^{994}$ Dieser Vorfall, den Gerd Münx als Leiter der geschlossenen Venerologischen Station zu verantworten hatte, bildete den Hintergrund für das erneute Disziplinarverfahren gegen ihn. Bereits im Januar 1979 heißt es in den Unterlagen der BStU, „daß der OMR Dr. Münx als leitender Arzt der Dermatolovenerologischen Abteilung der Poli-Mitte abgelöst wurde“. Nach einem Urlaub, den Münx im Januar 1979 antrat, sollte „eine neugeschaffene Planstelle im Bezirkskrankenhaus Dölau" mit ihm besetzt werden. ${ }^{395}$

Aus den Berichten vom IM Schneider geht hervor, das dessen Ehefrau die kommissarische Leitung der geschlossenen Venerologischen Station erhielt, nachdem Gerd Münx versetzt worden war. Weitere Berichte des IM Schneider dokumentieren die Auseinandersetzung um die Nachfolge von Münx. Auch der

394 Interview mit Frau HZE (Anm. 174).

395 BStU Archiv der Außenstelle Halle. MfS BV Halle. KD Halle. VIII 616/76. Information. Halle, den 31. Januar 1979, Bl. 000145 . 
Führungsoffizier des IM bemerkte das persönliche Interesse des IM Schneider an der Besetzung der Leitung der geschlossenen Venerologischen Station. ${ }^{396}$ Schließlich waren zwei Kandidaten im Gespräch, von denen sich Manfred Narwutsch durchsetzte und die Dermatologische Station in den neuen Räumen in der Hautklinik am Harz von der kommissarischen Leiterin übernahm. Mit der Entlassung von Gerd Münx endete der Terror auf der geschlossenen Venerologischen Station in Halle (Saale). Dass das Ministerium für Staatssicherheit zumindest indirekt an der Ablösung von Münx beteiligt war, belegen die ausgewerteten Unterlagen der BStU. 